\title{
Parametric modeling of bolted joints between components made of particulate composite materials
}

\author{
Vasudha Goteti \\ West Virginia University
}

Follow this and additional works at: https://researchrepository.wvu.edu/etd

\section{Recommended Citation}

Goteti, Vasudha, "Parametric modeling of bolted joints between components made of particulate composite materials" (2003). Graduate Theses, Dissertations, and Problem Reports. 1374.

https://researchrepository.wvu.edu/etd/1374

This Thesis is protected by copyright and/or related rights. It has been brought to you by the The Research Repository @ WVU with permission from the rights-holder(s). You are free to use this Thesis in any way that is permitted by the copyright and related rights legislation that applies to your use. For other uses you must obtain permission from the rights-holder(s) directly, unless additional rights are indicated by a Creative Commons license in the record and/ or on the work itself. This Thesis has been accepted for inclusion in WVU Graduate Theses, Dissertations, and Problem Reports collection by an authorized administrator of The Research Repository @ WVU. For more information, please contact researchrepository@mail.wvu.edu. 


\title{
PARAMETRIC MODELING OF BOLTED JOINTS BETWEEN COMPONENTS MADE OF PARTICULATE COMPOSITE MATERIALS
}

\author{
By \\ VASUDHA GOTETI
}

\author{
Thesis \\ Submitted to the College of \\ Engineering and Mineral Resources \\ At \\ West Virginia University
}

\begin{abstract}
In Partial Fulfillment of the Requirements
For the Degree of

Master of Science in Mechanical Engineering
\end{abstract}

\author{
Committee Members \\ Dr. Samir Shoukry \\ Dr. Jacky Prucz \\ Dr.Kenneth.H.Means
}
Morgantown, West Virginia
2003

Keywords: Finite element modeling, Bolted joints, Particulate MMCs 


\section{ABSTRACT \\ PARAMETRIC MODELING OF BOLTED JOINTS BETWEEN COMPONENTS MADE OF PARTICULATE COMPOSITE MATERIALS \\ VASUDHA GOTETI}

Particulate metal matrix composites (MMC) exhibit higher stiffness, strength and wear resistance compared to metal alloys. They exhibit superior compressive and buckling strength because of their higher plastic modulus. MMC's can operate at very higher temperatures than fiber-reinforced polymer composites. Their isotropic behavior and forming ability by conventional methods makes them a better choice for low-cost applications. They have good thermal conductivity, high electrical conductivity and low thermal expansion.

The main objective of this study is to predict numerically the stress distributions around the hole in a bolted joint made of particulate metal matrix composite and to investigate the associated load transfer efficiencies both for a single and double lap bolted joints. A three dimensional Finite Element parametric model has been developed to study the effects of various design parameters on the structural performance of such joints.

Single lap bolted joints experience bending when tension load is applied to the joint because of the unsymmetrical configuration of the joint. This effect is reduced in double lap bolted joints due to their symmetry. This research quantifies the relationship between the stress around the hole in bolted joints and the washer diameter, bolt diameter, tightening pressure, and the clearance between the hole and the bolt. It has also been observed that variations in Young's Modulus have no insignificant effect on the stress concentration around the hole. 


\section{ACKNOWLEDGEMENTS}

I would like to express my sincere appreciation to Dr. Samir Shoukry who has been my supervising professor and advisor through my master's degree program. I would like to express my deepest gratitude for his support, encouragement and guidance through out my graduate study at this university. His exemplary work ethic and dedication has provided me the inspiration and motivation towards my work. I will be always thankful for his extensive support through out my stay at West Virginia University and for spending valuable hours in solving my problems.

I would also like to thank Dr.Jacky Prucz for his assistance. I would also thank Dr.Kenneth.H.Means for being on my committee.

My special thanks go to Mr.Gergis Williams for his extensive assistance and support in my research work. He has always been very patient in listening to my queries and questions and giving appropriate suggestions for the improvement of my work. I sincerely thank him for all his support and encouragement throughout my research work.

I am deeply indebted to my parents, brother and sisters for their tremendous encouragement and support. This work would not have been complete without their moral support and love. I would also like to thank all my friends for their warm friendship and support. 


\section{TABLE OF CONTENTS}

$\begin{array}{ll}\text { Abstract } & \text { ii }\end{array}$

$\begin{array}{ll}\text { Acknowledgement } & \text { iii }\end{array}$

List of Figures vi vi

List of Tables $\quad$ xii

1. Introduction 1

1.1 Background 1

1.2 Objectives 3

$\begin{array}{ll}1.3 \text { Methodology } & 4\end{array}$

1.4 Thesis Organization 4

$\begin{array}{lr}\text { 2. Literature Review } & 6\end{array}$

2.1 Survey of Pertinent Literature 6

$\begin{array}{ll}2.2 \text { Summary } & 18\end{array}$

3. Finite Element Model 19

$\begin{array}{ll}3.1 \text { Introduction } & 19\end{array}$

$\begin{array}{ll}\text { 3.2 Joint Structural Model } & 19\end{array}$

$\begin{array}{ll}3.3 \text { Boundary and Loading Conditions } & 20\end{array}$

$\begin{array}{ll}\text { 3.4 Material Model } & 21\end{array}$

$\begin{array}{ll}\text { 3.5 Model Results } & 23\end{array}$

$\begin{array}{ll}\text { 3.6 Model Validation } & 24\end{array}$

3.6.1 Closed Form Solution for a Plate with a Hole 25 
4. Results for Single Lap Joint $\quad 38$

$\begin{array}{ll}\text { 4.1 Introduction } & 38\end{array}$

4.2 Stress Distribution Around the Hole 38

$\begin{array}{ll}4.3 \text { Effect of Tightening Pressures } & 40\end{array}$

4.4 Effect of Young's Modulus $\quad 41$

4.5 Effect of Bolt Diameter 42

4.6 Effect of Washer Diameter $\quad 42$

5. Results for Double Lap Joint 56

5.1 Introduction $\quad 56$

5.2 Stress Distribution Around the Hole 56

5.3 Effect of Tightening Pressure $\quad 58$

5.4 Effect of Young's Modulus

5.5 Effect of Applied Load $\quad 60$

$\begin{array}{ll}5.6 \text { Effect of Clearance } & 61\end{array}$

$\begin{array}{ll}\text { 5.7 Effect of washer Diameter } & 61\end{array}$

5.8 Effect of Bolt Diameter 62

6. Conclusions $\quad 76$

$\begin{array}{ll}\text { 6.1 Future Work } & 77\end{array}$

$\begin{array}{ll}\text { References } & 78\end{array}$ 


\section{List of Figures}

$\begin{array}{lll}\text { Figure Page } & \text { Pas }\end{array}$

3.1.1 Schematic of a single lap bolted joint 29

3.1.2 Schematic of a double lap bolted joint 29

3.2.1 Finite element model of the double lap bolted joint 30

3.2.2 Finite element mesh for the bolt and the washer of a bolted joint 30

3.3.1 Loading and boundary conditions for a single lap bolted joint 31

3.3.2 Loading and boundary conditions for a double lap bolted joint 32

3.4 Stress strain curve for linear elastic plastic material model 32

3.5 Deformed Configuration Predicted for single lap joint 33

3.6 Deformed Configuration Predicted for double lap joint 33

3.7 Von Mises stress field around the hole of a single lap joint 34

3.8 Von Mises stress distribution around the hole for double lap joint 34

3.9 Circular Hole in a Flat Plate for Validation of FEM Joint Model 35

3.10 Infinite Flat Plate with Circular a Hole for Correlation with Closed-Form Solution $\quad 35$

3.11 Distribution of $\sigma_{\mathrm{xx}} / \sigma_{0}$ and $\sigma_{\mathrm{yy}} / \sigma_{0}$ along the y-axis 36

3.12 Distribution of $\sigma_{\mathrm{xx}} / \sigma_{0}$ and $\sigma_{\mathrm{yy}} / \sigma_{0}$ along the x-axis 36

3.13.1 Distribution of $\sigma_{\mathrm{rr}} / \sigma_{0}$ ratio around the hole 37

3.13.2 Distribution of $\sigma_{\mathrm{r} \theta} / \sigma_{0}$ ratio around the hole 37

4.1 Predicted deformation of a single lap joint under axial loading 43

4.2 Predicted distribution of normal stresses in the $\mathrm{x}$-direction $\left(\sigma_{\mathrm{xx}}\right)$ in the lower plate of a single lap joint 
4.3 Distribution of maximum principal stress in the lower plate of single lap joint

4.4 Predicted distribution of shear stress $\left(\tau_{\mathrm{xy}}\right)$ in the lower plate of single lap joint

4.5 Predicted Distribution of normal stresses in the z-direction in the lower plate

4.6 Von Mises stress distribution around the hole in the lower plate

4.7 Predicted distribution of $\left(\sigma_{\mathrm{xx}}\right)$ stress components around the hole in the lower plate for different levels of bolt tightening pressure

4.8 Predicted distribution of Shear stress around the hole in the xy-plane for different levels of bolt tightening pressure

4.9 Distribution around the hole of the normal compressive stresses in the transverse, z-direction

4.10 Variations of Von Mises stress around the hole in the lower plate for various levels of bolt tightening pressure

4.11 Average effective stress in the connected plates for various levels of bolt tightening pressures

4.12 Distribution of Von Mises stress around the hole in the lower plate for various material systems used in the plates

4.13 Variations around the hole of $\sigma_{\mathrm{xx}}$-stresses in the lower plate for various material systems used in the plates

4.14 Variations around the hole of the normal strain component in the $\mathrm{x}$-direction, $\varepsilon_{\mathrm{xx}}$ in the lower plate for various material systems 
4.15 Variations around the hole of the normal strain component in the $y$-direction, $\varepsilon_{\mathrm{yy}}$ in the lower plate for various material systems

4.16 Variations around the hole of the normal strain component in the $\mathrm{z}$-direction, $\varepsilon_{\mathrm{zz}}$ in the lower plate for various material systems

4.17 Variations of Von Mises stress around the hole in the lower plate for various values of the bolt diameter

4.18 Variations of Maximum Principal stress around the hole in the lower plate for various values of the bolt diameter

4.19 Variations of $\sigma_{\mathrm{xx}}$ stresses around the hole in the lower plate for various values of bolt diameter

4.20 Variations of Von Mises stress around the hole in the lower plate for various values of the washer radius

4.21 Variations of Maximum Principal stress around the hole in the lower plate for various radii of the washer

4.22 Variations of $\sigma_{\mathrm{xx}}$ stresses around the hole in the lower plate for various radii of the washer

5.1 Predicted distribution of Normal Stresses in the x-Direction $\left(\sigma_{\mathrm{xx}}\right)$ in the Middle Plate of a Double Lap Joint

5.2 Predicted Distribution of Shear Stress $\left(\tau_{\mathrm{xy}}\right)$ in the Middle Plate of a Double Lap Joint

5.3 Predicted distribution of normal stresses in the z-direction $\left(\sigma_{\mathrm{zz}}\right)$ in the middle plate 
5.4 Von Mises stress distribution around the hole in the middle plate

5.5 Predicted distribution of $\left(\sigma_{\mathrm{xx}}\right)$ stress components around the hole in the middle plate for different levels of bolt tightening pressure

5.6 Predicted distribution of Shear stress around the hole in the xy-plane in the middle plate for different levels of bolt tightening pressure

5.7 Distribution around the hole of the normal compressive stresses in the transverse, z-direction for the middle plate

5.8 Distribution of Von Mises stress around the hole in the middle plate for various material systems used in the plates

5.9 Variations around the hole of $\sigma_{\mathrm{xx}}-$ stresses in the middle plate for various material systems used in the plates

5.10 Variations around the hole of the normal strain component in the $\mathrm{x}$-direction, $\varepsilon_{\mathrm{xx}}$ in the middle plate for various material systems

5.11 Variations of Von Mises stress around the hole in the middle plate for different values of the load applied

5.12 Variations of maximum principal stress around the hole in the middle plate for different values of load applied

5.13.1 Predicted distribution of normal stress in $\mathrm{x}$-direction $\left(\sigma_{\mathrm{xx}}\right)$ in the middle plate for a load of $30 \mathrm{MPa}$

5.13.2 Predicted distribution of normal stress in $\mathrm{x}$-direction $\left(\sigma_{\mathrm{xx}}\right)$ in the middle plate for a load of $120 \mathrm{MPa}$ 
5.14.1 Predicted distribution of shear stress $\left(\tau_{\mathrm{xy}}\right)$ in the middle plate for tensile load

5.14.2 Predicted distribution of shear stress $\left(\tau_{\mathrm{xy}}\right)$ in the middle plate for compressive load

5.15 Predicted distribution of $\left(\sigma_{\mathrm{xx}}\right)$ stress components around the hole in the middle plate for different loads

5.16 Predicted variations of shear stress around the hole in the xy-plane $\left(\tau_{\mathrm{xy}}\right)$ in the middle plate for different loads

5.17 Variations of Von Mises stress around the hole in the middle plate for various values of clearances

5.18 Distribution of maximum principal stress around the hole in the middle plate for various values of clearances

5.19 Predicted distribution of normal stresses in the $\mathrm{x}$-direction $\left(\sigma_{\mathrm{xx}}\right)$ in the middle plate for a clearance of $0.02 \mathrm{~mm}$

5.20 Predicted distribution of normal stresses in the $\mathrm{x}$-direction $\left(\sigma_{\mathrm{xx}}\right)$

I $\quad \mathrm{n}$ the middle plate for a clearance of $0.15 \mathrm{~mm}$

5.21 Variations of Maximum Principal stress around the hole in the middle plate for various radii of the washer

5.22 Variations of $\sigma_{\mathrm{xx}}$ stresses around the hole in the middle plate for various radii of the washer

5.23 Variations of Von Mises stress around the hole in the middle plate for various values of the bolt diameter 
5.24Variations of Maximum Principal stress around the hole in the middle plate for various values of the bolt diameter 


\section{List of Tables}

Table Page

3.1 Dimensions of lap joint elements used in this study 32

3.2 Material Properties used in parametric studies 32 


\section{CHAPTER ONE}

\section{INTRODUCTION}

\subsection{Background}

Structural joints are essential, critical elements, whose function is to transfer loads across different sections or components of a structural assembly. Optimal design of such joints improves the performance and structural integrity and minimizes the weight of the structures, leading directly to increases in their load-carrying capability. Mechanically fastened joints are frequently used in many structures, and their design is of great importance for weight savings and failure prevention.

Composite materials offer the potential for reducing the number of individual parts and joints in a structure because they are suitable for net-shape manufacturing and thus allow large one-piece components to replace multipart assemblies. The long term strength of mechanically fastened joints is dependent on the fastening, clamping forces, the material properties of the adherands, including possible viscoelastic behavior when they are made of polymer matrix composite. The load applied to a composite is transferred from the matrix to the fibers by means of shear stress acting on the fiber surface. Therefore, it is important to achieve large overall contact surface between the matrix and the reinforcement as compared with the cross-sectional area of the fibers. The matrix in the fiber reinforced composite binds the fibers to create an engineering material and increases 
the toughness of the system. It governs, usually, the material properties transverse to fiber direction.

Minimum weight design for given loading scenarios of a structural part made of composite materials requires special design criteria that account for the anisotropic behavior of composites. Similarly, in joining techniques, the anisotropic nature of these materials must be taken into consideration properly in order to achieve structural efficiency and safety. This observation is particularly important given the fact that structural failures usually originate at joints. In general joints may be designed by using either adhesive bonding or mechanical fastening, but maximum joint efficiency in terms of the load transfer capability throughout the joint, is obtained when bonding is used as the joining technique. Bolted joints are preferred however, over other techniques, since they permit disassembly and manufacturing requirements. Since the joints are critical elements in any structure, careful design and analysis are required during development of joining concept to maintain an acceptable level of structural efficiency and integrity. The anisotropic and non-homogeneous nature of composite materials makes the analysis of bolted joints a challenging technical problem whose solution is both more difficult and more critical, than in the case of conventional metallic joints. Moreover, some composites exhibit brittle elastic behavior, which may result in premature catastrophic joint failures unless considerable care is taken during design.

The inhomogeneous nature of fiber composites leads to non-uniform stress levels within the material. High local stresses are generated at the interfaces between different 
constituents, at the edges of loaded holes, around voids and local defects, thus possibly leading to structural failure, usually in the form fiber-matrix debonding and delaminations. High stress concentrations arise at locations of discontinuities and lead, consequently to the initiation of fatigue damage and ultimate failure. Both polymeric and metallic composite materials undergo fatigue failure that usually is caused by the initiation and incremental growth of cracks under respective cycles of mechanical or thermal loading. Structural joints between members made of fiber reinforced composites may exhibit multiple failure modes, like shear-out, delamination, or bending, which are not yet fully understood. Particulate reinforced composites, where the reinforcing elements are particles, whiskers or chopped fibers are extensively used today for lightweight, high-performance components in the aerospace, and more recently the automotive industries. Particulate metal matrix composites in particular have high stiffness, good strength, and low density and may be modeled as isotropic materials for the purpose of design and analysis. Structural joints made of MMC materials with ceramic reinforcing particles may exhibit different failure modes than those experienced by fiber reinforced composite materials, or metal alloys. The main concern associated with particulate MMC's is their high brittleness and non-homogeneous micro-structure, that may cause high stress concentrations and catastrophic crack propagations, when they are subjected to hole drilling and fastening in bolted joints.

\subsection{Research objectives}

The main objective of this study is to predict numerically the stress distribution around the holes drilled in particulate composite materials and investigate the load transfer 
efficiencies through single and double lap bolted joints between structural components made of metal matrix composite or conventional metal alloys such as aluminum and steel.

\subsection{Research Methodology}

A detailed three-dimensional finite element model (FEM) has been developed for single and double lap joints. Its main feature is an accurate, 3D modeling of the contact interfaces between the connected parts as well as between the hole and the bolt surfaces.

The results of the model are validated versus predictions of a closed form solution for a simple problem of determining the stress concentrations around a circular hole. Subsequently, a parametric study has been conducted to investigate the effects of Young's Modulus, as well as the size of the bolt and the washer on the stress fields developed around the hole.

\subsection{Thesis Organization.}

A major intention of this work is to advance the current body of knowledge concerning the influence of design and fabrication parameters on the stress fields development around the holes in bolted joints. To attain this goal, each of the following chapters represents one building block that establishes a foundation for subsequent chapters. 
A general literature review is provided in Chapter 2. It presents various analytical and finite element analysis methods, as they are applied to model and understand the 3D stress fields around holes in loaded bolted joints. Chapter 3 provides a brief description of the finite element model developed in this study to evaluate the various configurations of bolted joints. Chapter 4 details the stress distributions around the holes in single lap joints. Chapter 5 presents the stress distributions around the holes in double lap bolted joints. Finally, Chapter 6 presents and discusses the results obtained for predictions and tradeoffs of main structural performance characteristics in bolted joints. 


\section{CHAPTER TWO \\ LITERATURE REVIEW}

\subsection{Research Survey}

Extensive research has been conducted to study the bolted joints. This chapter is intended to review the past analyses of the fundamental joint configurations like bolted joints. Many finite element analyses and experimental work conducted on bolted joints are available in literature review.

Winter (1956) tested bolted connections covering variables such as bolt diameter, sheet thickness, mechanical properties of sheet and bolt steels, edge distance etc. All the tests were made on Baldwin Southwark hydraulic testing machine of four load ranges. A connection slip was attached to the upper half of the connection and the other to the lower half. It measures autographically by means of special adapter arms. Four types of failures were observed.

i) Type I Longitudinal Shearing

This failure suggests that the applied force is restricted along the two failure planes by the two shear forces whose magnitude is related to end-distance e. A better correlation was obtained with the yield stress $\sigma_{\mathrm{y}}$ than with the tensile strength $\sigma_{\mathrm{t}}$. It was observed that the test results group around a straight line.

$$
\frac{P_{f}}{\sigma_{y} t}=1.40 e
$$

Normal shear stress in the sheet at failure in the two failure planes is 


$$
\tau_{s}=\frac{P_{f}}{2 t e}=0.70 \sigma_{y}
$$

These two equations are valid only when e/d does not exceed 3.5.

ii) Type II Oblique Shearing-tearing

When edge distances exceed $\mathrm{e}=3.5 \mathrm{~d}$, the appearance of the failure tended to change from Type I to Type II and some of the specimens tended to fail at loads below the above mentioned equations upto about e/d $=3.5$, as e/d increases, the bearing stress ratio also increases.

$$
\frac{\sigma_{b}}{\sigma_{y}}=1.4 \frac{e}{d}
$$

For ratios e/d exceeding 3.5 , the bearing stress

$$
\sigma_{\mathrm{b}}=4.9 \sigma_{\mathrm{y}}
$$

iii) Type III Transverse Tearing

For this type of failure, yield stress $\sigma_{\mathrm{y}}$ is considered. The failure stress follows the equation

$$
\sigma_{n e t}=\left(0.10+3.0 \frac{d}{s}\right) \sigma_{t} \leq \sigma_{t}
$$

It is observed that failure load is reached when maximum localized stress becomes equal to $\sigma_{\mathrm{t}}$, effective stress concentration factor $\mathrm{k}$ can be written as

$$
k=\frac{\sigma_{t}}{\sigma_{n e t}}=\frac{1}{0.10+3.0 \frac{d}{s}}
$$

iv) Type IV Bolt shear 
Failure occurs in the threaded length through the root areas, hence $\tau_{\mathrm{b}}$ is failure load divided by the root area.

$$
\tau_{\mathrm{b}}=0.10 \sigma_{\mathrm{tb}}
$$

In black-bolt, hand tight connections, slip into bearing at or below design loads cannot be prevented with oversize holes. In many of these connections, at ultimate load deformation can be very large.

Cope et al (2000) developed a methodology to efficiently depict mechanical fasteners in lap joints using finite elements. For highly refined fastener models and for idealized spring element representations of fasteners, the fastener materials are determined based on an empirical force-displacement relationship. A simple lap joint with three rows of mechanical fasteners were modeled using different combinations of explicit and spring element representations of fasteners. The main objective of this study was to determine the appropriate level of model refinement that is necessary for accurate SIF solutions for cracks emanating from fastener holes. FRANC 2D/L (Fracture Analysis Code 2Dimensional / Layered) is used in this study. The combinations of explicit and spring element representations of fasteners may be used to develop efficient lap joint model with the essential features of the deformation and the load transfer within the joint being retained.

Lehnoff et al. (1998) performed axisymmetric finite element analysis on bolted joints to determine the effects of threads on the bolt and member stiffness. The member stiffness decreases for different bolt diameters as the magnitude of external load 
increases. The research in this paper includes both the thread geometry of the bolt and friction. The purpose of this analysis was to determine how the bolt stiffness change as the external load increases. The bolt stiffness decreases as the thickness of the top member increases from $12 \mathrm{~mm}$ to $20 \mathrm{~mm}$. The relationship between member stiffness and external load for steel, aluminum, cast iron and aluminum/cast iron members' material combination was that the member stiffness decreases as the magnitude of external load increases for all. When the thread geometry was included, there were significant differences in bolt and member stiffness. Increase in member stiffness was observed due to the decrease in the initial member deflection when the bolt preload was applied.

Mouritz (1993) examined the plastic deformation and failure behavior of mild steel bolts subjected to tensile loads exerted at strain rates ranging from about $10^{-5}$ and $10^{2} \mathrm{~s}^{-1}$. Three experimental techniques were used to generate different strain rates. The tests include tensile testing, impact testing and underwater explosion shock testing. The results for deformation and failure behavior of threads tested under the three techniques showed similar trend. A relatively large difference in the load bearing capacities was found in the measurements of the breaking strength of the shank and the threads. When loaded in tension, the threads were significantly weaker than the shank, stating that when bolts were used in structures, their ultimate strength is determined by the failure loads of the threads. As the strain rate increases, the relative strength of thread as compared to shank decreases. About $30 \%$ elongation of bolt shanks was observed before failing when loaded using these test techniques. This suggests that the strain rates do not influence the plastic deformation behavior of the shank. The failure strength of the threads has to be 
considered when designing the load bearing capacity of bolted joints, which was significantly weaker than the shank

Menzemer et al (1999) considered shear failure of aluminum connecting elements. An experimental and analytical program was employed to study the block shear failure of aluminum connecting elements. A study was conducted on extrinsic parameters such as specimen geometry to include variation in joint length, fastener gage spacing and specimen orientation. Gage for this specimen refers to the distance between the fastener lines. Four different specimen configurations or types were examined. During the early stages of testing, the load-displacement curve showed a progressive increase in slope. Such behavior is due to the removal of slack from the load train coupled with a gradual slip into bearing. A linear load-displacement region was revealed by majority of test records upon the removal of the initial load, followed by strain hardening into plastic domain. Majority of test specimens exhibited gradual decrease in load once the ultimate load has been reached. Yielding occurs in a gradual manner similar to stress-strain curve in a uniaxial tension test. It can be concluded that larger gage spacing results in enhanced deformation in the specimen. Increased gage spacing provides greater tensile ligament area and sufficient shear along the bolt line. Block shear failure is the potential limit for connection plates having mechanical fasteners. The average shear stress is dependent on the length of the connection. Total joint capacity increases with an increase in connection length. When tensile stresses between the upper most rows of bolt reach a point, the failure or rupture of the ligament between the fastener holes is reached. Samples from the deformed and failed surfaces were examined in JEOL scanning electronic microscope. 
The surface reveals clear evidence of elongated dimples and localized shearing. A large number of voids of varying size were found distributed randomly through the fracture surface. The presence of numerous voids, of varying size, and shallow dimples on the fracture surfaces suggests the existence of locally ductile mechanisms. For a bolted joint, the efficiency of the joint loaded in shear decreases with an increase in the connection length. The effective stress varies between ultimate strength and yield strength in shear and is expressed as

$$
\sigma_{e f f}=0.6 * \sigma_{y}+0.6 * C I *\left(\sigma_{u}-\sigma_{y}\right)
$$

where $\sigma_{\text {eff }}$ is the effective stress in shear, $\sigma_{\mathrm{y}}$ is the material yield strength, $\sigma_{\mathrm{u}}$ is the material ultimate strength, and $\mathrm{CI}$ is the connection length factor.

The connection length factor becomes equal to zero and/or the effective stress equals the yield strength in shear at some joint length. For joints longer than the critical length, the average shear stress would fall below the yield stress. The shear stress would approach the ultimate tensile strength for very short joints.

Shankar et al. (2002) investigated the effect of oily film corrosion-prevention compounds on the fatigue behavior of aluminum alloy 7075-T6 mechanically fastened joints. Double lap joints with a single bolt fastener were tested under constant-amplitude fatigue loading with and without treatment with lubricative corrosion prevention compound. The final fracture occurred in the middle plate for all the specimens or in the vicinity of the reduced section at the fastener hole. Bearing mode failure initiates at the bore of the hole and 
spreads diametrically across the fastener hole while fretting mode failure initiates from flaws created by fretting damage on the surface of the middle plate. Increasing the clamping force shifts the fracture line away from the centerline of the fastener hole towards the loaded end of the middle plate. For each load case and surface condition, higher lives were recorded for specimens that failed in fretting mode than those failed in the bearing mode. This is due to the fact that the bearing failure occurs at the edge of the fastener hole, where the stress concentrations are high, while fretting mode failures occur away from the edge of the hole, wherein stress concentrations are much lower. Increasing clamping force reduces the bearing stresses and the stress intensities at the two locations become comparable, shifting the failure from one mode to another. At certain levels of friction load transfer ratio, all failure occurs in bearing mode, while at higher values of friction force, the failure occurs in fretting mode. The transition between bearing and failure modes occurs at the same load transfer ratio for both the specimens. The application of $\mathrm{CPC}$ has no effect on the fatigue life for joints that fail in bearing mode as long as the maximum friction force is maintained. At higher values of friction force, the application of CPC increases the fatigue life for specimens that fail in fretting mode.

Failure usually initiates at the first root of the bolt thread in a bolted joint. In this paper, Fukuoka et al (1998) analyzed the mechanical behaviors of bolted joints in various clamping configurations using FEM as multi-body elastic contact problem, and the effects of nominal diameter, friction and pitch error upon stress concentrations were evaluated for through bolts, studs and tap bolts. The stress concentration at the thread root becomes remarkable with increase of $\mu$. On the contrary, under the bolt head subjected to 
pure tension, it is observed that as $\mu$ increases, the stress concentration factor decreases. This opposing phenomenon on the stress concentrations occurring under the bolt head and at thread root may be explained due to difference in the sliding directions of these two regions, i.e., the bolt thread slides relatively inwards, while the bolt head expands outwards. In the tap bolt head, the stress concentration under the bolt head increase with smaller radial coefficient of friction and larger circumferential coefficient. Mechanical behavior of studs is not sensitive to friction on the contact surface compared with through bolts. Due to imperfect geometry induced by low accuracy in machining, high stress concentration factor is likely to occur at the thread roots located in the rear of the bolt hole. Recessed internal threads are effective for reducing high stress concentrations. In the loosening process, the magnitude of the bottoming torque should be more than half the tightening torque in order to restrict the rotation of a bottoming stud.

Gerbert et al (1993) investigated external loaded bolted joints of different designs. The predicted mounting stiffness of the bolt and abutment was substantially higher than the bolt load. A load application factor was introduced in VDI 2230 and a new fraction was determined which was much lower than the existing ones. The application factor was independent of the location of the external load in practical design but it was influenced by the layout of the bolt joint.

Jung et al (2000) investigated the fatigue life prediction of SUS304 stainless steel with bolted joints using fatigue modulus concept. A modified fatigue life prediction equation as an exponential function of fatigue modulus, fatigue cycle and load transfer level was 
derived to consider the relaxation of stress concentration due to fasteners. The main objective of this study was to characterize the fatigue behavior of mechanically fastened joints, identifying the relaxation of stress concentration and the effect of clamping force on the fatigue strength. Fatigue tests were conducted for plate-type specimens with bolted holes and finite element model was used to observe the stress concentration near bolts. The extension of fatigue life is obtained due to relaxation of stress concentration due to fasteners. The gradient of the stress distribution was affected nonlinearly by the clamping force. The predicted life was close to the test data, this shows that the constants of fatigue modulus degradation model contain geometry data representing notch effects.

Pratt et al (2002) developed nonlinear Finite element models to predict the loadelongation behavior of single- and dual-bolted conical-head bolted lap joints. This research shows that the test specimen results of conical-head bolts, the dual-fastener, and the axisymmetric underestimate those of the single-fastener joints upto $17 \%$ in thick panels. This underestimation of joint strength results in overly conservative joint designs with corresponding excess weight and cost. The load elongation trace was used to determine the joints stiffness and joint yield strength. "The joint yield strength is defined as the load at which a line, offset from the origin by $4 \%$ of the fastener hole size and having slope equal to the joint stiffness, intersects the load-elongation trace"[14]. The area under the load-elongation trace, or deformation energy, provides a direct measure of resistance to joint elongation. A nonlinear finite-element code NIKE3D was used to develop the models. A bilinear elastic-plastic material model was used. The effective coefficient of friction $\mu$ for subsurface shear is given by 


$$
\mu=\tau_{0} \frac{A}{P}
$$

where $\mathrm{P}=$ normal force and $\mathrm{A}=$ contact area.

The fastener-to-panel friction coefficient and the residual fastener clamp are useful in predicting the slip resistance of experimental test specimens. The dual-fastener results were halved to enable a comparison with single-fastener specimen results. The dual fastener results underestimate the yield strength of the single-fastener joint by up to $10 \%$ in thick panels. The slip resistance of the single-fastener lap joint was up to $17 \%$ higher than the thicker panels than that predicted with the dual-fastener test results. The experimental data was substantiated with finite-element analyses. The model loadelongation predictions were in excellent agreement with experimental test data.

Lehnhoff et al (1996) performed axisymmetric finite element modeling of bolted joints to show the effects of the magnitude as well as the radial location of the externally applied load on the member separation radius and the stress on the surface between the two members. Separation of the members at a certain radial distance is a phenomenon that can be detrimental to maintaining a sealed joint. The member separation is caused by the compression of the connected members in the near vicinity of the bolt. Thus, controlling this tendency for the members to separate by proper spacing of bolts in joint group can help to prevent leakage. The separation radius is the point where the two members separate due to loading. The separation radius is a function of bolt size, external load magnitude and location, and connected material thickness ratio. Larger bolts have larger separation radii. This is due to the larger contact area between the bolt head and the member. The separation was found to be nonlinearly related to changes in the magnitude 
as well as position of the external load. A 27 percent decrease for $24 \mathrm{~mm}$ bolts to 39 percent decrease for $8 \mathrm{~mm}$ bolts in the separation radius resulted with changes in the load magnitude. The external load varied from zero to the maximum that could be sustained before the joint separation for steel members. The change in separation radius for the aluminum members, cast iron members, and a combination of the two materials was on the order of 2-10 percent. Changes in the stress on the surface between the members occurred with changes in magnitude as well as radial position of the external load. The stress was found to be higher near the bolt for larger external loads and also when the radial location of the external load was increased.

A three dimensional finite element model of composite joints was developed by Ireman (1998) to determine non-uniform stress distributions through the thickness of composite laminate in the vicinity of the bolt hole. The objective of the study was to develop a three-dimensional FE model of an isolated region of the joint. The model was validated against experimental strain and deformation measurements. A number of joint configurations including variations of many significant joint parameters like laminate layup, bolt diameter, bolt type, bolt pre-tension and lateral support condition were studied. The FE models were created with IDEAS [12] and the analysis was carried out with ABAQUS [7]. The specimens used were quasi-isotropic $\left.( \pm 45 / 0 / 90)_{4}\right]_{\mathrm{s} 32}$, zerodominated $\left[\left( \pm 45 / 90 / 0_{2} / 90 / 0_{2}\right)_{2}\right]_{\mathrm{s} 32}$ and quasi-isotropic $\left[( \pm 45 / 0 / 90)_{8}\right]_{\mathrm{s} 64}$. The aluminum plates were made from AA7475-T76 and the bolt material was Titanium Ti6A114VSTA. The fitting between bolt and hole was ISO f7/H10 for all specimen configurations. For the quasi-isotropic specimens with countersunk bolts, without lateral support and no pre- 
tension of the bolt, there was good agreement between measured and computed strains. The measured and calculated relative displacement between parts is of the same magnitude. For protruding head bolts, with same conditions there was good agreement between measured and computed strains in the $45^{\circ}$ direction, while for other directions the calculated strains are slightly smaller than the measured ones. There was good agreement between the measured and calculated displacements. For zero-dominated laminates with countersunk bolts, there was good agreement between the measured and calculated strains is very good for the case without lateral support and somewhat less good for the case with lateral support. The computed and measured relative displacement curves are in good agreement for the case with lateral support, with the calculated displacement larger than the measured ones. For the case with lateral support, the experimental curves differ considerably between the two sides of the specimen and the computed curves fall between the experimental curves. The secondary bending measure was higher in experiments than in tests. This indicates that the FE models were too stiff in bending, which could be due to use of linear elements. The limitation of the model is that same friction coefficient had to be used in the ABAQUS [7] version. The friction coefficient is very uncertain as it is assumed on the basis of friction coefficient measurements at fracture surfaces. Friction coefficient measurements for a material combinations used in composite bolted joints are therefore proposed as an important subject for future research.

\subsection{Summary of Pertinent Publications}

Mechanically fastened joints typically display three failure modes: net tension, shear out and bearing. Combinations of these failures are also a possibility. There are number of 
parameters that affect the strength of mechanically fastened joints. Some are geometric parameters while others are physical parameters. The two parameters that have the most influence on the failure mode of bolted joints are the width of the joint and the distance from the bolt to the edge of the laminate. Clearance between the fastener and the hole also affects the strength of the joint. Friction between the washer and the laminate should have an effect on the joint strength. Hence all these parameters have to study to design a joint. A better method to predict bearing failures for composite laminates from the constituent lamina properties must be developed. 


\section{CHAPTER 3}

\section{FINITE ELEMENT MODEL}

\subsection{Introduction}

This chapter contains a complete description of the three-dimensional finite element model developed in order to predict the stress distribution fields around holes drilled through composite materials connected through either single or double lap bolted joints. The model results were verified theoretically by comparisons with a closed form solution.

\subsection{Modeling of the Structural joint}

General layouts of single and double lap joints, along with the geometric parameters of their elements, (adherends, bolt, and washer) are shown in Figures 3.1.1 and 3.1.2, respectively. The main dimensions selected for these elements are illustrated in Table 3.1. The joint is assumed to be assembled from prismatic connected plates made of metal alloys or composite materials, fastening bolts and washers that can spread the contact stresses between the plates and the bolt heads or nuts. For detailed modeling of the contact surfaces between the adherands of the joint, as well as between the hole and the bolt, each adherand plate was meshed by using 8-node solid brick elements as shown in Figures 3.2.1 and 3.2.2. The mesh used to model the interface between the hole and the bolt is very fine in order to simulate accurately the cylindrical surface of such hole and also capture the high stress concentrations expected to be generated around the hole as the joint is loaded. A coarser mesh was used to model the regions away from the hole, since they are expected to be subjected mainly to a uniform stress field. 
The contact surface between the connected plates is modeled chosen as a sliding interface with a friction coefficient equal to 0.05 . Such a sliding interface is placed between the upper plate and the middle plate, between the middle plate and the lower plate, between washers and the bolt and between washers and the plates. One role of such interfaces is to prevent the penetration of the elements of each plate across the contact surface when a load is applied.

\subsection{Boundary and Loading Conditions}

In the case of single lap joint, the left end of the upper plate is assumed to be fixed, whereas the uniaxial tension stress of $120 \mathrm{MPa}$ is applied at the right boundary of the bottom plate, as shown in Figure 3.3.1

In the case of the double lap joint, the left ends of the upper and lower plates are fixed, whereas the uniaxial tension stress of $30 \mathrm{MPa}$ is applied at the right edge surface of the middle plate, as shown in Figure 3.3.2

Both the single and double lap joint configurations are symmetric about the longitudinal centerline, as shown in Figures 3.3.1 and 3.3.2, respectively. Consequently, only one half of the joint is simulated in the finite element model as shown in Figure 3.2, which reduces the number of required elements and decreases the execution time for stress analysis of such joints. 


\subsection{Material model}

The material behavior of the plates, the washers and the bolt of the joint is simulated by a linear elastic plastic model. This model assumes an equivalent isotropic homogeneous material, which can be used in conjunction with beam, shell, or solid elements [6]. The parametric studies conducted by using this model assume that the jointed plates are made of metal matrix composite materials or conventional metal alloys. Both the bolt and the washers were assumed to be made of steel. To investigate the effects of the elastic properties of the jointed plated materials on the stress fields developed around the holes of the bolted joints, the parametric studies were expanded over a broad range of traditional metallic materials such as aluminum and steel as well as equivalent models of various particulate metal and polymer matrix composites.

In the linear elastic plastic material model, the stress-strain curve is represented by a bilinear relation as shown in Figure 3.4. The material behave is assumed to as a linear elastic material until the applied effective stress reaches the initial yielding stress, $\sigma_{0}$. In this elastic zone, the stress-strain relation is described by Hook's Law as:

$$
\sigma=\mathrm{E} \varepsilon
$$

where $\sigma$ is the applied uniaxial stress and $\varepsilon$ is the induced uniaxial strain. When the applied stress increases beyond the initial yield stress of the material its behavior enters the work-hardening zone, results it in both elastic and plastic deformations [2]. At each stage of the plastic deformation, a new yield surface, called subsequent yield surface, is created. The subsequent yield stress, $\sigma_{\mathrm{y}}$ is given as a function of the effective plastic strain, $\varepsilon_{e f f}^{p}$, and the plastic hardening modulus, $\mathrm{E}_{\mathrm{p}}$ according to the following relation: 


$$
\sigma_{y}=\sigma_{o}+E_{p} \varepsilon_{e f f}^{p}
$$

The plastic hardening modulus associated with the plastic component of the deformation is defined in terms of the elastic modulus, $\mathrm{E}$, and the tangent modulus, $\mathrm{E}_{\mathrm{t}}$ as follows;

$$
E_{p}=\frac{E E_{t}}{E-E_{t}}
$$

For such material model, the yielding surface is given by the Von Mises yield condition:

$$
\phi=J_{2}-\frac{\sigma_{y}^{2}}{3}
$$

where the second stress invariant, $\mathrm{J}_{2}$ is defined in terms of the components of the deviatoric stress tensor, $\mathrm{S}$, in accordance with the following equation;

$$
J_{2}=\frac{1}{2} S_{i j} S_{i j}
$$

The effective plastic strain is defined as:

$$
\varepsilon_{e f f}^{p}=\int_{0}^{t} d \varepsilon_{e f f}^{p}
$$

where

$$
d \varepsilon_{e f f}^{p}=\sqrt{\frac{2}{3}} d \varepsilon_{i j}^{p} d \varepsilon_{i j}^{p}
$$

The material properties for all the materials used in this simulation are listed in Table 3.2. 


\subsection{Results of the Finite Element Model}

The elastic deformations predicted for the single and double lap joints under the applied load as depicted in Figure 3.5 and 3.6, respectively. As one can expect, bending is observed in the single lap joint. In the double lap joint no bending is observed since the configuration is symmetric in regard with geometry, boundary and loading conditions. In a single lap joint, the bending is due to the asymmetric loading conditions about y-axis although the joint is symmetric about the $\mathrm{x}$-axis.

The triaxial state of stress that is developed around the holes in bolted joints requires the use of a failure criterion that replaces the actual stresses by an equivalent uniaxial stress. For metallic materials, the strain energy density yield criterion (Von Mises yield criterion) has been widely used for failure analysis. This theory is based on the assumption that the actual strain energy at failure of a solid body is equal to that corresponding to the equivalent uniaxial state [1]. Material failure occurs, according to this criterion, when the effective stress, $\sigma_{\mathrm{e}}$, exceeds the yield strength of the material. The effective stress or Von Mises equivalent stress can be expressed as follows in terms of the cartesian components of the 3D stress tensor:

$$
\sigma_{e}=\sqrt{\frac{1}{2}\left(\left(\sigma_{x}-\sigma_{y}\right)^{2}+\left(\sigma_{x}-\sigma_{y}\right)^{2}+\left(\sigma_{x}-\sigma_{y}\right)^{2}+3 \tau_{x y}+3 \tau_{y z}+3 \tau_{x z}\right)}
$$

The predicted distributions of Von Mises Stresses around the holes of single or double lap joint configuration are shown in Figures 3.7 and 3.8, respectively. A symmetric stress 
distribution is observed in a double lap joint, but the stress distribution around the hole of a single lap joint is asymmetric because of the associated bending deformation.

\subsection{Model Validation}

The finite element model developed in this study was validated by comparing its results with those obtained by using a closed form solution.

The classical problem of a circular hole in a flat plate has been chosen for the above validation study since the stress concentration around a hole such as shown in Figure 3.9 can be calculated through a closed-form solution. The edges of the plate are assumed to be subjected to a uniform axial stress with a value $\sigma_{0}$, as shown in Figure 3.9. The plate has a uniform thickness of $\mathrm{t}=3 \mathrm{~mm}$.

One end of the plate is fixed and at the other end a uniform stress, $\sigma_{0}$, is applied. The same finite element mesh used to model the connected plates in a bolted joint is used to model the plate under consideration for this problem. The three-dimensional stress fields generated around the hole by this finite element model are compared with those obtained by using the classical closed form solution (Timoshenko, 1959). 


\subsubsection{Closed Form Solution for a Plate with a Circular Hole}

Assuming an infinite plate in the y-direction, as shown in Figure 3.10, and elastic material behavior under the applied uniaxial load, $\sigma_{0}$, the following closed form solution is available in classical literature [1]:

$$
\left.\begin{array}{l}
\left.\sigma_{r r}=\frac{\sigma_{0}}{2}\left(1-\frac{a^{2}}{r^{2}}\right)+\frac{\sigma_{0}}{2}\left(1-\frac{a^{2}}{r^{2}}\right)\left(1-\frac{3 a^{2}}{r^{2}}\right) \cos 2 \theta\right) \\
\sigma_{\theta \theta}=\frac{\sigma_{0}}{2}\left(1+\frac{a^{2}}{r^{2}}\right)-\frac{\sigma_{0}}{2}\left(1+\frac{3 a^{4}}{r^{4}}\right) \cos 2 \theta \\
\sigma_{r \theta}=-\frac{\sigma_{0}}{2}\left(1-\frac{a^{2}}{r^{2}}\right)\left(1+\frac{3 a^{2}}{r^{2}}\right) \sin 2 \theta
\end{array}\right\}
$$

These equations predict the polar components of the stress field at any point defined by the polar coordinates $r, \theta$.

The Cartesian stress components along the $\mathrm{x}$-axis and along $\mathrm{y}$-axis can easily be obtained from the equations (3.1) at any points around the boundary of the circular hole, by using two-dimensional stress transformation equations.

The stress distribution along the $\mathrm{y}$ axis can be obtained by setting $\theta=90^{\circ}$ and $\mathrm{r}=\mathrm{x}$ in the equation (3.1): 


$$
\left.\begin{array}{l}
\sigma_{r r}=\sigma_{y y}=\frac{\sigma_{0}}{2}\left(1-\frac{a^{2}}{y^{2}}\right)+\frac{\sigma_{0}}{2}\left(1-\frac{a^{2}}{y^{2}}\right)\left(1-\frac{3 a^{2}}{y^{2}}\right) \\
\sigma_{\theta \theta}=\sigma_{x x}=-\frac{\sigma_{0} a^{2}}{y^{2}} \\
\sigma_{r \theta}=\tau_{x y}=0
\end{array}\right\}
$$

The distribution of the stress ratios $\sigma_{\mathrm{xx}} / \sigma_{0}$ and $\sigma_{\mathrm{yy}} / \sigma_{0}$ along the y-axis, as calculated from the equation (3.2) is plotted in Figure 3.11 together with the corresponding results obtained from the finite element analysis.

Similarly, the stress distribution along the $\mathrm{x}$-axis can be obtained by setting $\theta=0^{\circ}$ and $\mathrm{r}=\mathrm{x}$ in the equation (3.1).

$$
\left.\begin{array}{l}
\sigma_{r r}=\sigma_{x x}=\frac{\sigma_{0}}{2}\left(\frac{3 a^{2}}{x^{2}}-\frac{3 a^{4}}{x^{4}}\right) \\
\sigma_{\theta \theta}=\sigma_{y y}=\frac{\sigma_{0}}{2}\left(2+\frac{a^{2}}{x^{2}}+\frac{3 a^{4}}{x^{4}}\right) \\
\sigma_{r \theta}=\tau_{x y}=0
\end{array}\right\}
$$

The distributions of the $\sigma_{\mathrm{xx}} / \sigma_{0}$ and $\sigma_{\mathrm{yy}} \sigma_{0}$, stress ratio, as calculated from the equation (3.3), are plotted in Figure 3.12, along those obtained from finite element analysis. Similar comparisons between the finite element and closed form solutions are illustrated in Figure 3.14 for the distribution around the hole of radial and shear stress ratios in polar 
coordinates. A good agreement was noticed in all these graphs between finite element values and the closed form solutions. The small differences observed between these two approaches especially at the free edges, can be attributed to both numerical inaccuracies in the finite element results, and the simplifying assumptions included in the closed-form solution, such as that of an infinitely extended plate in the y-direction. 
Table 3.1 Dimensions of Lap Joint Elements used in this study

\begin{tabular}{|c|c|c|c|c|}
\hline$r_{b}(\mathrm{~mm})$ & $r_{\mathrm{w}}(\mathrm{mm})$ & $\mathrm{e}(\mathrm{mm})$ & $\mathrm{I}(\mathrm{mm})$ & $\mathrm{w}(\mathrm{mm})$ \\
\hline 3 & 4.5 & 16 & 246 & 20 \\
\hline 3 & 4.5 & 16 & 230 & 20 \\
\hline
\end{tabular}

Table 3.2 Material Properties used in Parametric Studies

\begin{tabular}{|c|c|c|c|}
\hline Material & Material Model & Property & value \\
\hline Aluminum & Linear Elastic plastic & $\begin{array}{l}\text { Density }\left(\mathrm{Kg} / \mathrm{m}^{3}\right) \\
\text { Young's Modulus }(\mathrm{GPa}) \\
\text { Poisson's Ratio } \\
\text { Yield Strength }(\mathrm{MPa})\end{array}$ & $\begin{array}{l}2700 \\
70 \\
0.35 \\
103 \\
\end{array}$ \\
\hline Steel & Linear Elastic plastic & $\begin{array}{l}\text { Density }\left(\mathrm{Kg} / \mathrm{m}^{3}\right) \\
\text { Young's Modulus }(\mathrm{GPa}) \\
\text { Poisson's Ratio } \\
\text { Yield Strength }(\mathrm{MPa})\end{array}$ & $\begin{array}{l}8030 \\
193.1 \\
0.29 \\
275\end{array}$ \\
\hline $\begin{array}{l}\text { Metal Matrix } \\
\text { Composite } \\
\text { (Lanxide Reinforced } \\
\text { Aluminum -30\% silicon } \\
\text { carbide reinforcement) }\end{array}$ & Linear Elastic plastic & $\begin{array}{l}\text { Density }\left(\mathrm{Kg} / \mathrm{m}^{3}\right) \\
\text { Tensile Strength } \\
\text { Young's Modulus }(\mathrm{GPa}) \\
\text { Yield Strength }(\mathrm{MPa}) \\
\text { Strain to failure }\end{array}$ & $\begin{array}{l}2800 \\
225 \\
127 \\
177.6 \\
0.62\end{array}$ \\
\hline $\begin{array}{l}\text { Metal Matrix } \\
\text { Composite } \\
\text { (Lanxide Reinforced } \\
\text { Aluminum -30\% silicon } \\
\text { carbide reinforcement) }\end{array}$ & $\begin{array}{l}\text { Linear Elastic plastic } \\
\text { in }\end{array}$ & $\begin{array}{l}\text { Density }\left(\mathrm{Kg} / \mathrm{m}^{3}\right) \\
\text { Young's Modulus }(\mathrm{GPa}) \\
\text { Poisson's Ratio } \\
\text { Yield Strength }(\mathrm{MPa})\end{array}$ & $\begin{array}{l}8030 \\
193.1 \\
0.29 \\
275\end{array}$ \\
\hline
\end{tabular}




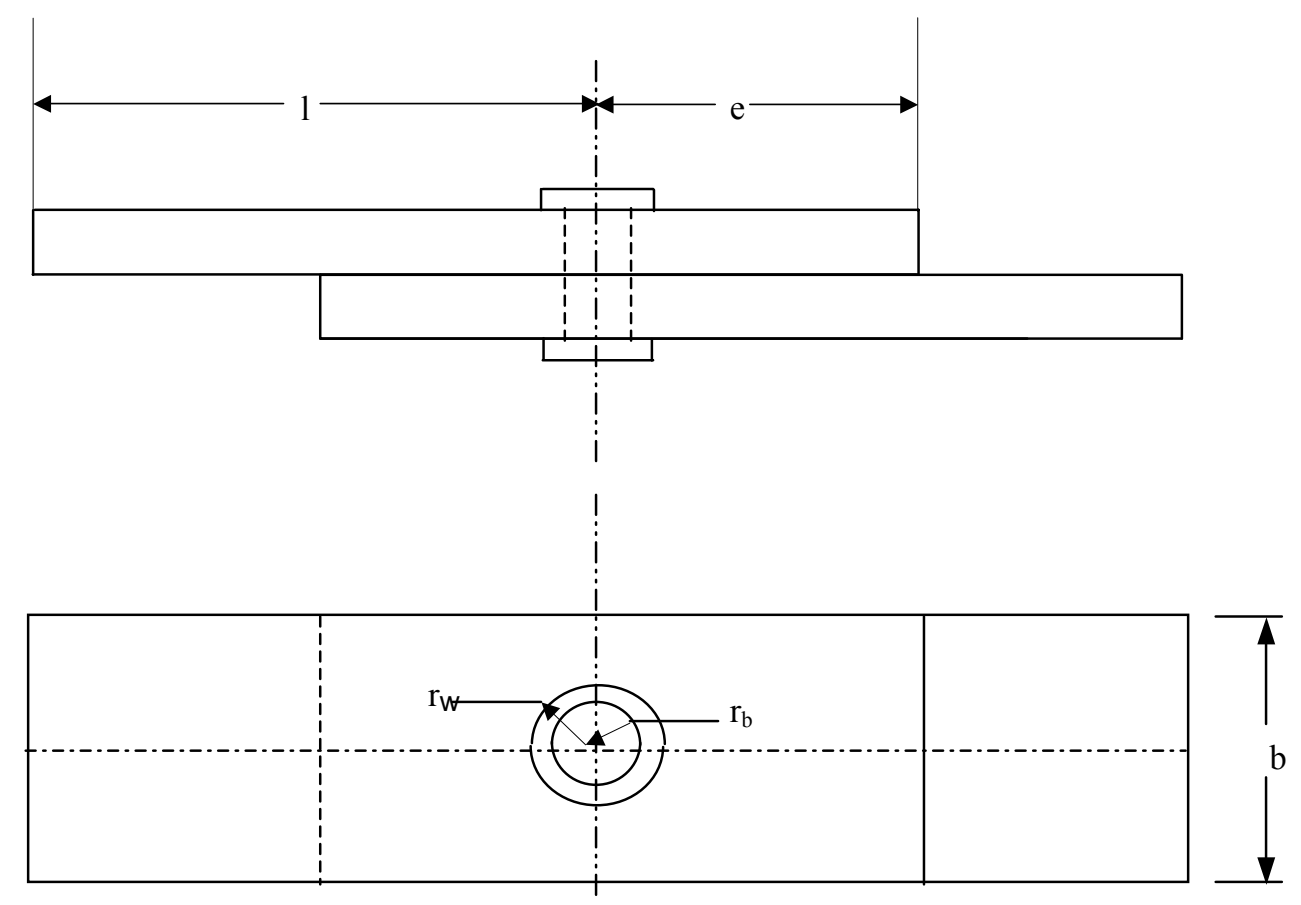

Fig. 3.1.1 Schematic of a Single Lap Bolted Joint



Fig. 3.1.2 Schematic of a Double Lap Bolted Joint 


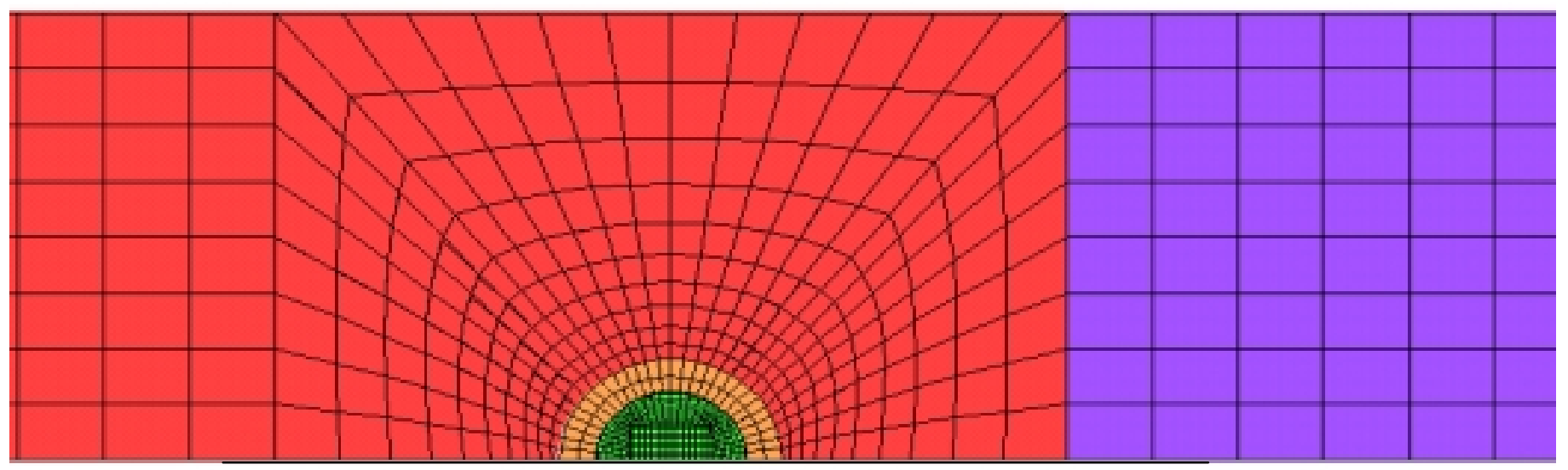

Figure 3.2.1 Finite Element Model of the Double Lap Bolted Joint
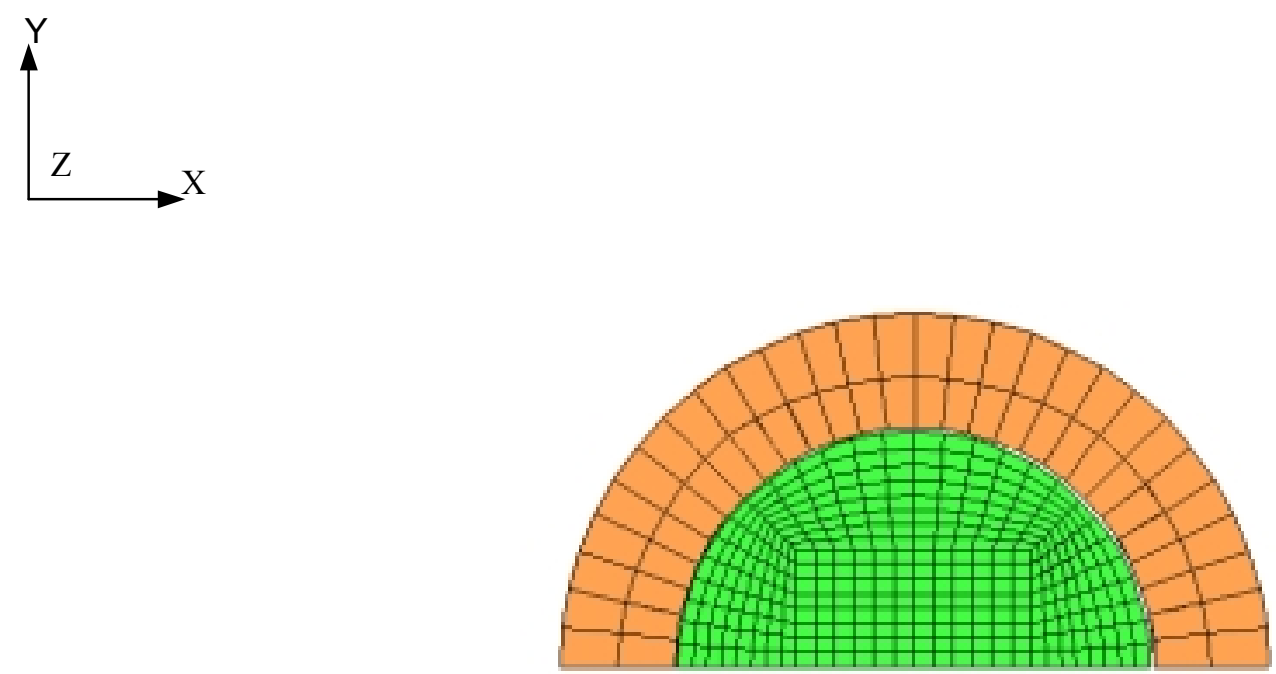

Figure 3.2.2 Finite Element Mesh for the Bolt and the Washer of a Bolted Joint 


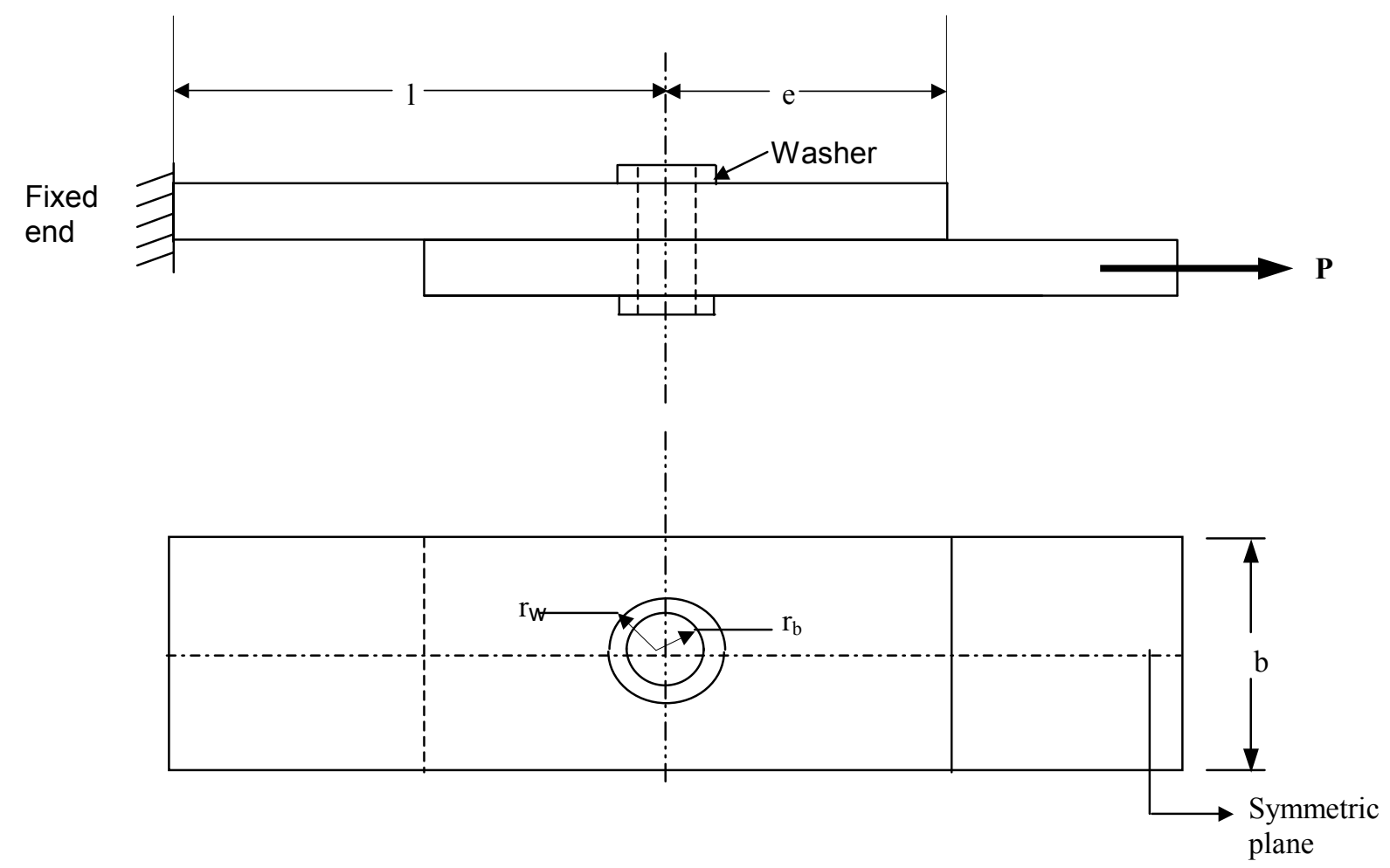

Fig. 3.3.1 Loading and Boundary Conditions for a Single Lap Bolted Joint

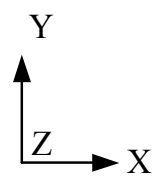





Fig. 3.3.2 Loading and Boundary Conditions for a Double Lap Bolted Joint

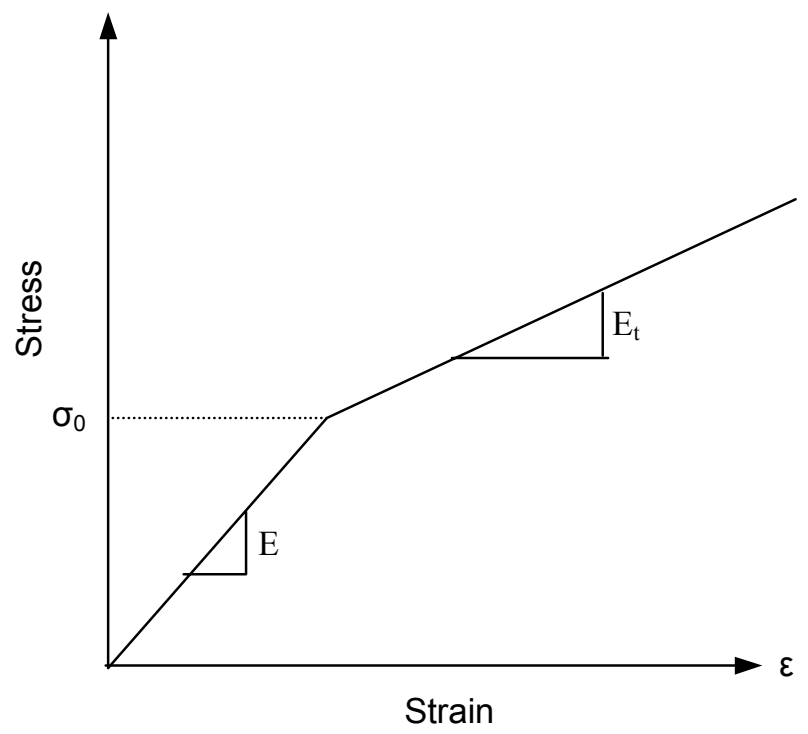

Figure 3.4 Stress Strain Curve for Linear Elastic Plastic Material Model 


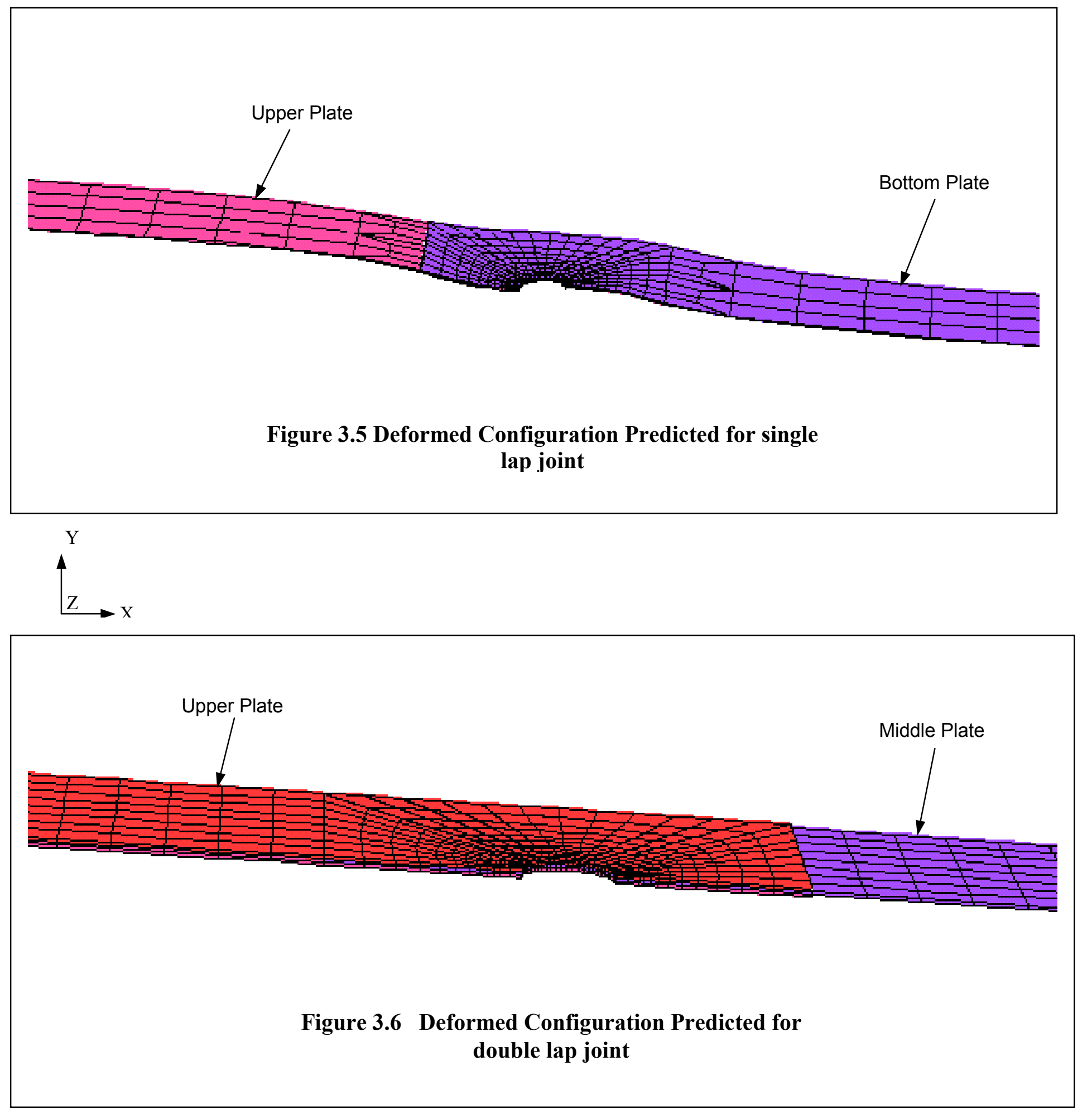




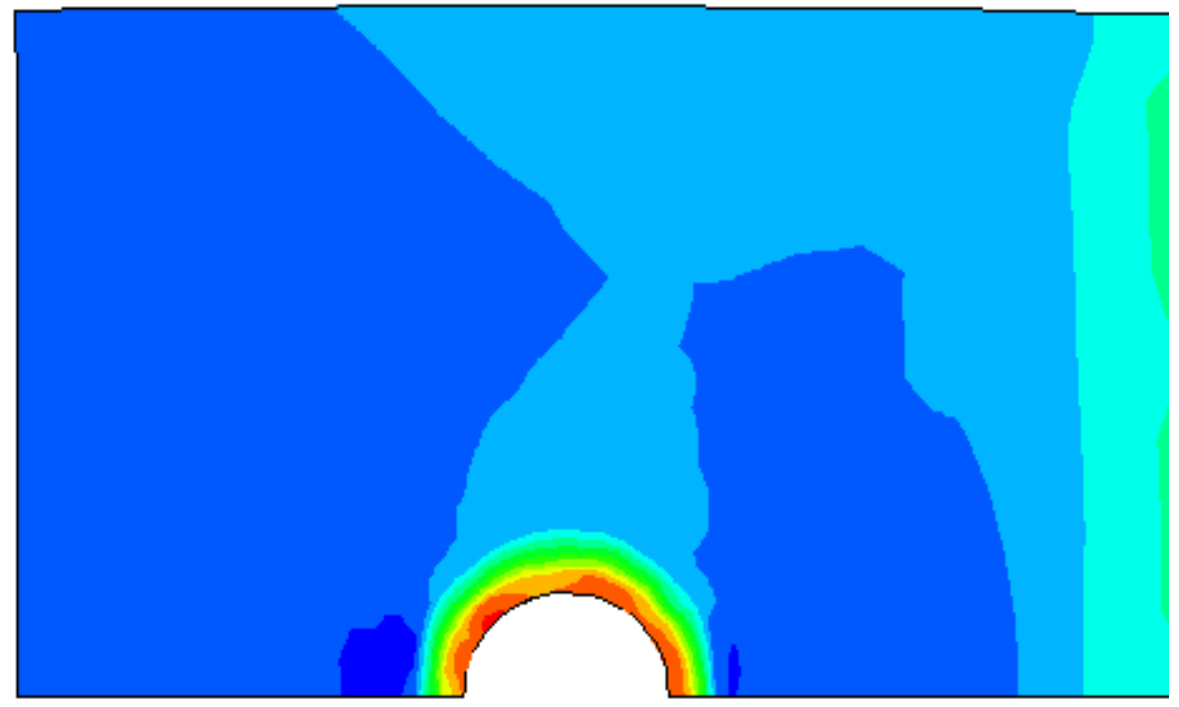

$1.324 \mathrm{E}+01$ $2.347 \mathrm{E}+01$ 3.371E +01 4.334E+01 $5.417 \mathrm{E}+01$ $6.440 \mathrm{E}+01$ $7.463 \mathrm{E}+01$ $8.486 \mathrm{E}+01$ $9.510 \mathrm{E}+01$ $1.053 \mathrm{E}+02$

$1.156 \mathrm{E}+02$

$1.258 \mathrm{E}+02$

$1.360 \mathrm{E}+02$

Figure 3.7 Von Mises Stress Field Around the Hole for the lower plate Y of a Single Lap Joint
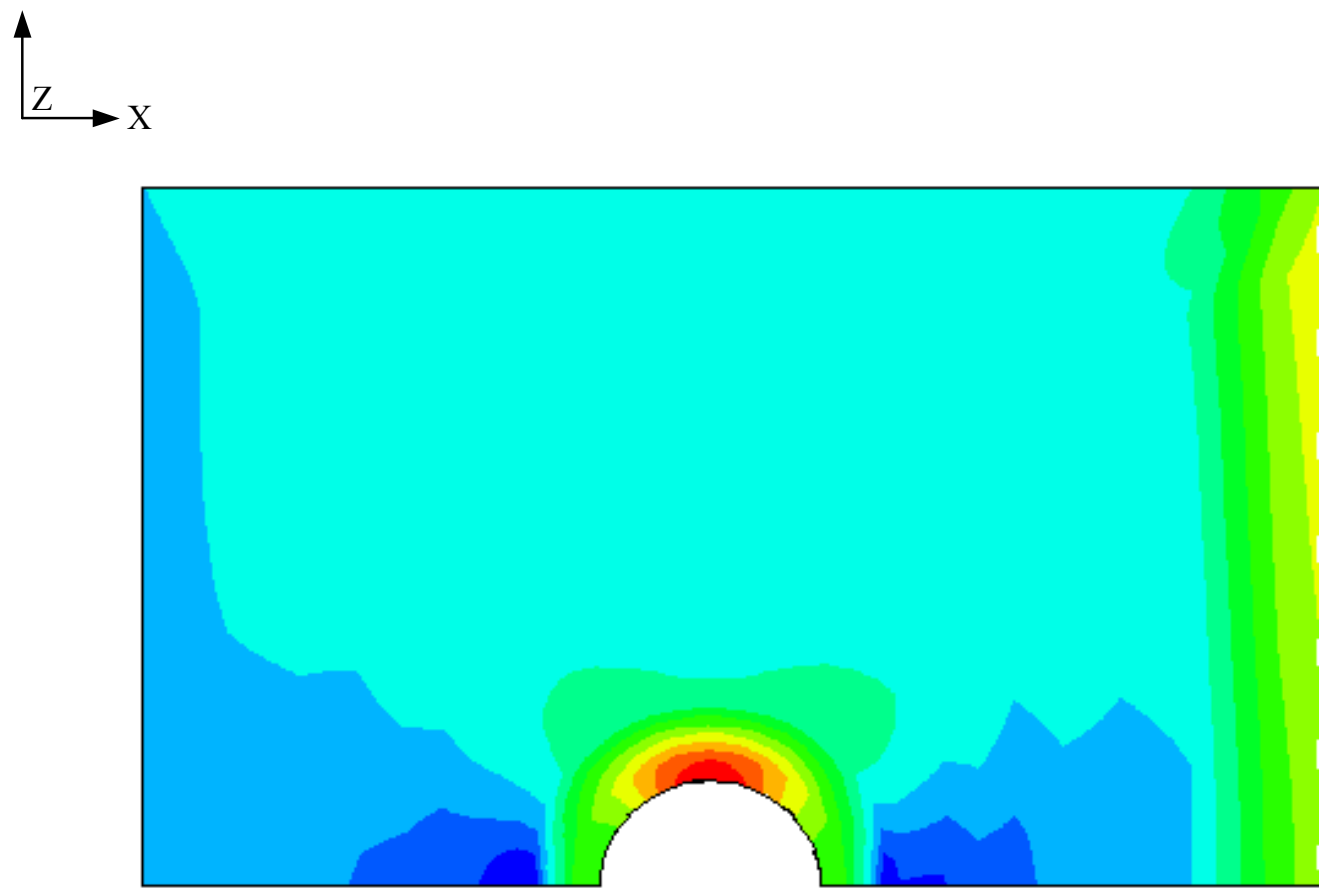

$2.045 \mathrm{E}+00$

$4.691 \mathrm{E}+00$

$7.398 \mathrm{E}+00$

$9.984 \mathrm{E}+00$

$1.263 \mathrm{E}+01$

$1.528 \mathrm{E}+01$

$1.792 \mathrm{E}+01$

$2.057 \mathrm{E}+01$

$2.322 \mathrm{E}+01$

$2.586 \mathrm{E}+01$

$2.851 \mathrm{E}+01$

$3.116 \mathrm{E}+01$

$3.380 \mathrm{E}+01$

Figure 3.8 Von Mises Stress Field Around the Hole for the middle plate of a Double Lap Joint 


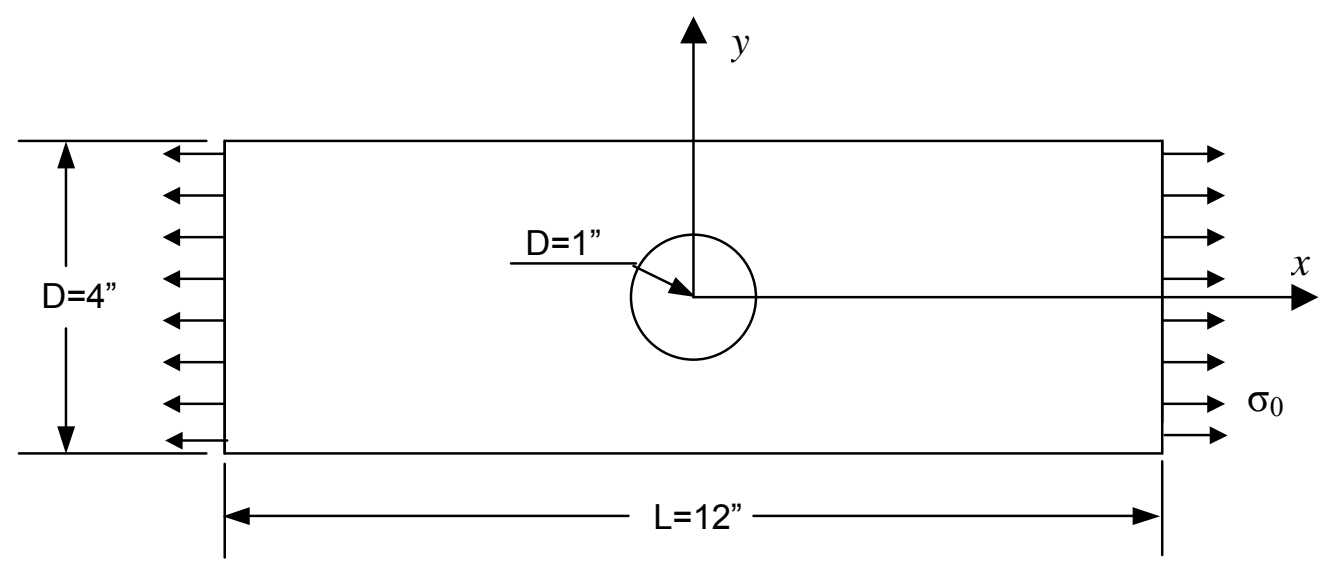

Figure 3.9 Circular Hole in a Flat Plate for Validation of FEM Joint Model

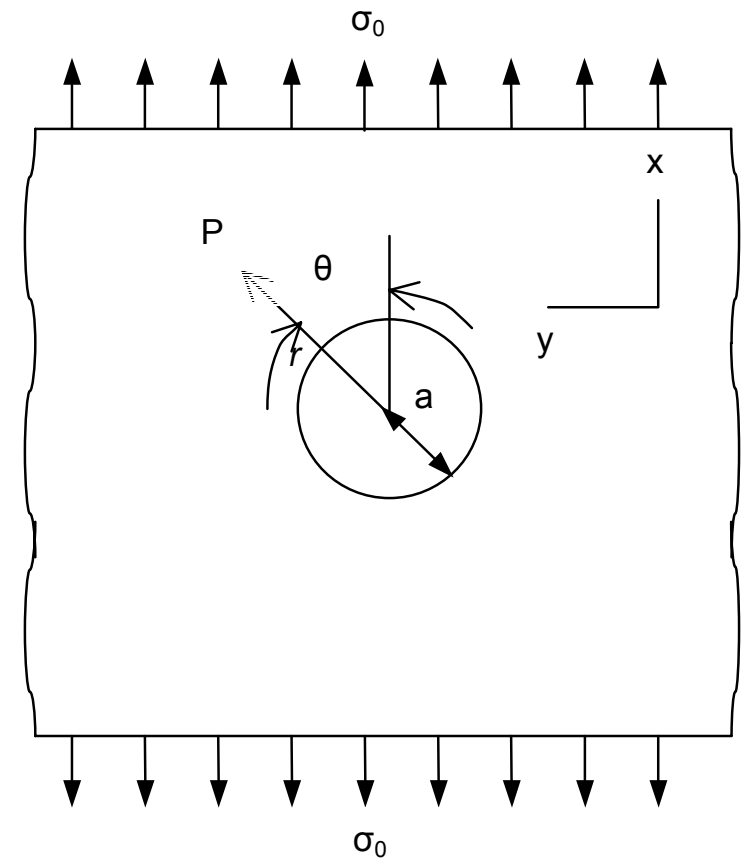

Figure 3.10 Infinite Flat Plate with Circular a Hole for Correlation with Closed-Form Solution 


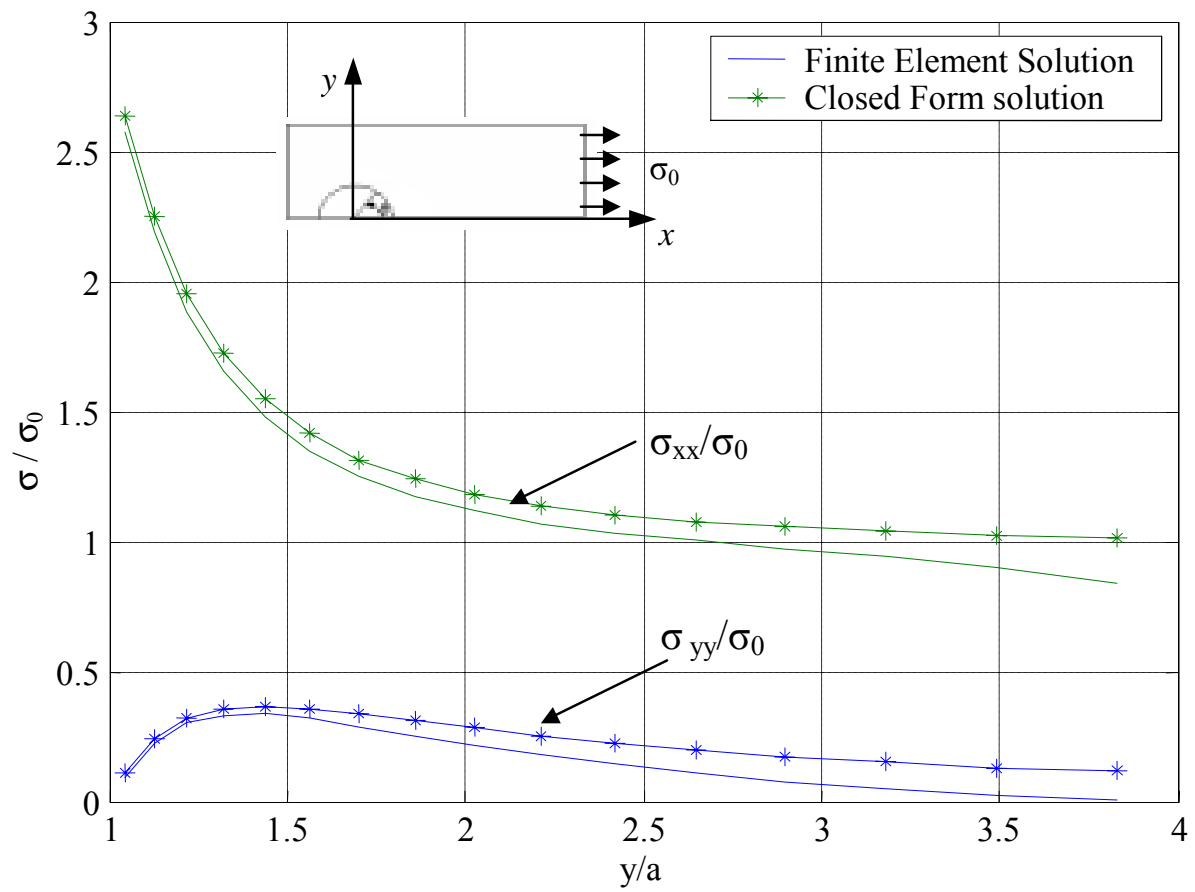

Figure 3.11 Distribution of $\sigma_{\mathrm{xx}} / \sigma_{0}$ and $\sigma_{\mathrm{yy}} / \sigma_{0}$ Stress Ratios Along the $y$-axis

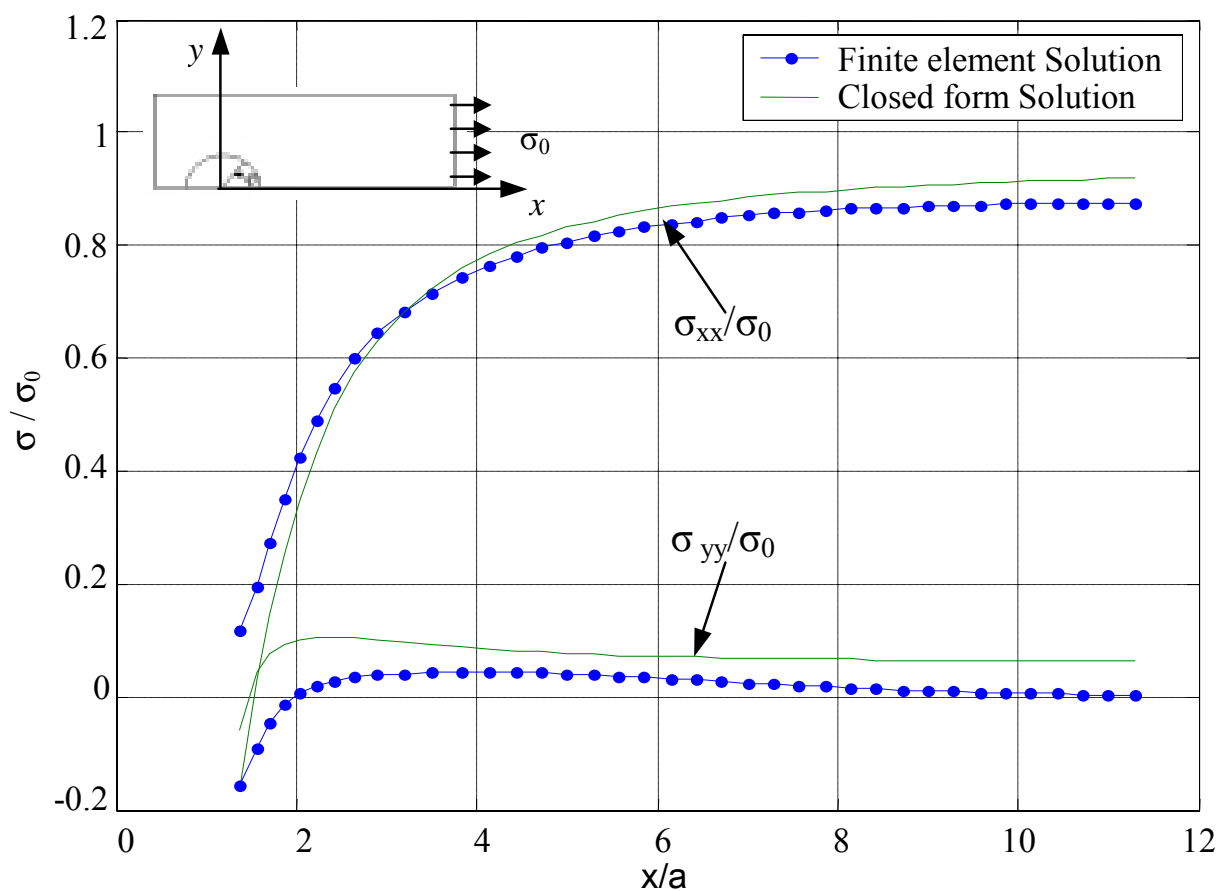

Figure 3.12 Distribution of $\sigma_{\mathrm{xx}} / \sigma_{0}$ and $\sigma_{\mathrm{yy}} / \sigma_{0}$ Stress Ratios Along the $x$-axis 


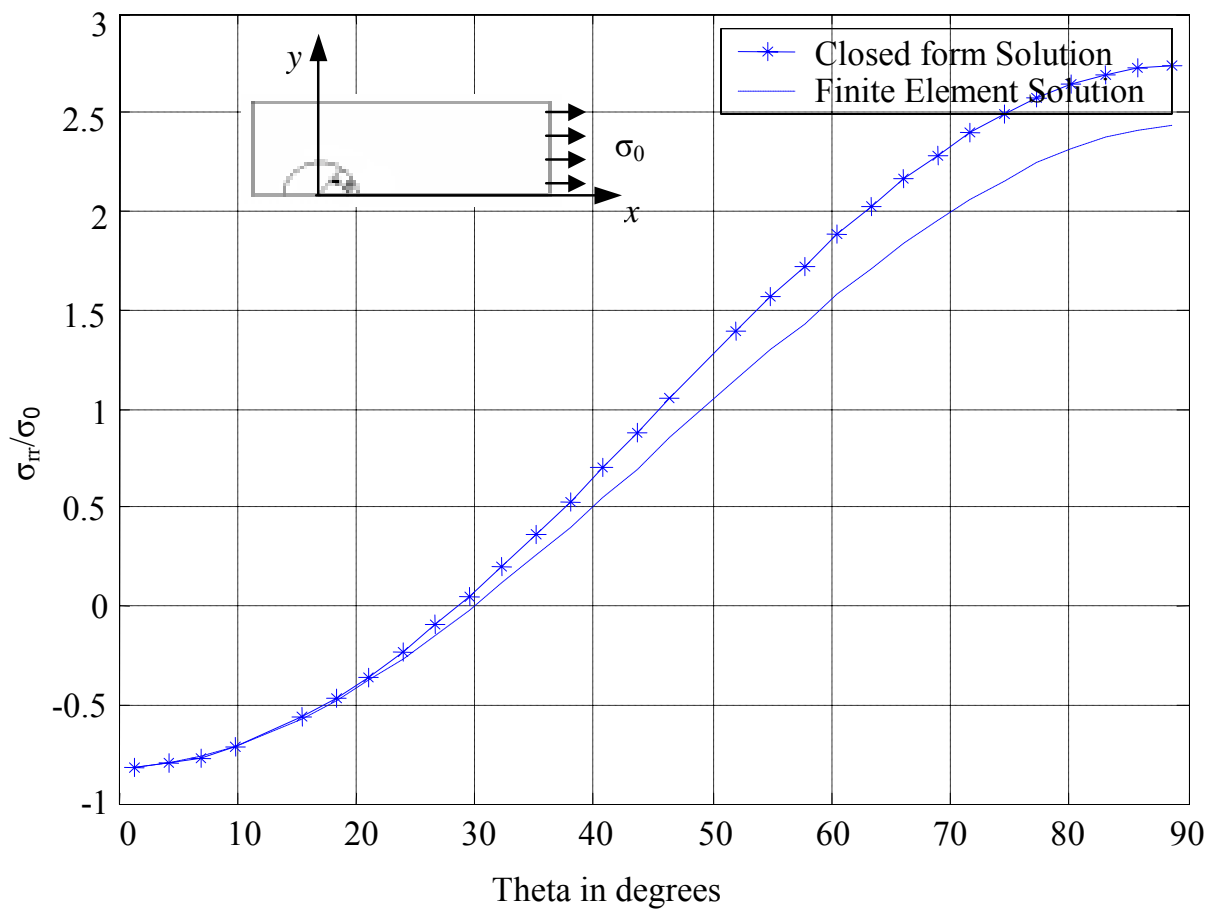

Figure 3.13.1 Distribution of $\sigma_{\mathrm{rr}} / \sigma_{0}$ Ratio Around the Hole

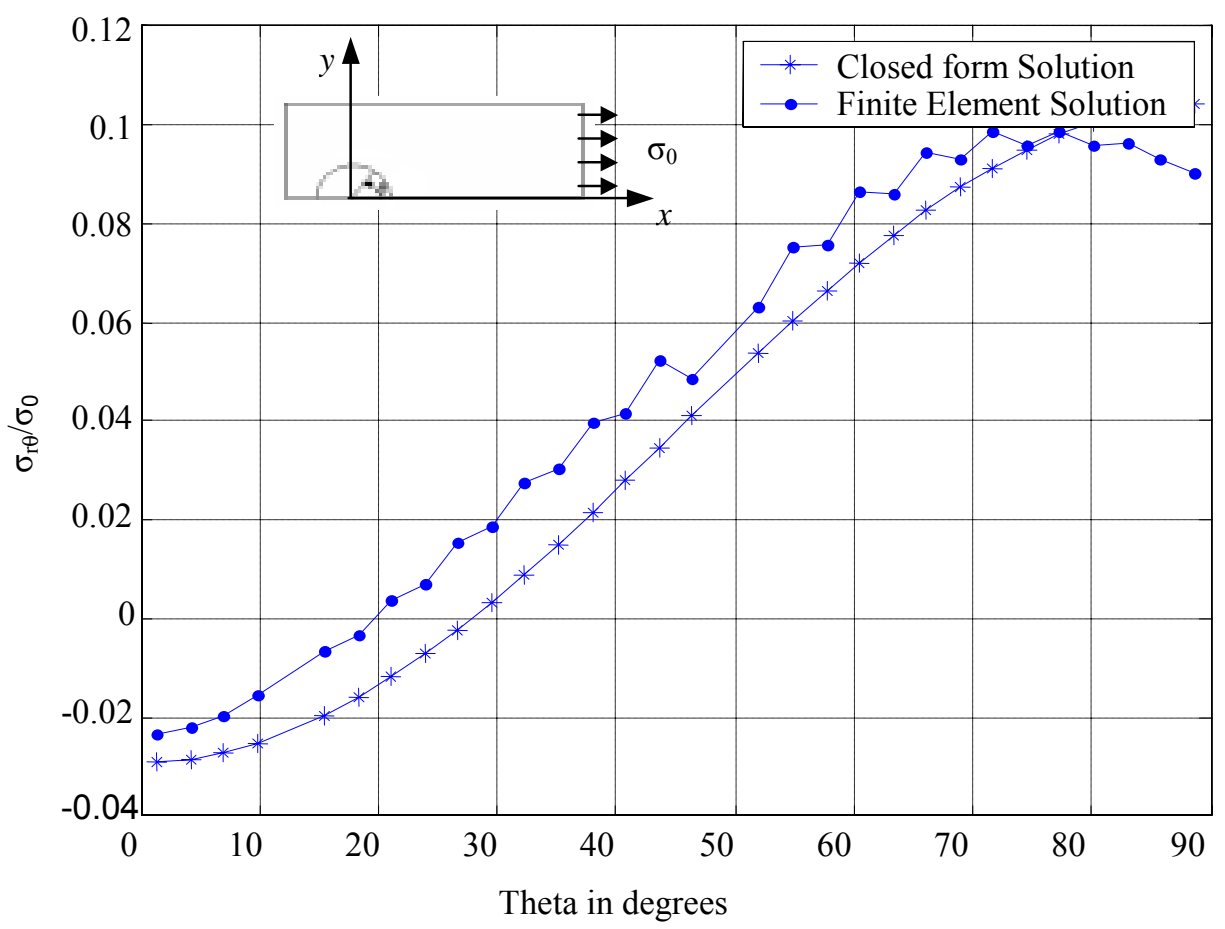

Figure 3.13.2 Distribution of $\sigma_{\mathrm{r} \theta} / \sigma_{0}$ Ratio Around the Hole 


\section{CHAPTER FOUR}

\section{RESULTS FOR SINGLE LAP JOINT}

\subsection{Introduction}

This chapter presents a detailed description of the stress fields calculated through the finite element model for a single lap joint configuration. A parametric study has been conducted to examine the effects of certain design parameters such the tightening pressure, the Young's Modulus, the diameters' of the washer and the bolt on the stress distributions around the hole.

\subsection{Stress Distribution Around the Hole}

In single lap joints, the axial load applied on the joint is transferred from one member to the other through two main types of mechanisms mainly the friction at the interface between the jointed plates and the transverse shear force transmitted to the bolt through the contact between the bolt and the plates. The eccentricity of the loading in a single lap joint, as shown in Figure 3.3.1, causes bending of the joint as shown in Figure 4.1. The possible failure modes of single lap joints are more complex and difficult to predict then in double lap joints, because of the bending effects associated with the fact that the load path through the joint is not a straight line. 
Figure 4.2 shows the fringes describing the distribution of axial stresses in the $\mathrm{x}$ direction, as developed around the hole in the lower plate, as the lower plate is subjected to an axial tensile load applied along its right edge. A uniform stress distribution is observed away from the hole that is equal in magnitude as one might expect to the applied tensile stress at right edge boundary of the joint. A very low compressive stress at the contact side between the bolt surface and the hole indicates that the joint is transferring most of the applied load through friction at the interfaces between the connected plates.

Figure 4.3 illustrates that the maximum principal stress distribution around the hole of the lower plate is similar to the distribution of the $\left(\sigma_{\mathrm{xx}}\right)$ stress components, which is expected for a uniaxial loading case as assumed here. Figure 4.4 illustrates the predicted distribution of shear stresses $\left(\tau_{\mathrm{xy}}\right)$ around the hole in the lower plate. One may notice that this stress distribution is not symmetric, most likely this can be because of the bending effects associated with the axial loading of single lap joints. Figure 4.5 depicts the predicted distribution of normal stresses in the transverse $\mathrm{Z}$, direction $\left(\sigma_{\mathrm{zz}}\right)$ which turn out to be almost equal as required by equilibrium conditions, to the applied tightening pressure on the washer.

Figure 4.6 shows the distribution of the effective stress developed in the lower plate of the joint where the axial load is applied. It can be noticed that the area around the hole is subjected to high concentration of stresses indicating a high probability that potential failure will be initiated in that region. 


\subsection{Effect of tightening pressures}

The effect of tightening pressure is investigated by applying various levels of pressure on the washer surfaces, and examining the associated changes in the distribution of stresses developed in the connected plates around the hole for each case. Three different levels of tightening pressure $30 \mathrm{MPa}, 60 \mathrm{MPa}$ and $120 \mathrm{MPa}$ are applied on the washer surface in the $\mathrm{z}$-direction while an axial load of $120 \mathrm{MPa}$ is applied on the right edge of the lower plate in the $\mathrm{x}$-direction. The distribution of normal stresses in the $\mathrm{x}$-direction $\left(\sigma_{\mathrm{xx}}\right)$ developed around the hole for different cases of tightening pressures are plotted in Figure 4.7. It can be noticed that increasing the tightening pressure on the bolt results in a decrease in the $\left(\sigma_{\mathrm{xx}}\right)$ stress levels. This is attributed to the increase in the amount of the load transferred through friction as the tightening pressure increases. Since frictional forces are likely to increase with the increase of the bolt tightening pressure, the shear stresses in the plane of the plate (xy-plane) will also increase as can be seen in Figure 4.8.

Figure 4.9 displays the variations around the hole of the normal stresses in the z-direction $\left(\sigma_{\mathrm{zz}}\right)$. The plots validate that indeed this is a uniform distribution, where the magnitude of the $\sigma_{\mathrm{zz}}$-stresses is equal to the applied tightening pressure. Figure 4.10 illustrates for the distribution of effective stresses developed around the hole for different tightening pressures. It can be seen that increasing tightening pressures results in an increase of equivalent stresses. The relationship between the bolt tightening pressure and the average value of effective stress is nonlinear as indicated by the curve shown in Figure 4.11. 


\subsection{Effect of Young's Modulus}

This effect is studied by changing the Young's Modulus of the jointed plates. Three different materials have been chosen for this study, namely aluminum, whose Young's modulus is $\mathrm{E}=70 \mathrm{GPa}$, steel or aluminum reinforced with $55 \%$ silicon carbide for which $\mathrm{E}=199 \mathrm{GPa}$ and aluminum reinforced with $30 \%$ silicon carbide for which the equivalent Young's modulus is E=127GPa. The curves plotted in Figure 4.12 indicate that the effective stress around the hole is not affected significantly by changing the Young's Modulus. Therefore, the choice of a material of the connected plates has an insignificant effect on the stresses developed around the hole. The normal stress components in the xdirection $\left(\sigma_{\mathrm{xx}}\right)$, appears, however, to display a higher sensitivity to the material properties of the plates than the effective stresses, as indicated by the plots in Figure 4.13.

A variation in the Young's Modulus of the connected plates has an effect however, on the strains developed around the hole. This effect is illustrated in figure 4.14 for the normal strain component in the $\mathrm{x}$-direction, $\left(\varepsilon_{\mathrm{xx}}\right)$. One could expect, the strains around the hole are reduced when stiffer materials are used for the connected plates. Similar trends are observed in figures 4.15 and 4.16 for the normal strain component in the y-direction and the normal strain component in the z-direction, respectively. 


\subsection{Effect of bolt diameter}

The effect of the bolt diameter on the stress fields in the connected plates is studied by running the finite element model for various values of the bolt diameter value keeping other parameters constant. Bolt diameters of $5 \mathrm{~mm}, 6 \mathrm{~mm}$ and $6.5 \mathrm{~mm}$ are used.

Larger bolt diameters lead to higher stresses in the connected plates, as illustrated in Figure 4.7, 4.18 and 4.19 for the effective stress, the maximum principal stresses and the $\sigma_{\mathrm{xx}}$ stress component, respectively.

\subsection{Effect of Washer Diameter}

Three different values of the washer diameters namely $8 \mathrm{~mm}, 12 \mathrm{~mm}$ and $18 \mathrm{~mm}$ have been used to investigate the effect of this parameter on the associated fields of stress. Figures $4.20,4.21$ and 4.22 show that larger washers lead to higher average values of the effective stress, the maximum principal stress and the $\sigma_{\mathrm{xx}}$-stress components respectively. A larger washer diameter transfers high axial stresses to the back of the hole due to friction, hence high stresses are found at the back of the hole. 


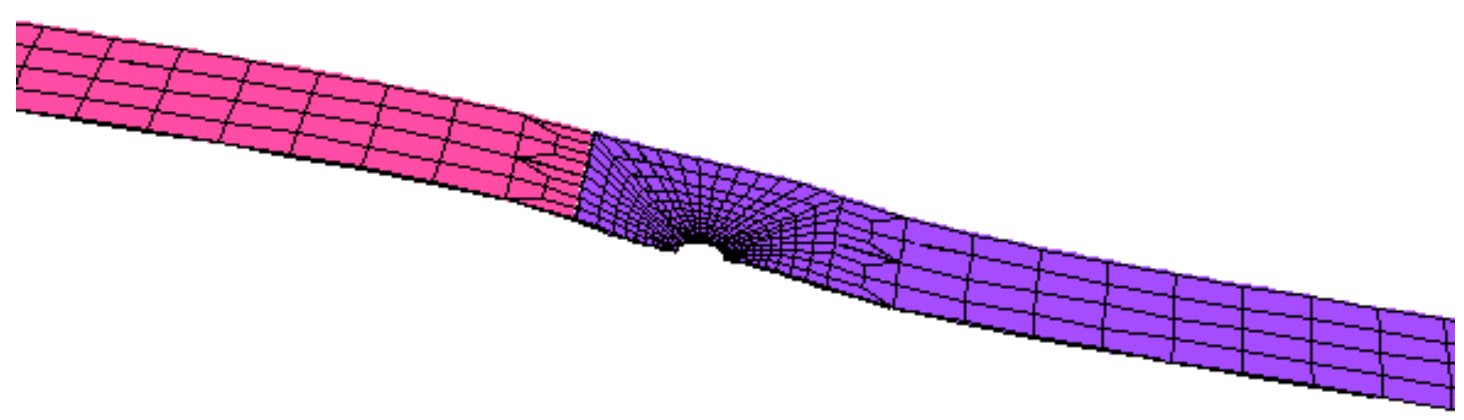

Figure 4.1 Predicted Deformation of a Single Lap Joint Under Axial Loading

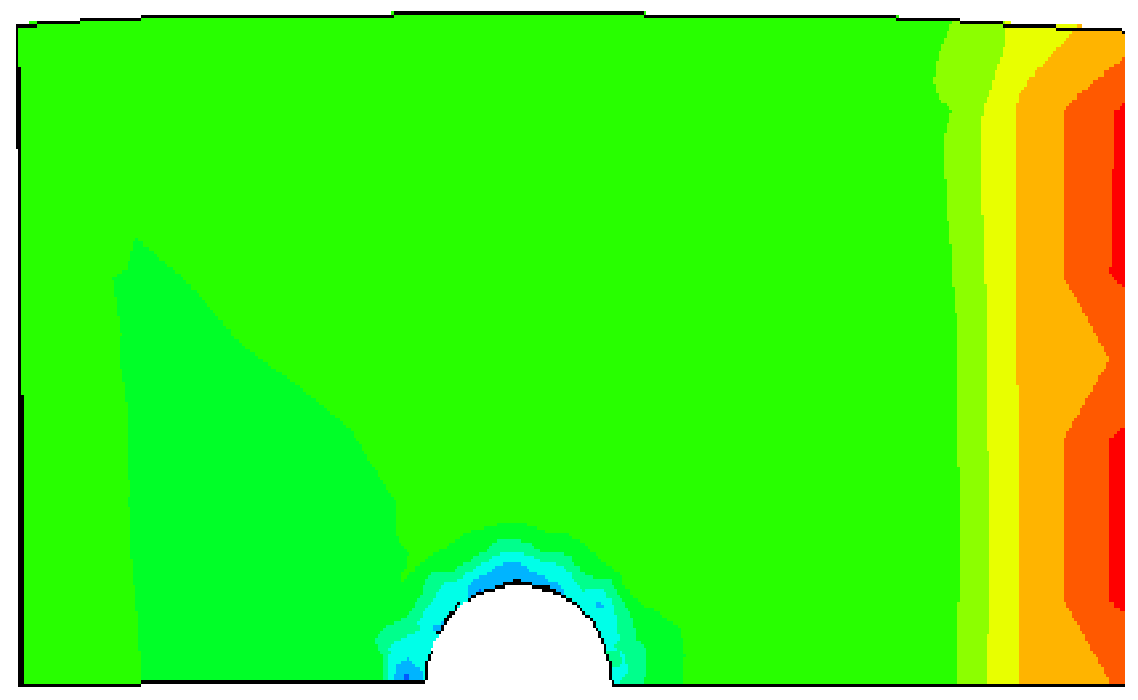

$-8.575 \mathrm{E}+00$ $4.653 \mathrm{E}+00$

$1.789 \mathrm{E}+01$

$3.113 \mathrm{E}+01$

$4.436 \mathrm{E}+01$

$5.759 \mathrm{E}+01$

$7.083 \mathrm{E}+01$

$8.406 \mathrm{E}+01$

$9.729 \mathrm{E}+01$

$1.105 \mathrm{E}+02$

$1.238 \mathrm{E}+02$

$1.370 \mathrm{E}+02$

$1.502 \mathrm{E}+02$

Figure 4.2 Predicted Distribution of Normal Stresses in the x-Direction $\left(\sigma_{\mathrm{xx}}\right)$ in the Lower Plate of a Single Lap Joint 




$-6.400 \mathrm{E}+00$

$6.653 \mathrm{E}+00$

$1.970 \mathrm{E}+01$

$3.276 \mathrm{E}+01$

$4.581 \mathrm{E}+01$

$5.886 \mathrm{E}+01$

$7.191 \mathrm{E}+01$

$8.497 \mathrm{E}+01$

$9.802 \mathrm{E}+01$

$1.111 \mathrm{E}+01$

$1.241 \mathrm{E}+02$

$1.372 \mathrm{E}+02$

$1.502 \mathrm{E}+02$

Figure 4.3 Distribution of Maximum Principal Stress in the Lower Plate of Single Lap Joint

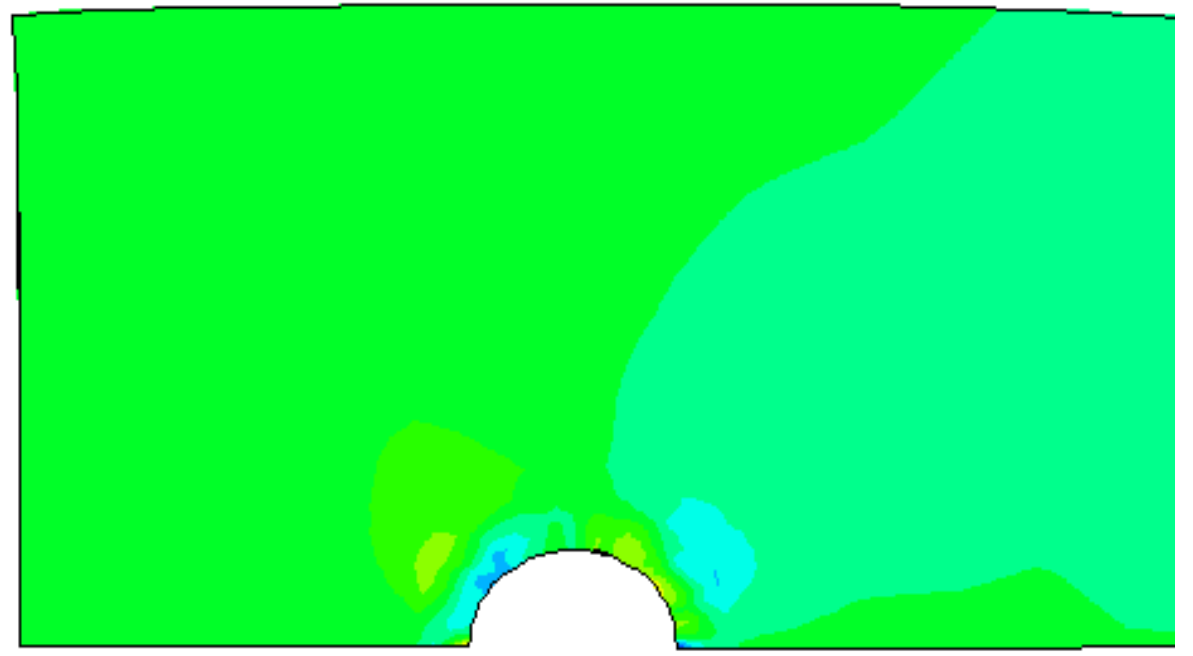

$-2.274 \mathrm{E}+01$

$-1.835 \mathrm{E}+01$

$-1.396 \mathrm{E}+01$

$-9.568 \mathrm{E}+00$

$-5.176 \mathrm{E}+00$

$-7.854 \mathrm{E}-01$

$3.606 \mathrm{E}+00$

$7.997 \mathrm{E}+00$

$1.239 \mathrm{E}+01$

$1.678 \mathrm{E}+01$

$2.117 \mathrm{E}+01$

$2.556 \mathrm{E}+01$

$2.995 \mathrm{E}+01$

Figure 4.4 Predicted Distribution of Shear Stress $\left(\tau_{x y}\right)$ in the Lower Plate of Single Lap Joint 


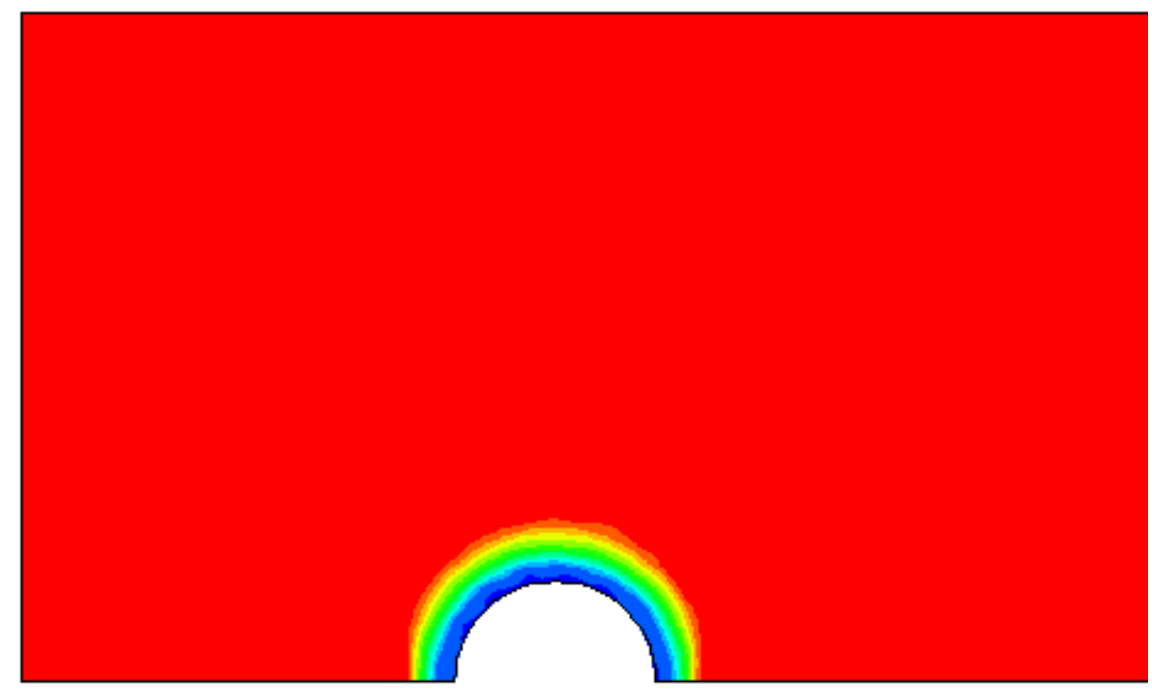

$-1.361 \mathrm{E}+02$

$-1.241 \mathrm{E}+02$

$-1.121 \mathrm{E}+02$

$-1.002 \mathrm{E}+02$

$-8.820 \mathrm{E}+01$

$-7.642 \mathrm{E}+01$

$-6.427 \mathrm{E}+01$

$-5.231 \mathrm{E}+01$

$-4.035 \mathrm{E}+01$

$-4.035 \mathrm{E}+01$

$-2.838 \mathrm{E}+01$

$-1.642 \mathrm{E}+01$

$-4.456 \mathrm{E}+00$

$7.507 \mathrm{E}+00$

Figure 4.5 Predicted Distribution of Normal Stresses in the Lower Plate Z-Direction $\left(\sigma_{\mathrm{zz}}\right)$

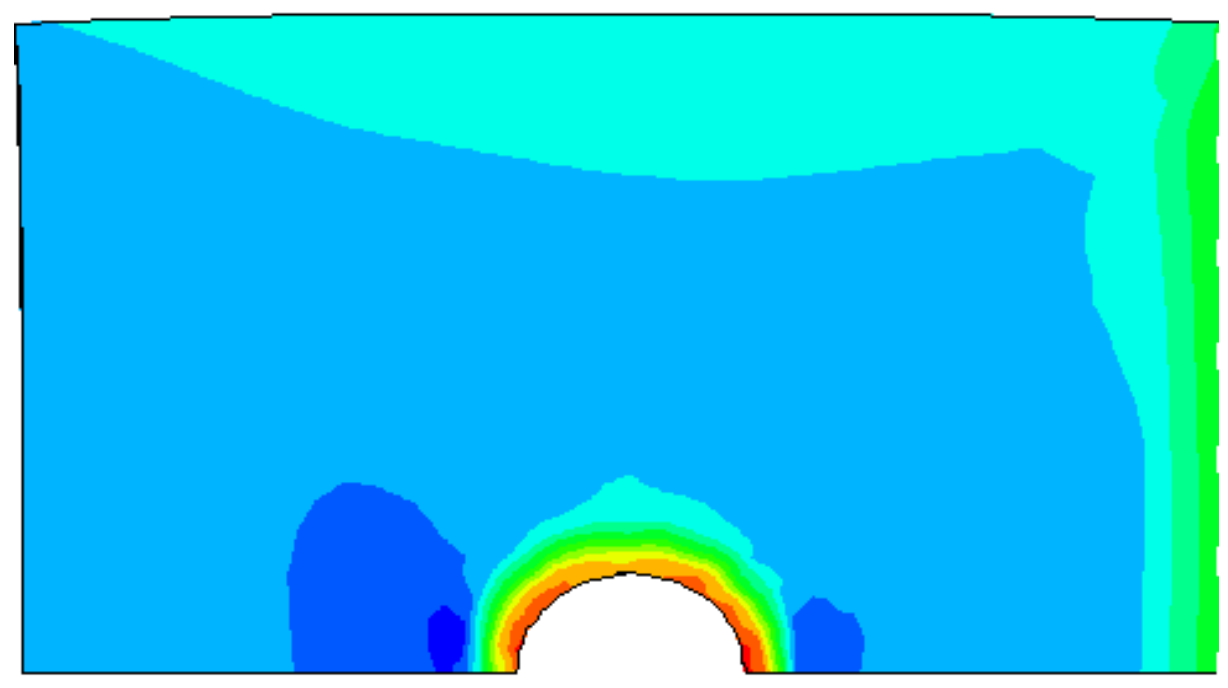

$5.140 \mathrm{E}+01$

$6.033 \mathrm{E}+01$

$7.838 \mathrm{E}+01$

$8.711 \mathrm{E}+01$

$9.604 \mathrm{E}+01$

$1.050 \mathrm{E}+02$

$1.139 \mathrm{E}+02$

$1.228 \mathrm{E}+02$

$1.317 \mathrm{E}+02$

$1.407 \mathrm{E}+02$

$1.496 \mathrm{E}+02$

$1.515 \mathrm{E}+02$

Figure 4.6 Von Mises Stress Distribution Around the Hole for the Lower Plate 


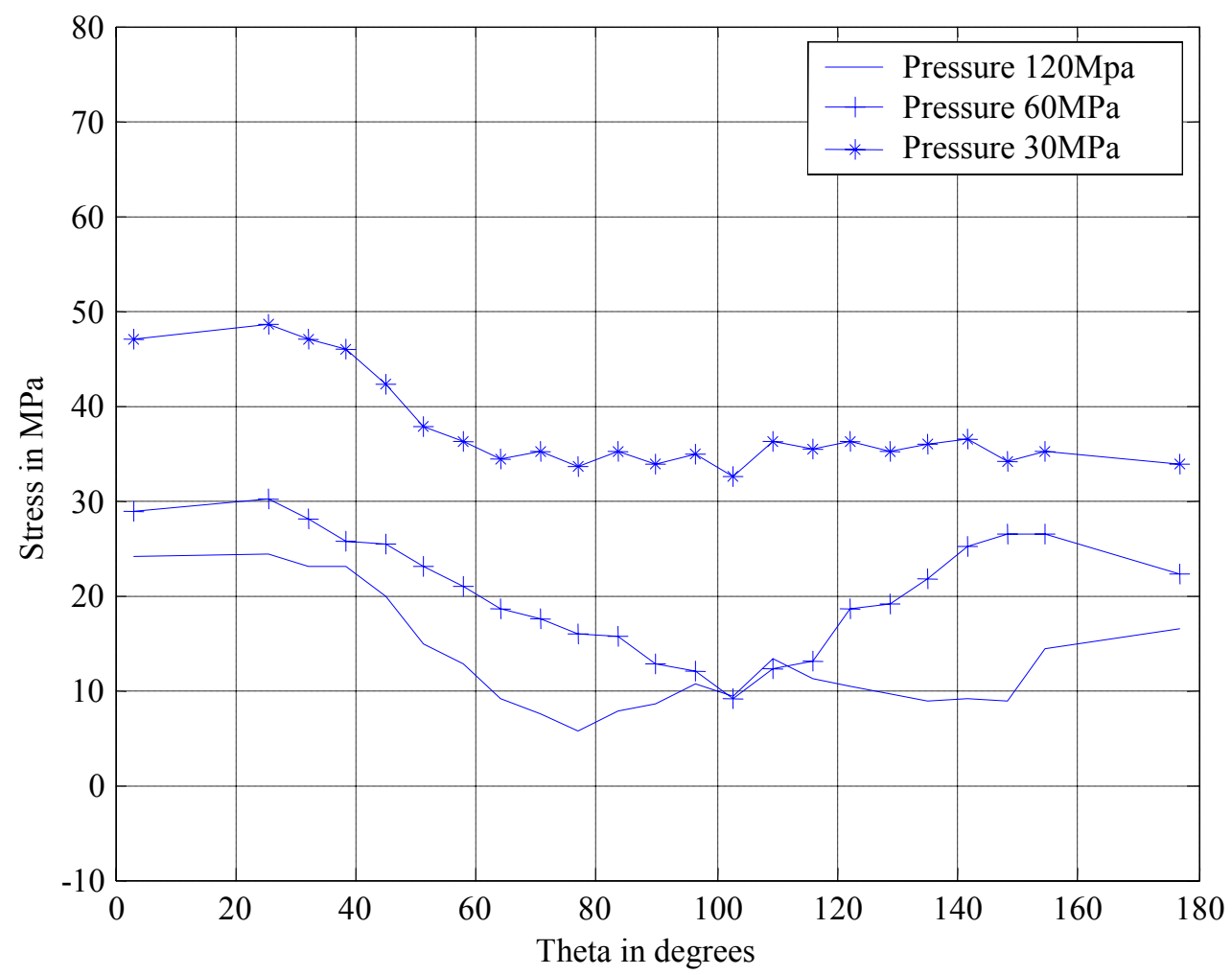

Figure 4.7 Predicted Distributions of $\left(\sigma_{\mathrm{xx}}\right)$ Stress Components Around the Hole in the Lower Plate for Different Levels of Bolt Tightening Pressure

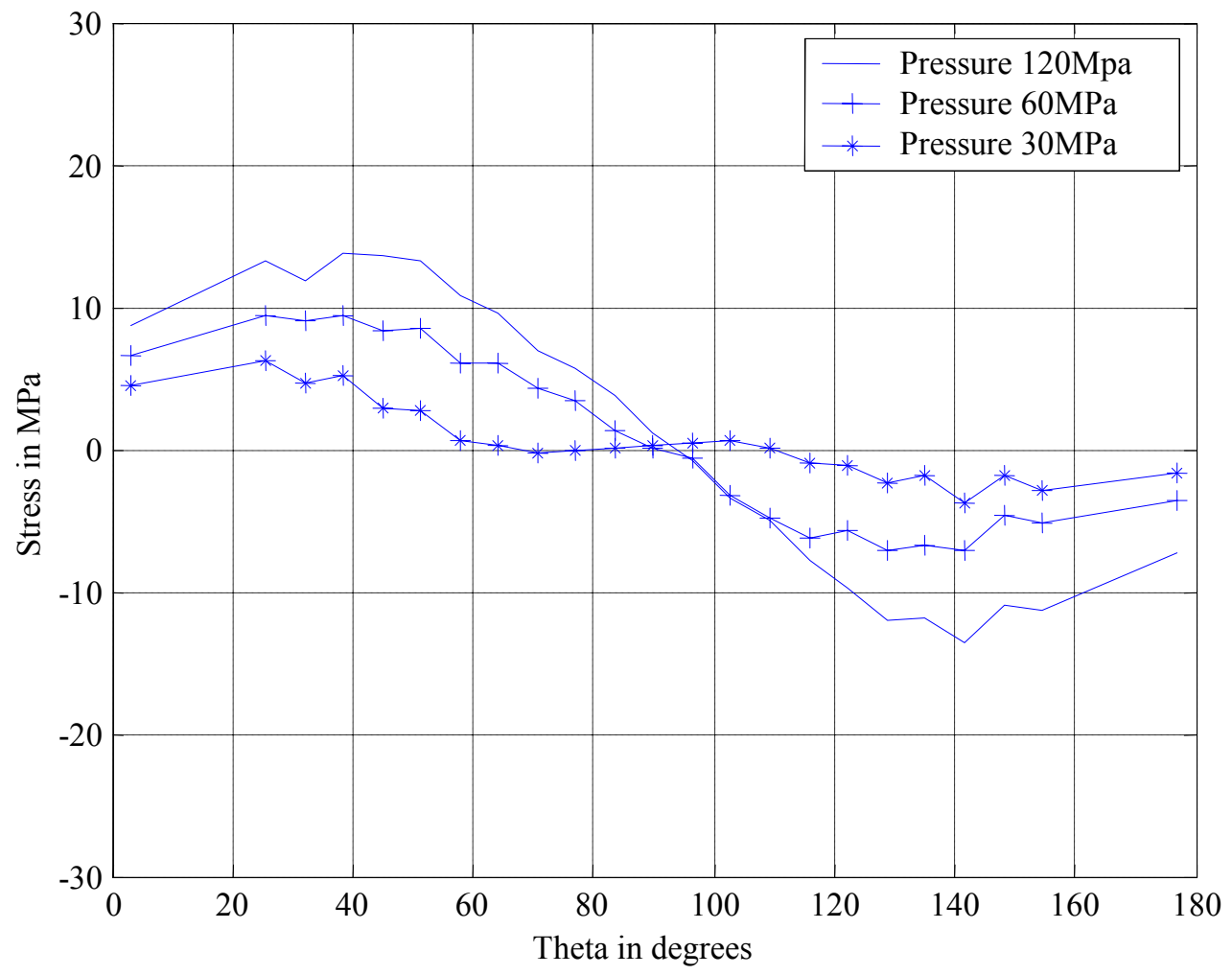

Figure 4.8 Predicted Variations of Shear Stress Around the Hole in the Lower Plate in the XY-Plane $\left(\tau_{\mathrm{xy}}\right)$ for Different Levels of Bolt Tightening Pressure 


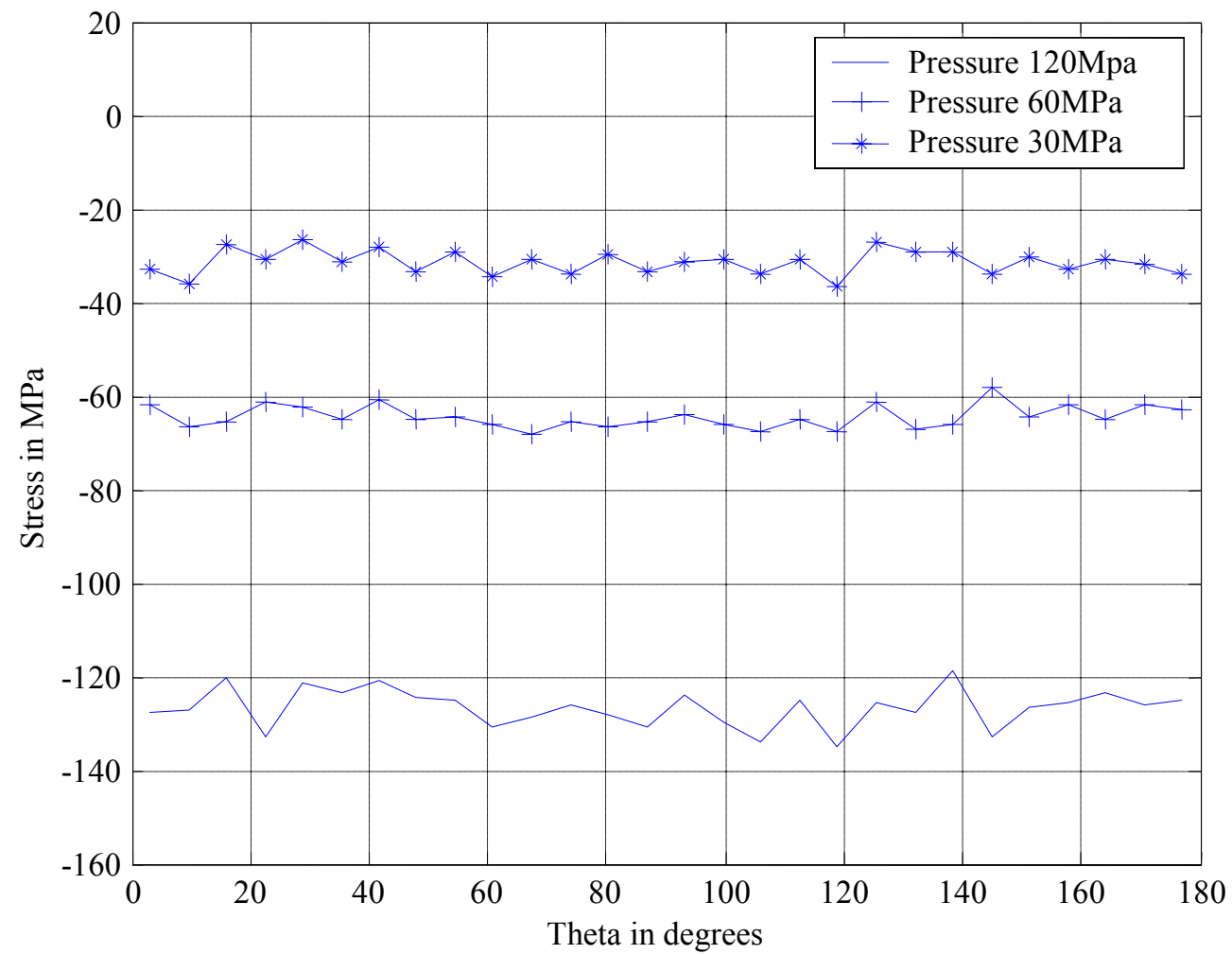

Figure 4.9 Distributions Around the Hole in the Lower Plate of the Normal Compressive Stresses in the Transverse, z-Direction

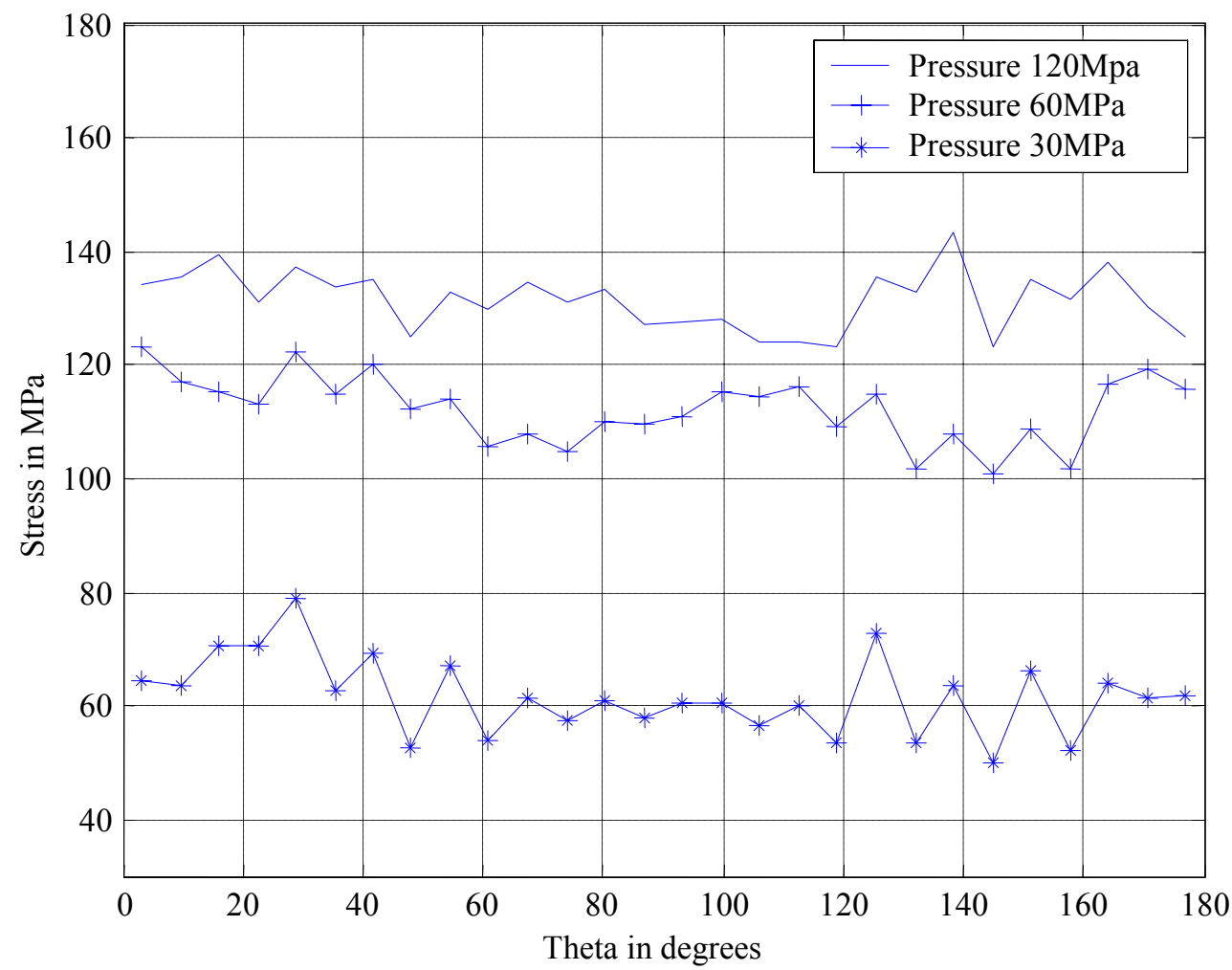

Figure 4.10 Variation of Von Mises Stress Around the Hole in the Lower Plate for Various Levels of Bolt Tightening Pressure 


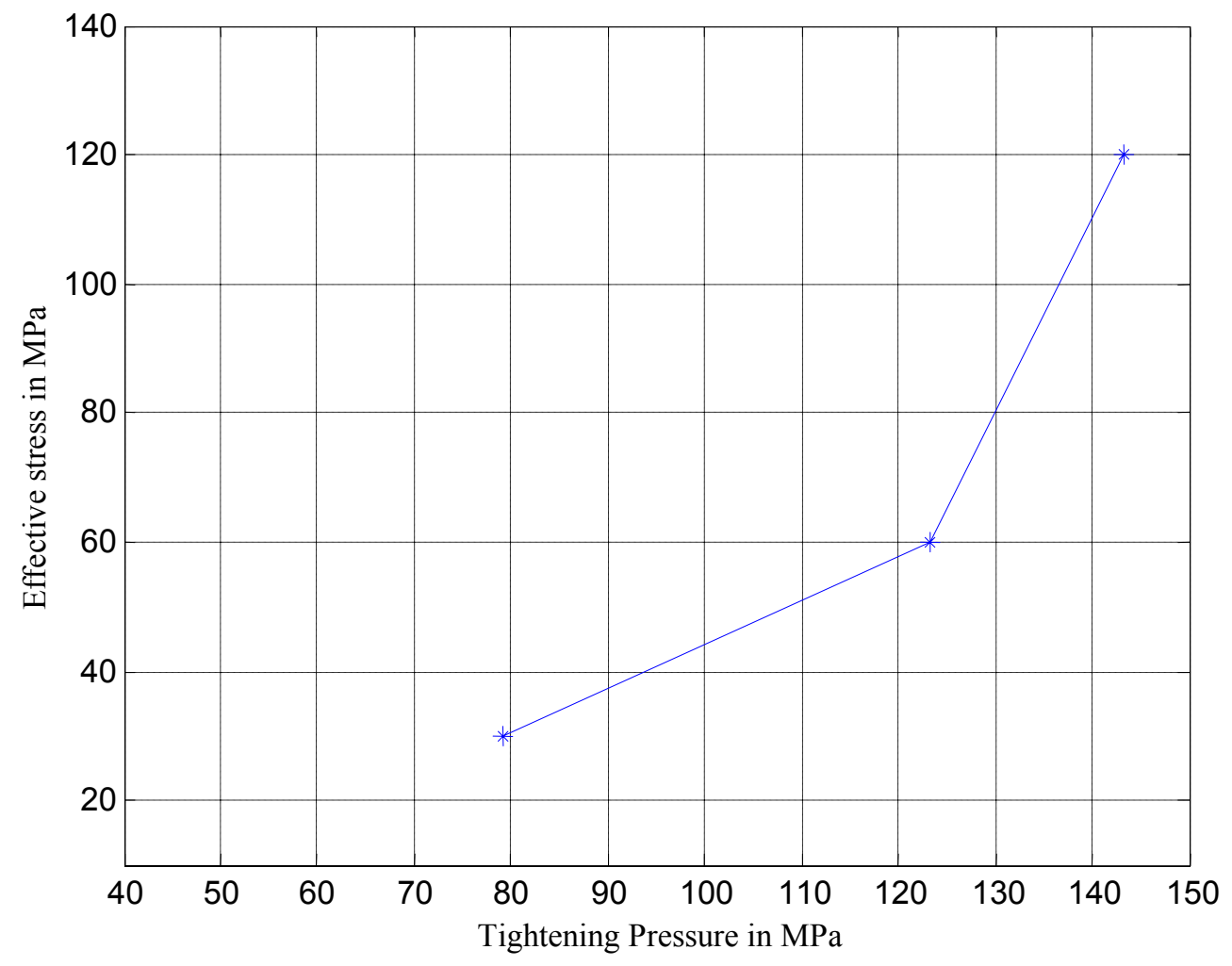

Figure 4.11 Average Effective Stress in the Connected Plates for Various Loads of Bolt Tightening Pressures

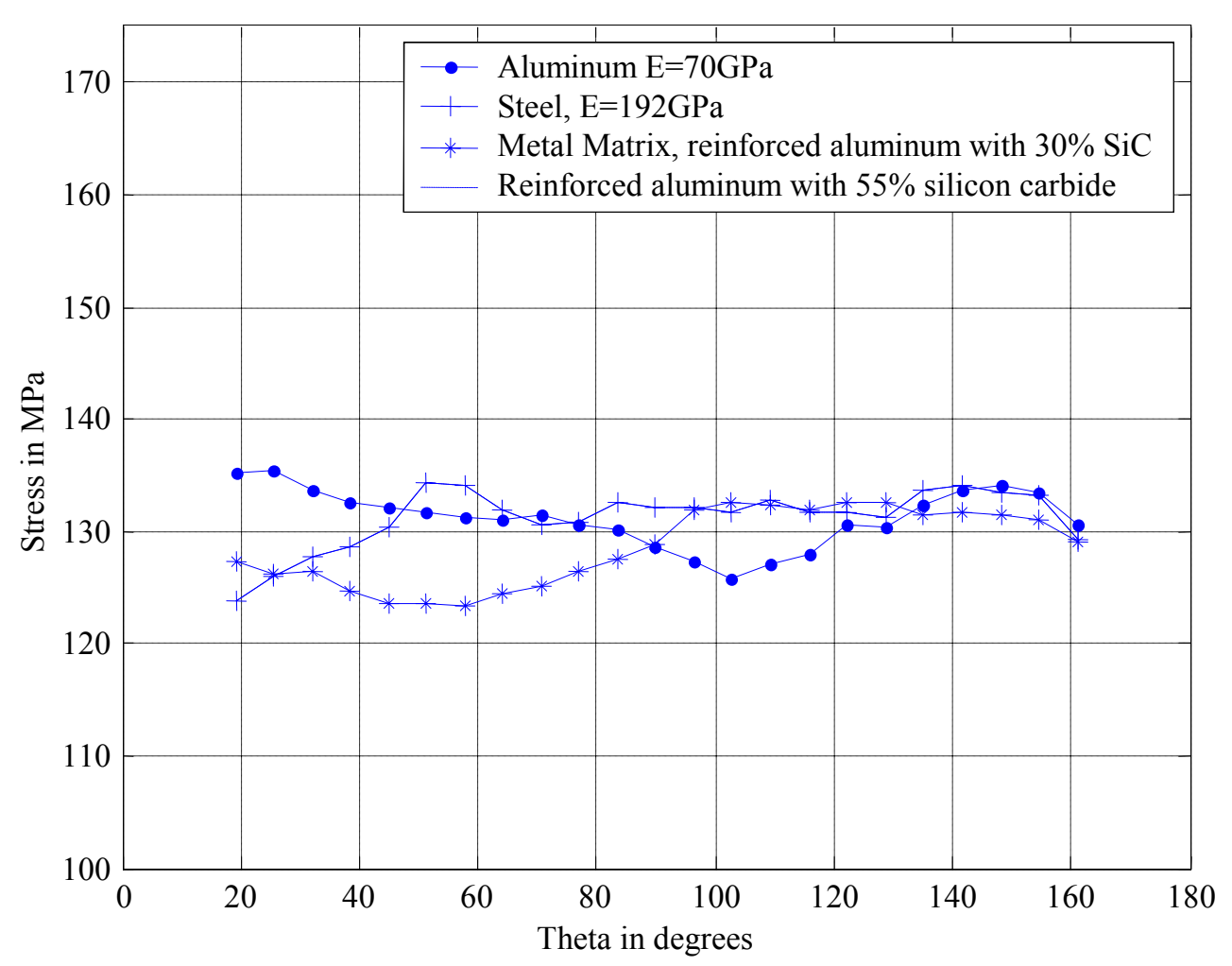

Figure 4.12 Distribution of Von Mises Stress Around the Hole in the Lower Plate for Various Material Systems Used in the Plates 




Figure 4.13 Variations Around the Hole of $\sigma_{x x}-$ Stresses in the Lower Plate for Various Material Systems Used in the Plates

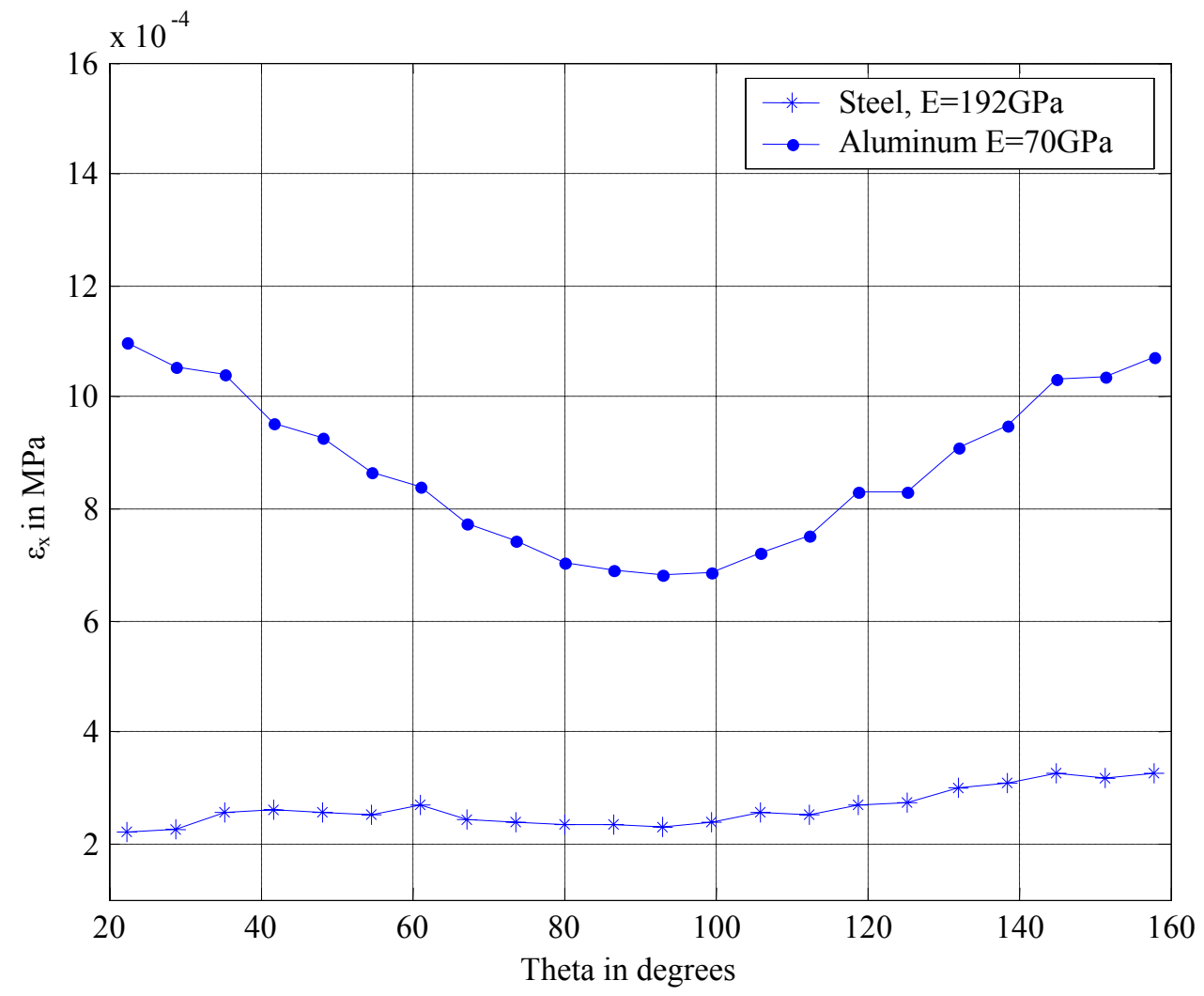

Figure 4.14 Variation Around the Hole of the Normal Strain Component in the $\mathrm{x}$-direction $\left(\varepsilon_{\mathrm{xx}}\right)$ in the Middle Plate for Various Material Systems 


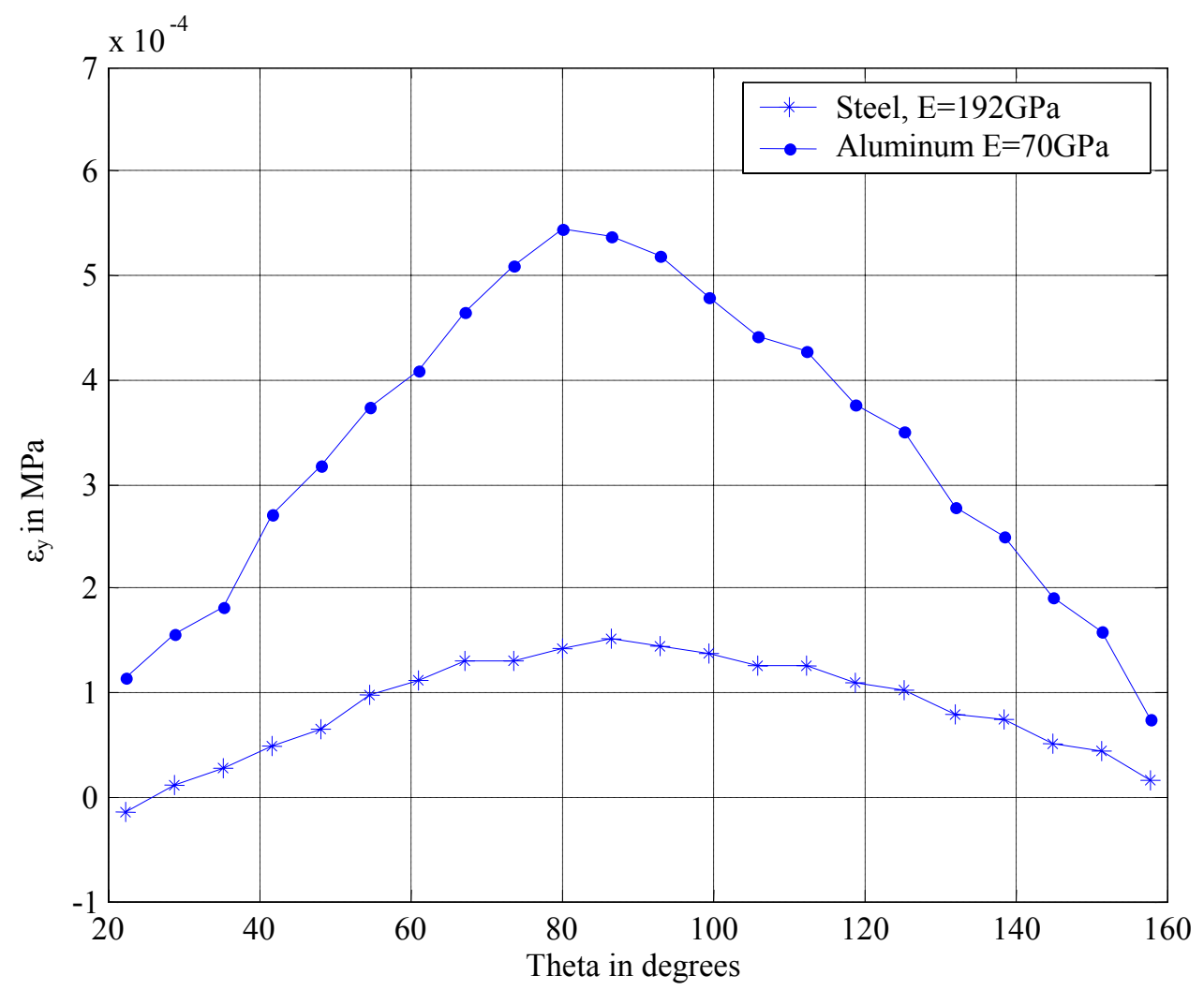

Figure 4.15 Variation Around The Hole of the Normal Strain Component in the $y$-Direction $\left(\varepsilon_{\mathrm{yy}}\right)$ in the Lower Plate for Various Material Systems

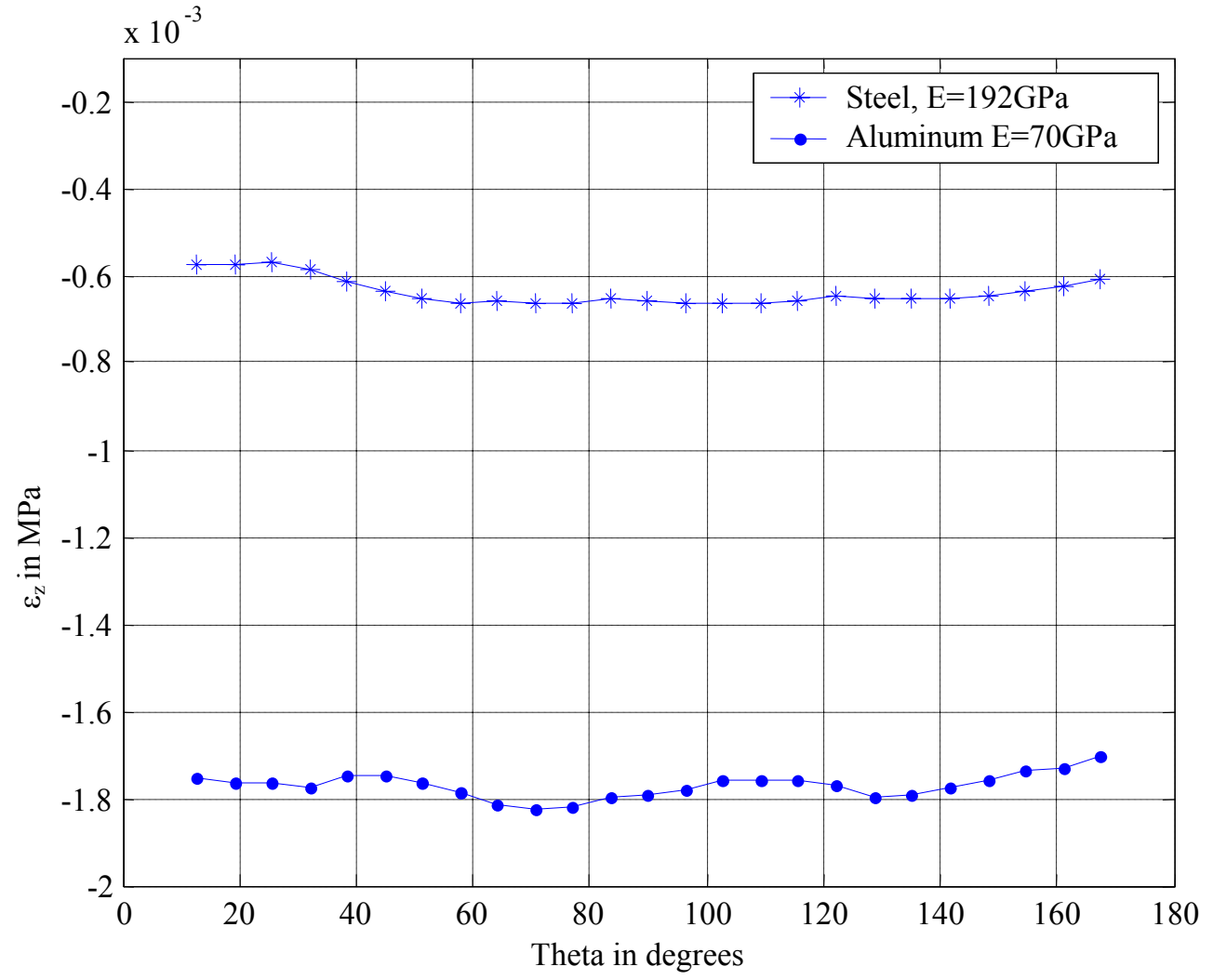

Figure 4.16 Variation Around The Hole of the Normal strain Component in the $z$-Direction $\left(\varepsilon_{z z}\right)$ for the lower plate for Various Material Systems 


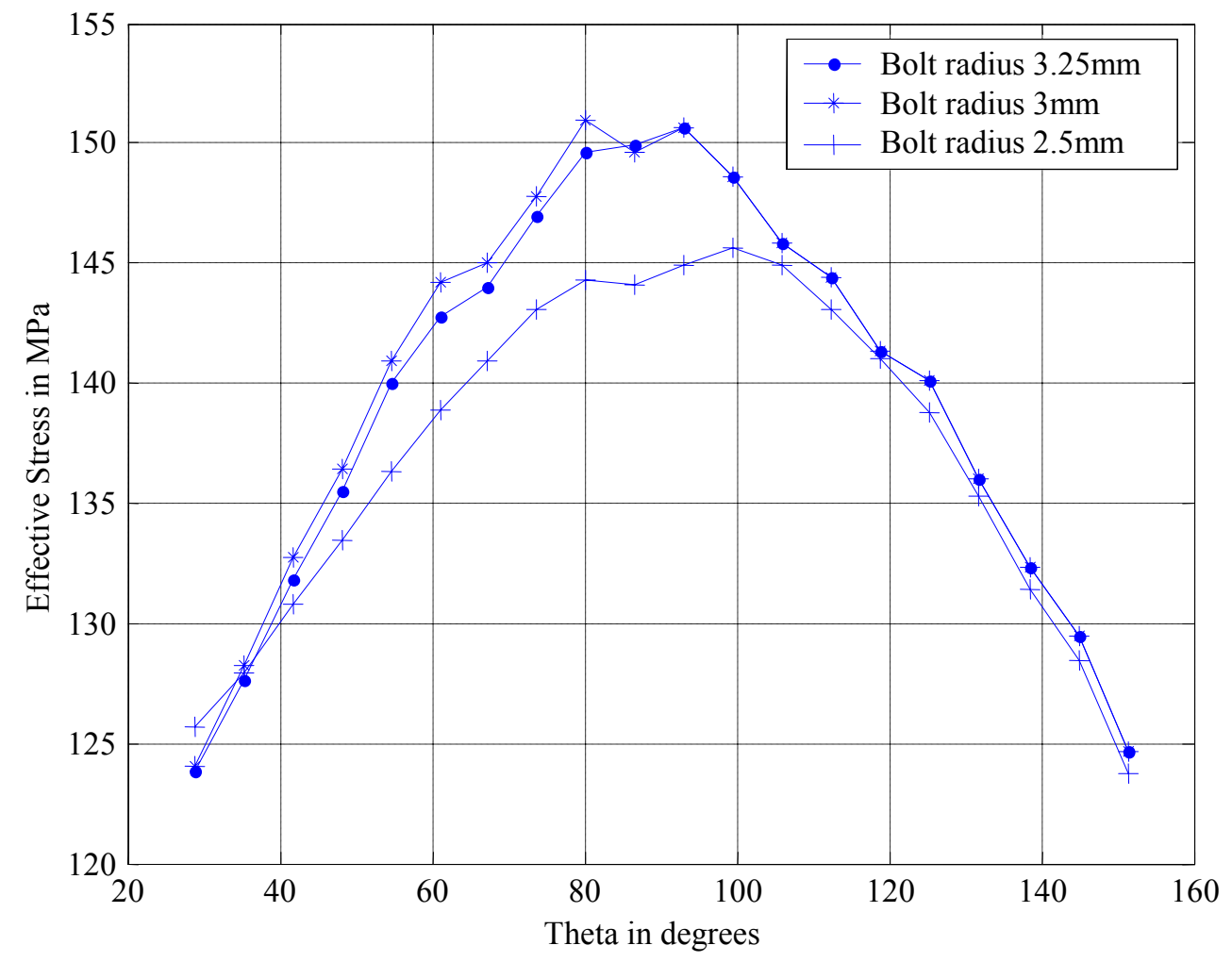

Figure 4.17 Variations of Von Mises Stress Around the Hole in the Lower Plate for Various Values of the Bolt Diameter

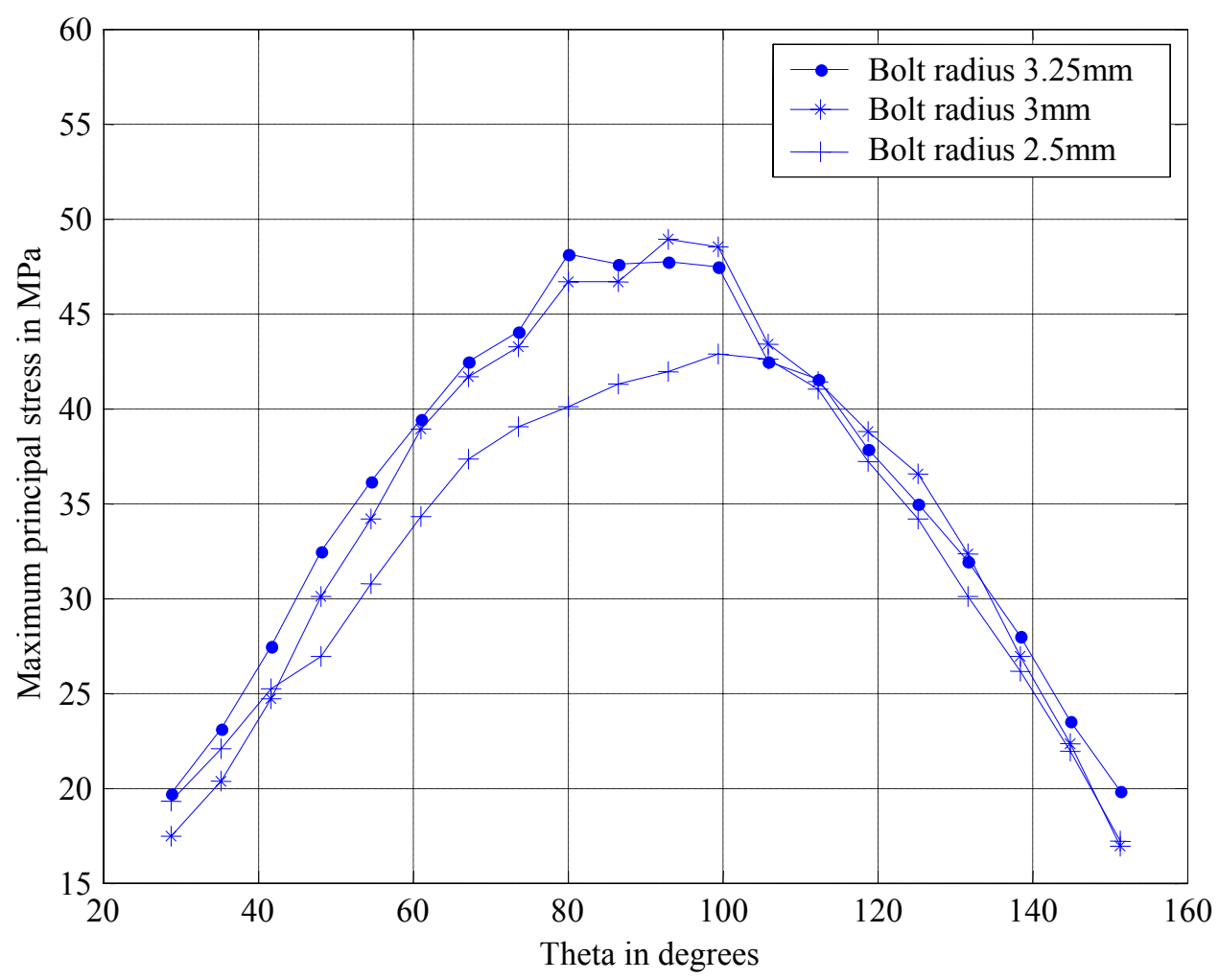

Figure 4.18 Variations of Maximum Principal Stresses Around the Hole in the Lower Plate for Various Values of the Bolt Diameter 


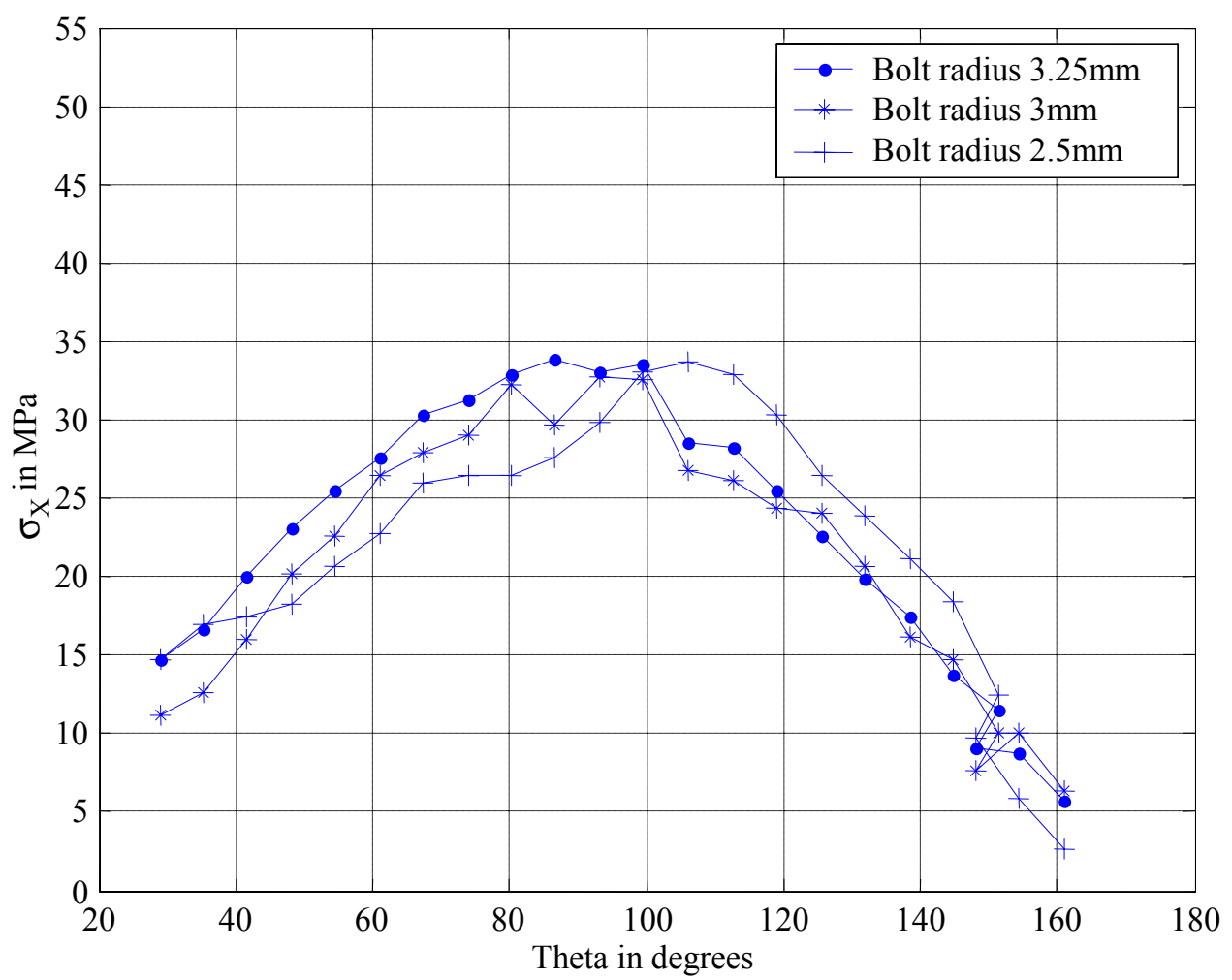

Figure 4.19 Variation of $\sigma_{x x}$ Stress Around the Hole in the Lower Plate for Various Values of the Bolt Diameter

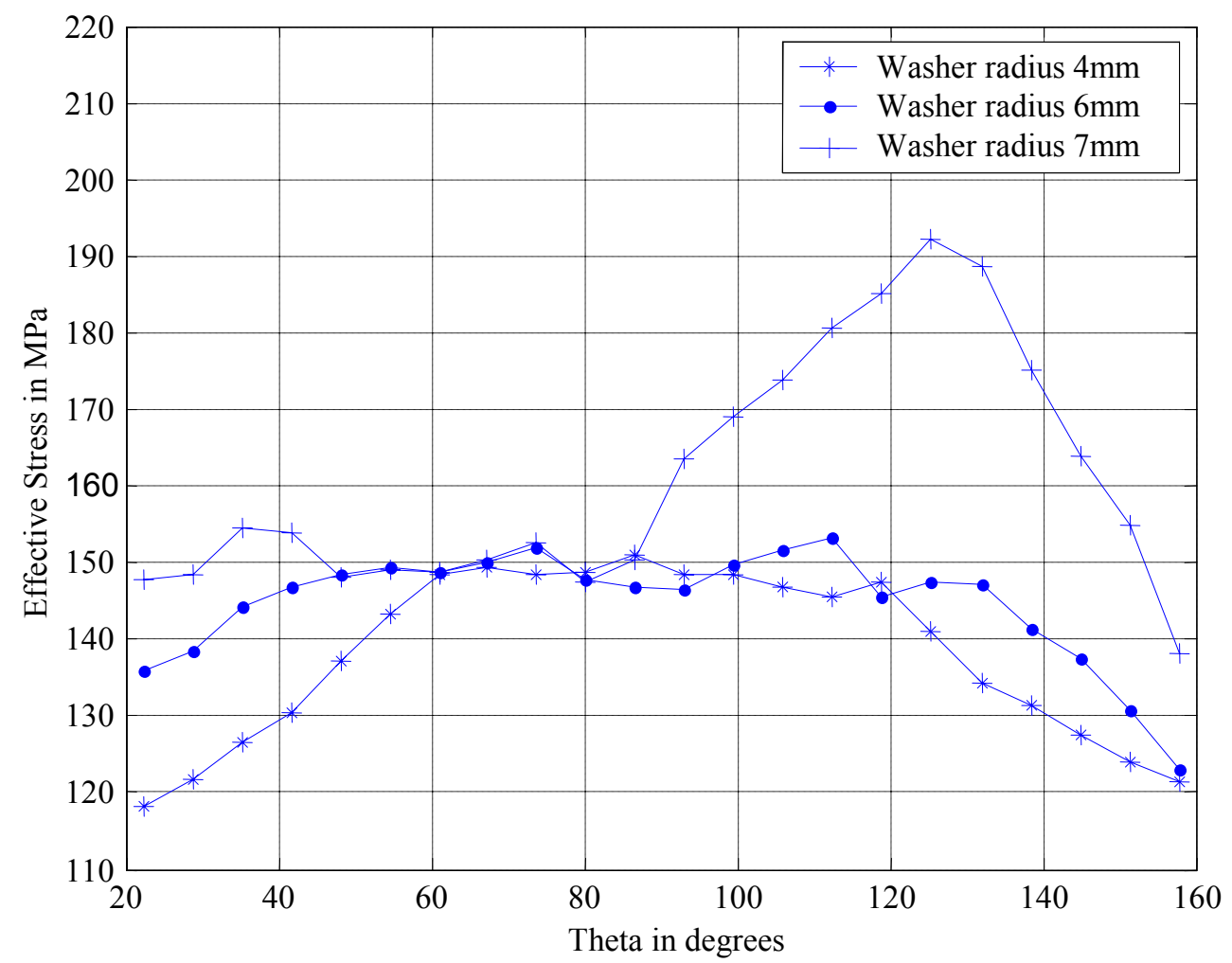

Figure 4.20 Variations of Von Mises Stress Around The Hole in the Lower Plate for Various Values of the Washer Radius 


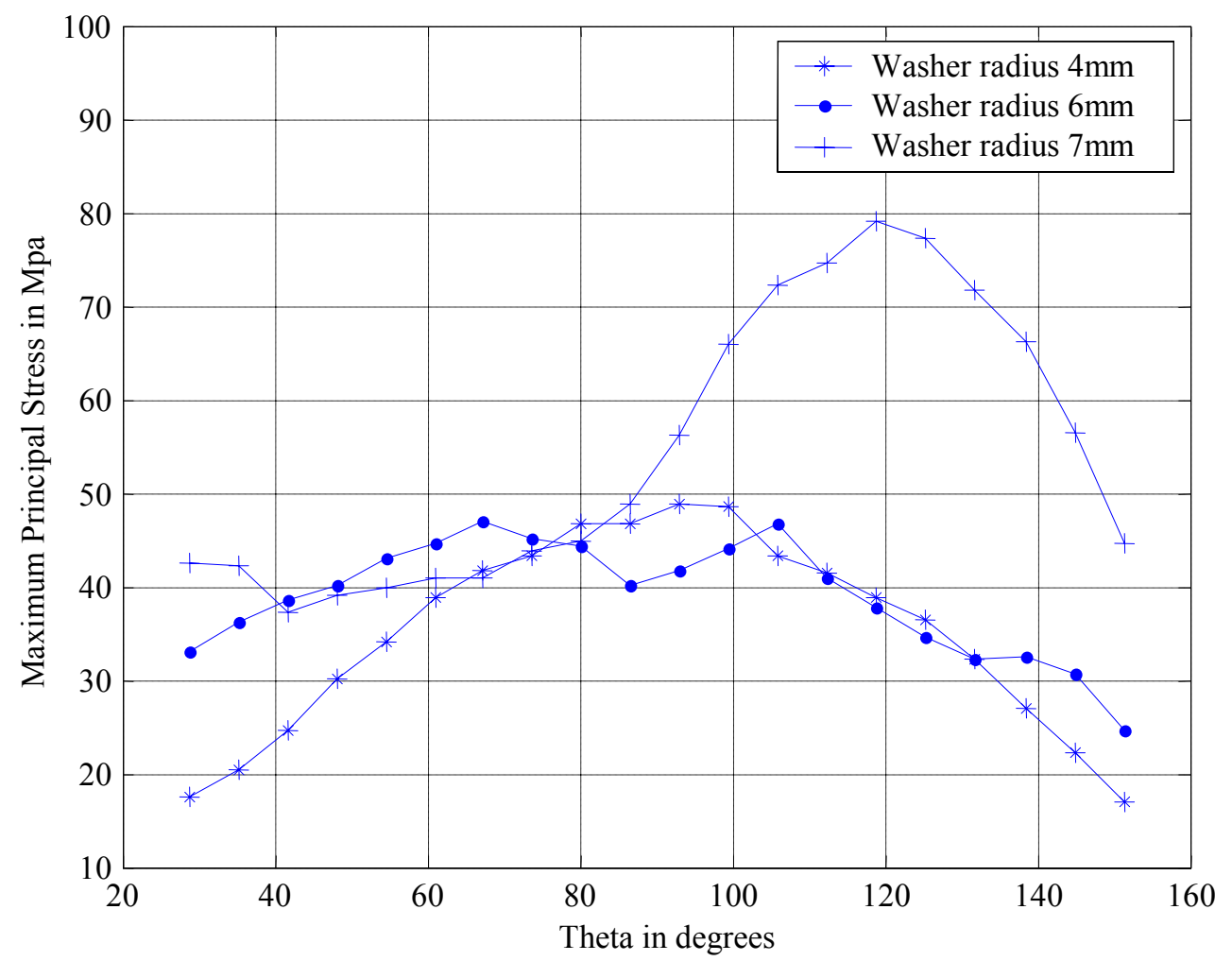

Figure 4.21 Variations of Maximum Principal Stresses Around The Hole in the Lower Plate for Various Radii of the washer

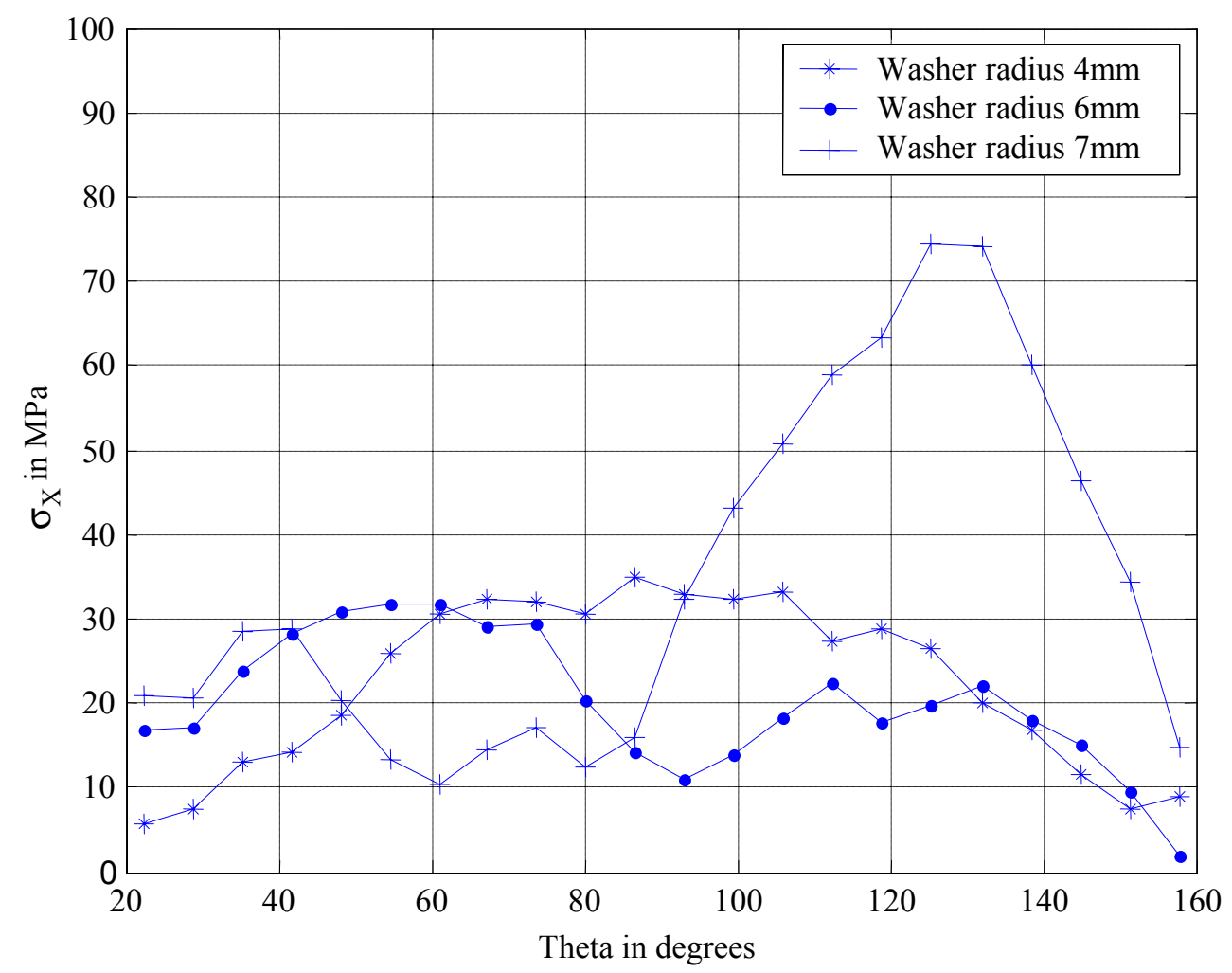

Figure 4.22 Variations of the $\sigma_{\mathrm{xx}}$ Stress Around The Hole in the Lower Plate for Various Radii of the Washer 


\section{CHAPTER FIVE}

\section{STRESS DISTRIBUTION FOR A DOUBLE LAP JOINT}

\subsection{Introduction}

This chapter presents a detailed description of the stress field calculate through the finite element model for a double lap bolted joint configuration. A parametric study has been conducted to investigate the effect of certain design parameters such as the tightening pressure of the bolt, magnitude of the load applied, the Young's modulus, the diameters of the washer and the bolt, and clearance between the hole and bolt on the stress distributions around the hole.

\subsection{Stress Distribution around the Hole}

In double lab joints, the axial load applied on the joint is transferred from one member to the other through mechanisms, namely the friction at the interfaces between the jointed plates and the transverse shear forces transmitted to the bolt through the contact between the bolt and the plate. As the load is applied at the plate edges, it is transferred to the other two plates through the first mechanism until the magnitude of the applied load overcomes the frictional forces at the interfaces between the jointed plates. Then, the plates slide over each other with the amount of the clearance between the bolt and the hole and a contact occurs between them. At this time, the bolt transfers the amount of load that excess the frictional forces by shear to the other plates. The amount of load 
that is transferred by friction at the interface is a function of the bolt tightening pressure, the friction coefficient between the plates, and the overlapped area between the plates.

Figure 5.1 illustrates by fringes describing the distribution of axial stresses in the $\mathrm{x}$ direction, as developed around the hole in the middle plate, as the plate is subjected to an axial tensile load applied along its right edge. A uniform stress field is observed away from the hole that is equal in magnitude as one might expect to the applied tensile stress at the joint edge. Figure 5.1 indicates a formation of a zone of very low compressive stresses at the contact side between the bolt surface and the hole, which indicates that the joint is transferring most of the applied load through the friction at the interfaces between the connected plates. Figure 5.2 illustrates the predicted distribution of shear stresses $\left(\tau_{\mathrm{xy}}\right)$ in the middle plate. A zone of the high shear stresses in the vicinity of the hole due to the friction forces at the interfaces between the plates is observed in this area. Figure 5.3 depicts the predicted distributions of normal stresses in the transverse $\mathrm{z}$, direction $\left(\sigma_{\mathrm{zz}}\right)$ which turn out to be almost equal as required by equilibrium conditions, to the applied tightening pressure on the washer.

Figures 5.4 illustrate the distribution of the effective stresses developed in the middle plate of the joint, where the axial load is applied. It can be noticed that the area around the hole is subjected to high concentration of stresses indicating a high probability that potential failure will be indicated in that region. 


\subsection{Effect of tightening pressure}

The effect of tightening pressure is investigated by applying pressures of various levels on the washer surfaces, and examining the associated changes in the distribution of the stresses developed in the connected plates around the hole for each case. Four different levels of tightening pressure $0 \mathrm{MPa}, 10 \mathrm{MPa}, 20 \mathrm{MPa}$ and $30 \mathrm{MPa}$ are applied on the washer surface in the z-direction while an axial load of $30 \mathrm{MPa}$ is applied on the right edge of the middle plate in the x-direction. The distribution of normal stresses in the $\mathrm{x}$ direction $\left(\sigma_{\mathrm{xx}}\right)$ developed around the hole for different cases of tightening pressures are plotted in Figure 5.5. It can be noticed that increasing the tightening pressure on the bolt results in a decrease in the $\sigma_{\mathrm{xx}}$ stress values. This is attributed to the increase in the amount of load transferred through friction as the tightening pressure increases, which can be observed from the distribution of the shear stresses around the hole shown in Figure 5.6. Since the frictional force are likely to increase with the increase of the bolt tightening pressure, the shear stresses in the plane of the plate (xy plane) will also increase.

Figure 5.7 displays the variations around the hole of the normal stresses in the zdirection $\left(\sigma_{\mathrm{zz}}\right)$. The plots validate that, indeed this is a uniform distribution, where the magnitude of the $\sigma_{z z}$-stresses is equal to the applied tightening pressure. Figure 5.8 illustrates the distribution of effective stresses developed around the hole for different tightening pressures. It can be seen that increasing the tightening pressure results in an increase of equivalent stresses. 


\subsection{Effect of Young's Modulus}

This effect is studied by changing the Young's Modulus of the jointed plates. Three different materials have been chosen for this study, namely aluminum, whose Young's modulus is $\mathrm{E}=70 \mathrm{GPa}$, steel or aluminum reinforced with $55 \%$ silicon carbide for which $\mathrm{E}=199 \mathrm{GPa}$ and aluminum reinforced with $30 \%$ silicon carbide for which the equivalent Young's modulus is E=127GPa. The curves plotted in Figure 5.8 indicate that the effective stress around the bolt is not affected significantly by changing Young's modulus. Therefore, the choice of a material for connected plates has an insignificant effect on the stresses developed around the hole.

The normal stress components in the $\mathrm{x}$-direction $\left(\sigma_{\mathrm{xx}}\right)$, appears, however, to display a higher sensitivity to the material properties of the plates than the effective stresses, as indicated by the plots in Figure 5.9.

A variation in the Young's Modulus of the connected plates has an effect however, on the strains developed around the hole. This effect is illustrated in figure 5.10 for the normal strain component in the $\mathrm{x}$-direction, $\left(\varepsilon_{\mathrm{xx}}\right)$. One could expect, the strains around the hole are reduced when stiffer materials are used for the connected plates.

\subsection{Effect of Load applied on the joint}

The effect of the load applied on the stress fields in the connected plates is studied by running the finite element model for various values of the load applied. Loads of $30 \mathrm{MPa}$ 
and $120 \mathrm{MPa}$ are applied to the joint. Figure 5.11 illustrates the distribution of the effective stresses developed around the hole for different loads applied to the joint. It can be seen that increase in the applied load results in an increase of effective stresses. The relationship between the load applied and the effective pressure is nonlinear.

Figure 5.12 depicts the effect of maximum principal stress around the hole. Increase in the load applied increases these stresses. The distribution of normal stresses in the $\mathrm{x}$ direction $\left(\sigma_{\mathrm{xx}}\right)$ developed around the hole for various loads are plotted in Figure 5.13 .It can be observed that increasing the applied load increases the $\left(\sigma_{\mathrm{xx}}\right)$ stress levels.

The effect of compressive load is observed by applying a compressive load to the joint. Figure 5.14 illustrates the predicted distribution of shear stresses $\left(\tau_{\mathrm{xy}}\right)$ around the hole in the middle plate. It is observed that the shear stress is positive on one side of the hole and negative on the other side when tensile load is applied whereas it is opposite for the compressive load.

Figure 5.15 displays the normal stresses in the $\mathrm{x}$-direction $\left(\sigma_{\mathrm{xx}}\right)$ developed around the hole for the tensile and compressive load applied, respectively. The shear stress distribution around the hole is as shown in Figure 5.16.

\subsection{Effect of clearance between the hole and the bolt}

The effect of clearance is observed by running the finite element model for various values

of clearances between the bolt and the hole. A clearance of $0.15 \mathrm{~mm}$ and $0.02 \mathrm{~mm}$ are 
used. The stress distribution of bolted joints is dependent on the magnitude of hole clearance. The effect of clearance has a significant effect on the stress distribution around the loaded hole. This clearance would decrease the load carrying capacity of the bolted joint.

Lower clearance between the bolt and the hole leads to higher stresses in the connected plates, as illustrated in Figures 5.17 and 5.18 for the effective stress and the maximum principal stress, respectively.

Figures 5.19 and Figure 5.20 shows the distribution of the normal stresses in the $\mathrm{x}$ direction $\left(\sigma_{\mathrm{xx}}\right)$ for both the clearances. It can be clearly seen that high longitudinal stresses are obtained around the hole for a clearance of $0.02 \mathrm{~mm}$ than for a clearance $0.15 \mathrm{~mm}$.

\subsection{Effect of washer diameter}

The effect of the washer diameter on the stress fields in the connected plates is investigated by running the finite element model for various values of the washer diameter. Four different washer diameters, $8 \mathrm{~mm}, 12 \mathrm{~mm}, 14 \mathrm{~mm}$, and $18 \mathrm{~mm}$ are used. Figures 5.21 and 5.22 show that larger washer lead to lower average values of the effective stress and the $\sigma_{\mathrm{xx}}$-stress component. Larger washer diameter bears higher stresses and thus the stresses in the plates reduce. 


\subsection{Effect of bolt diameter}

The effect of the bolt diameter on the stress fields in the connected plates is studied by running the finite element model for various values of the bolt diameter value keeping other parameters constant. Bolt diameters of $5 \mathrm{~mm}, 6 \mathrm{~mm}$ and $6.5 \mathrm{~mm}$ are used.

Larger bolt diameters lead to lower stresses in the connected plates, as illustrated in Figures 5.23 and 5.24 for the effective stress, and the $\sigma_{\mathrm{xx}}$ stress component, respectively. 


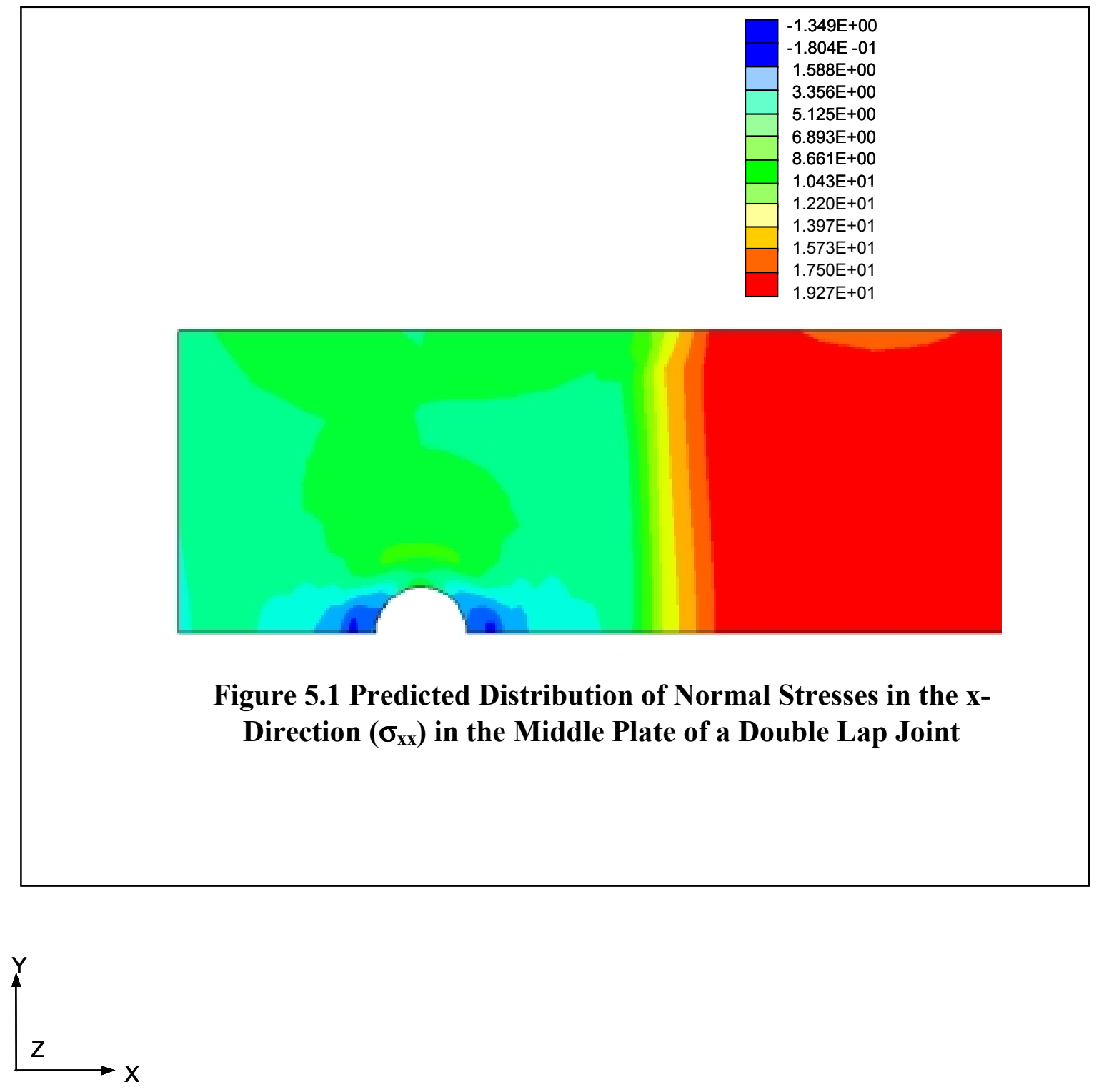




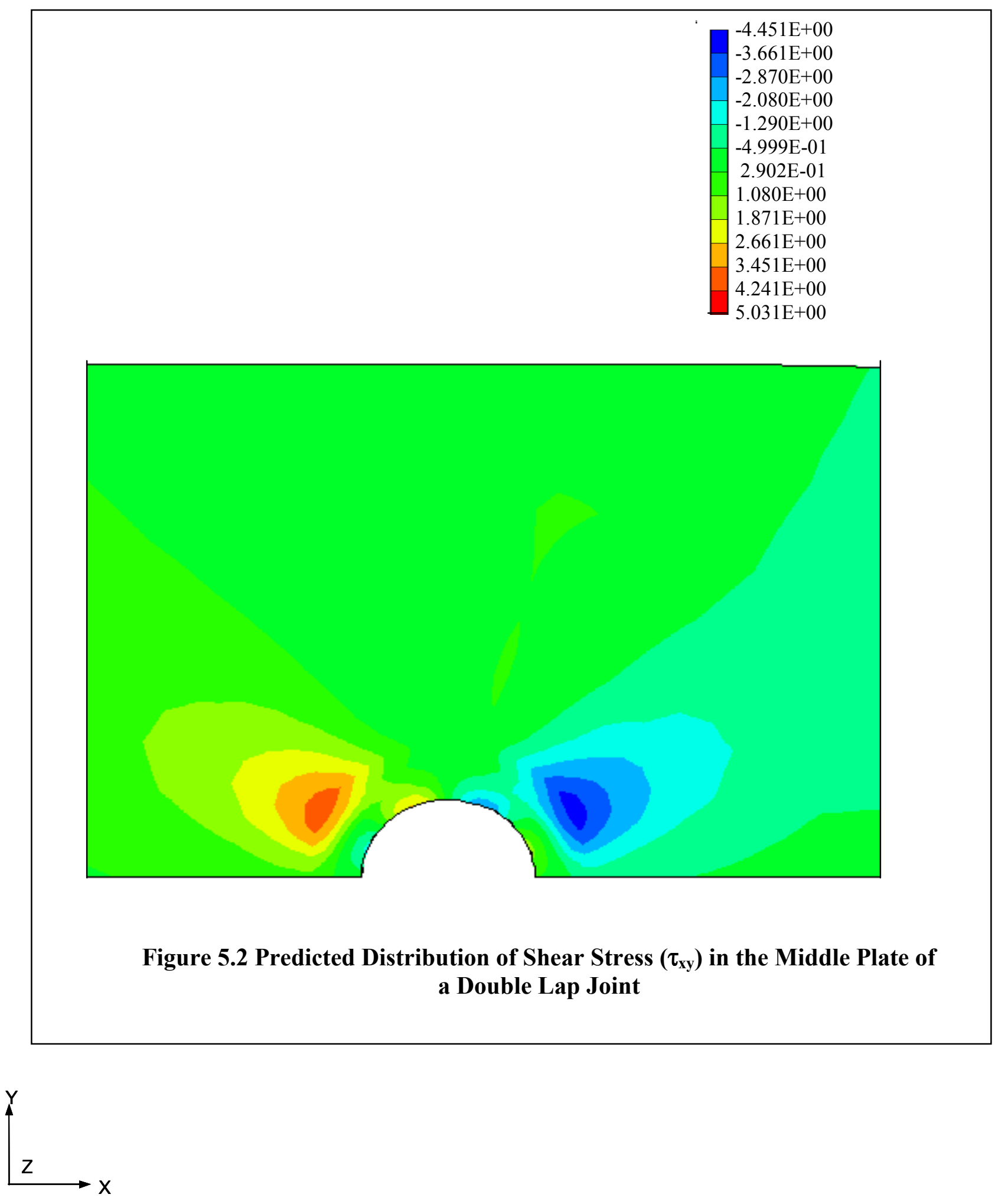




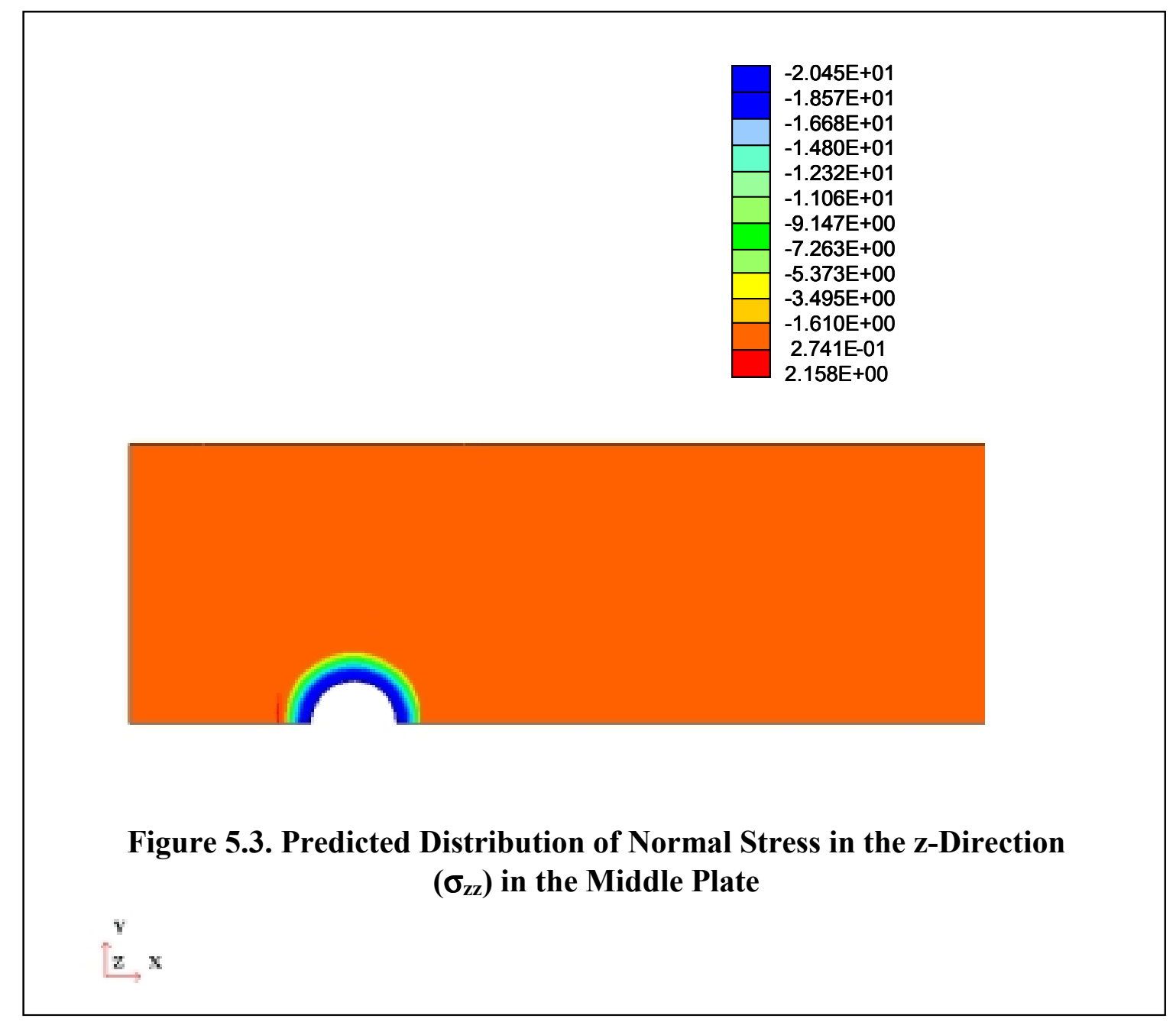



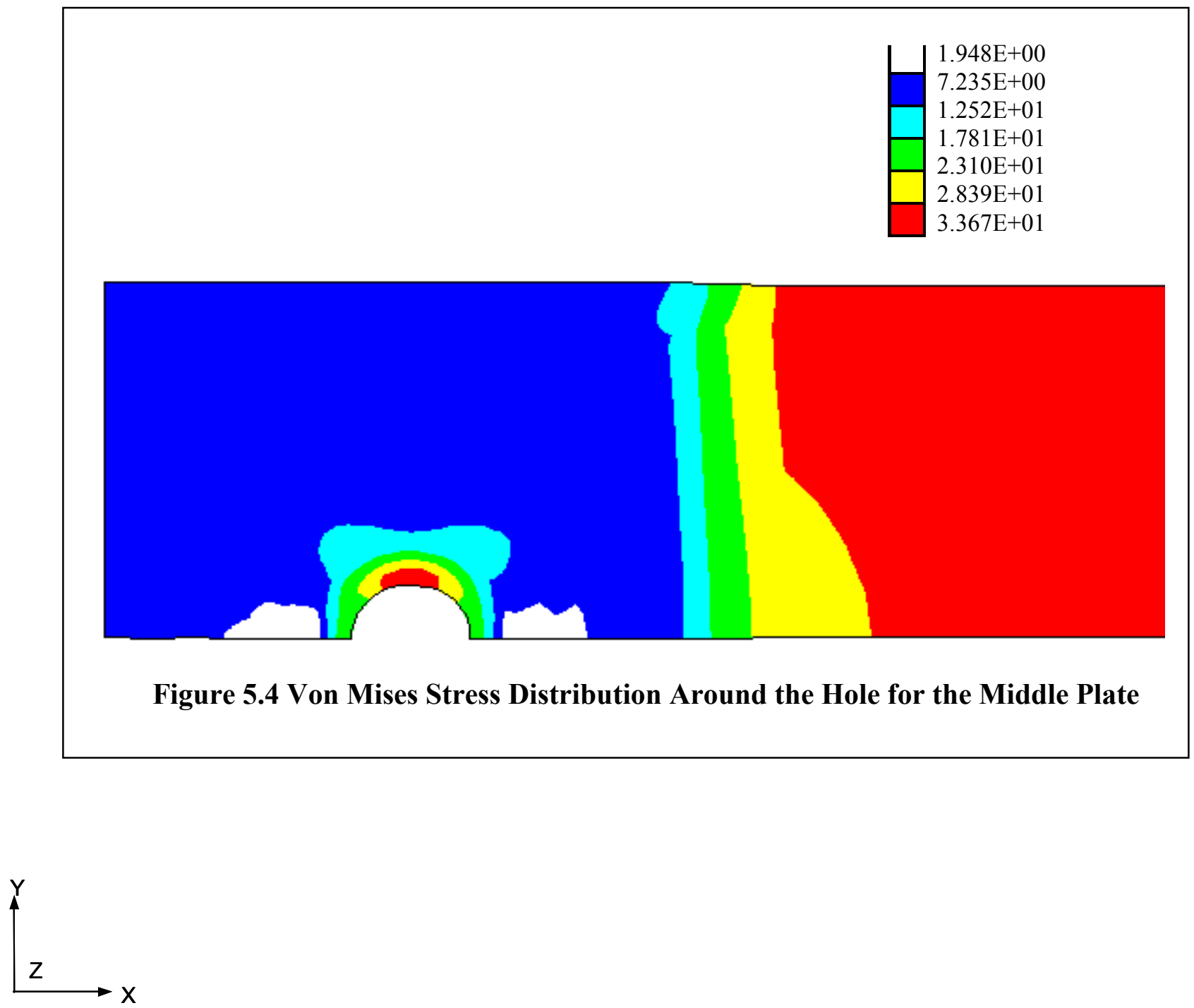


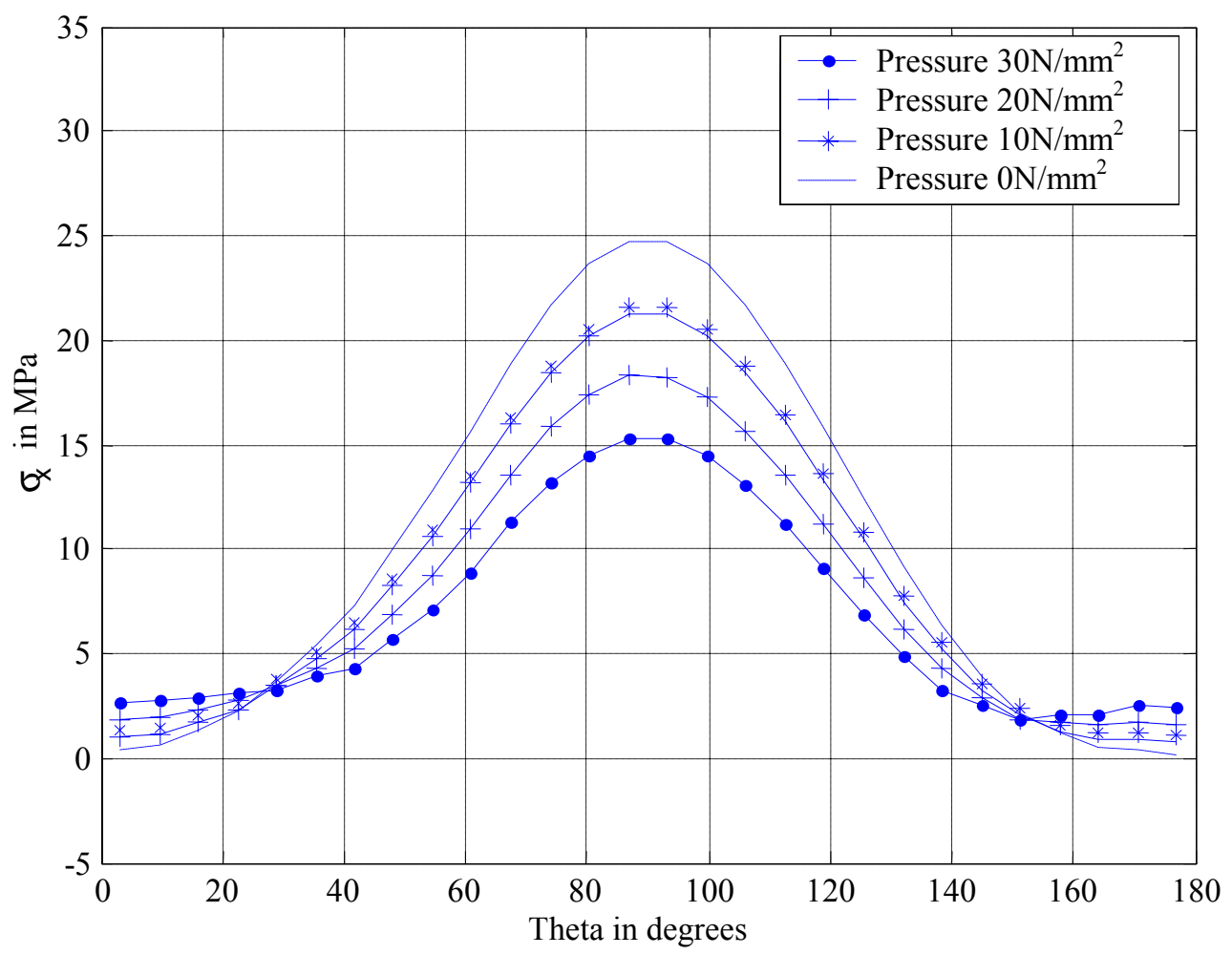

Figure 5.5 Predicted Distributions of $\left(\sigma_{\mathrm{xx}}\right)$ Stress Components Around the Hole in the Middle Plate for Different Levels of Bolt Tightening Pressure

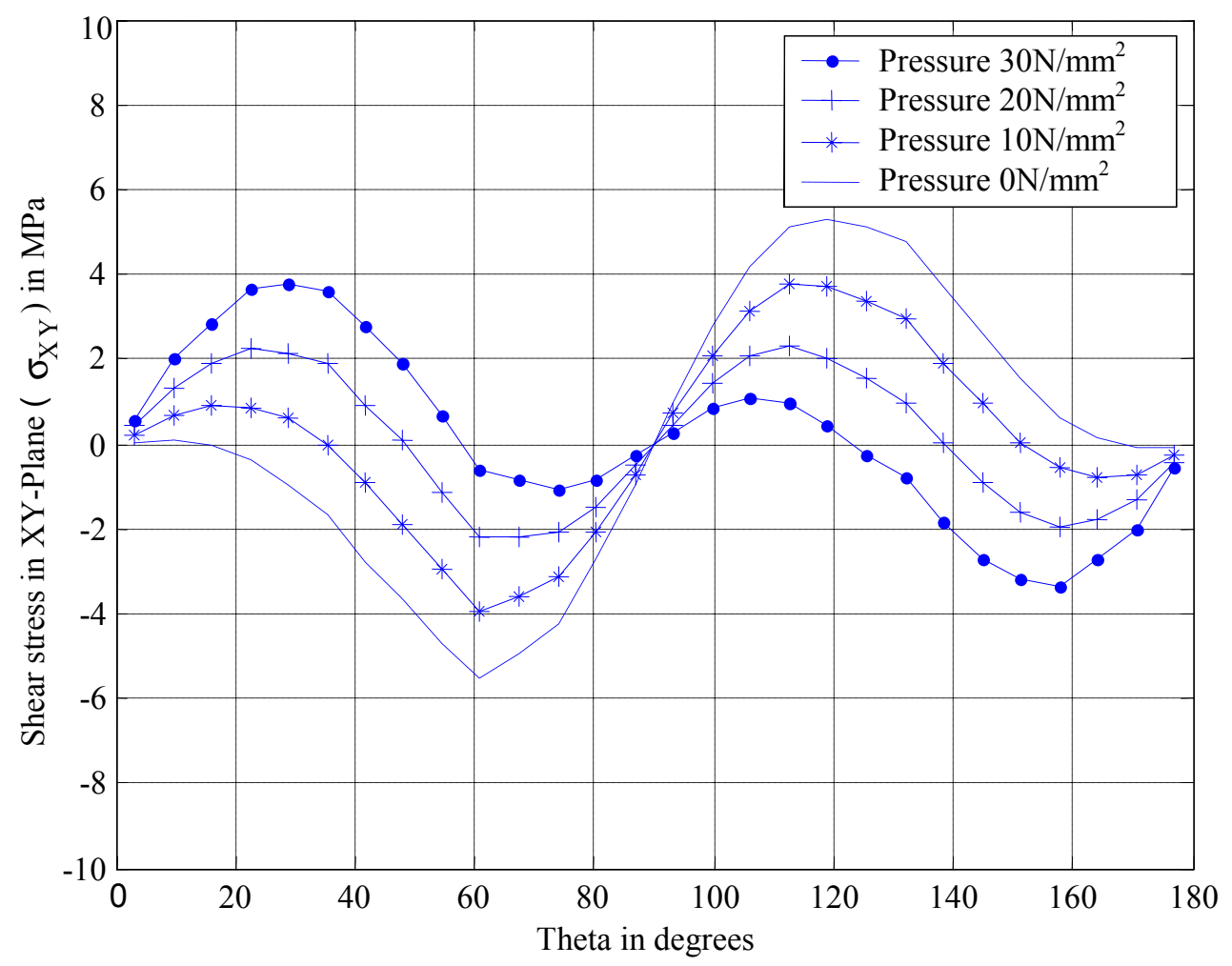

Figure 5.6 Predicted Variation of Shear Stress Around the Hole in the XY-Plane $(\tau x y)$ in the Middle Plate for Different Levels of Bolt Tightening Pressure 


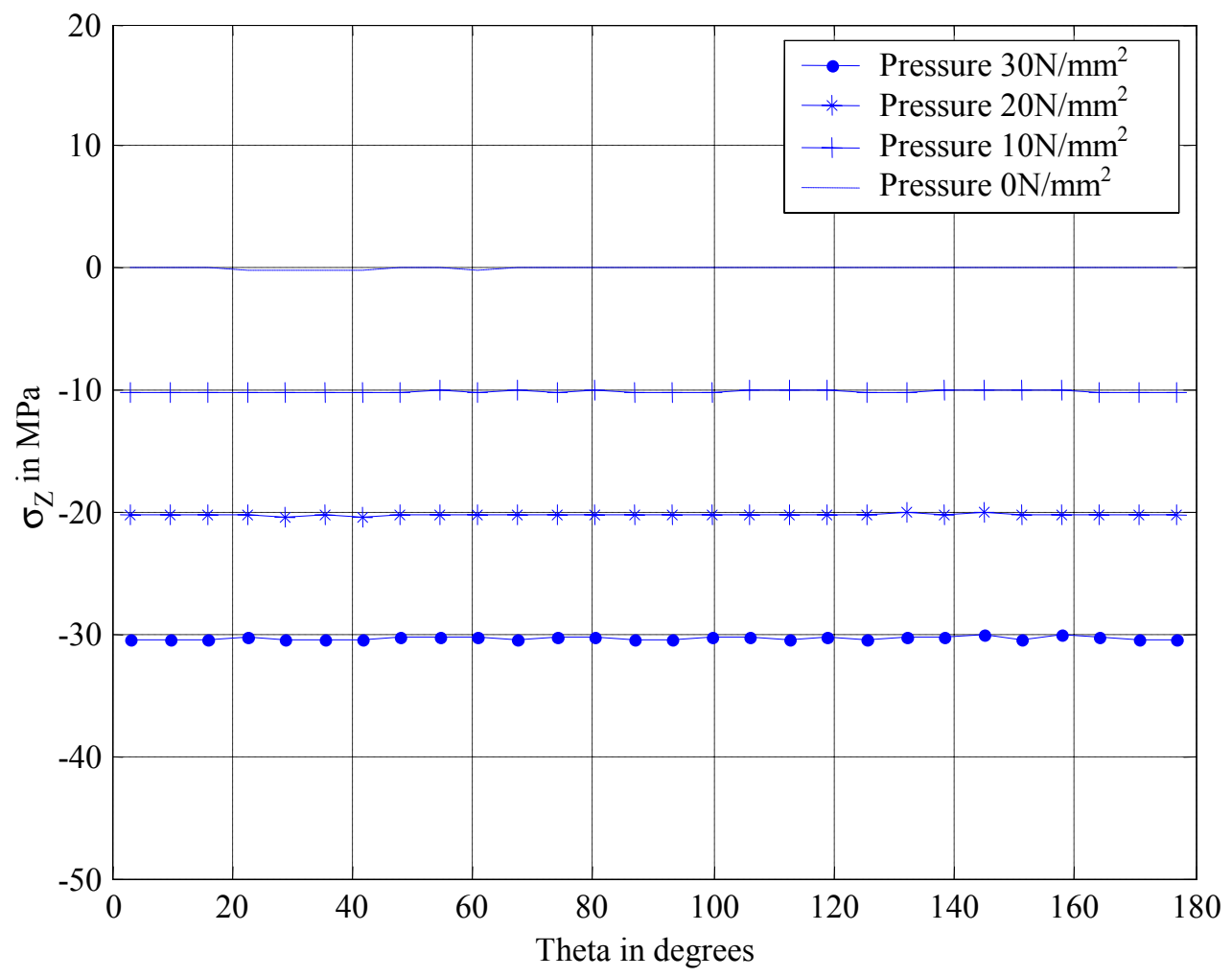

Figure 5.7 Distribution Around the Hole of the Normal Compressive Stresses in the Transverse, $z$-Direction for the Middle Plate

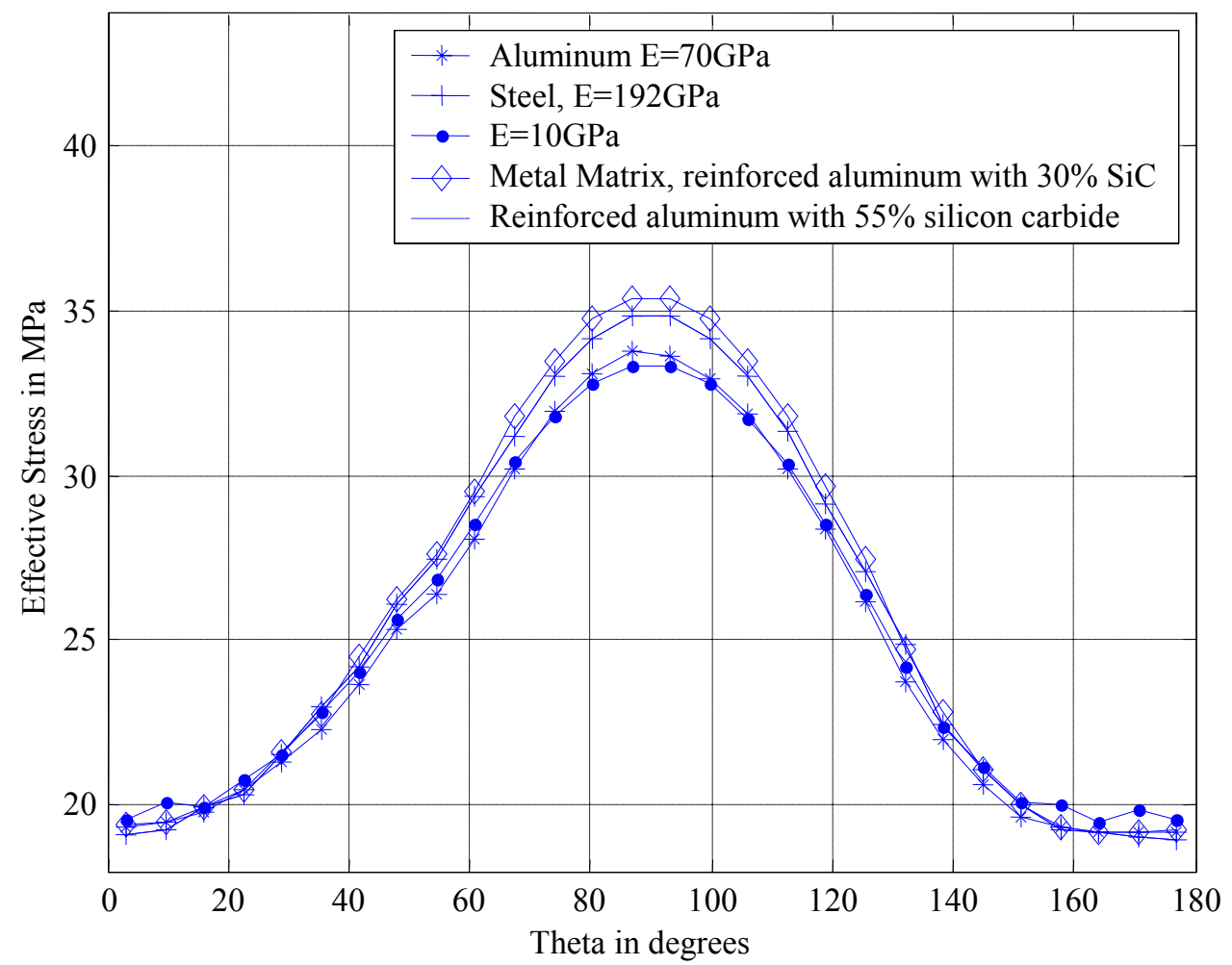

Figure 5.8 Variations of Von Mises Stress Around the Hole in the Middle Plate for Various Material Systems Used in the Plates 


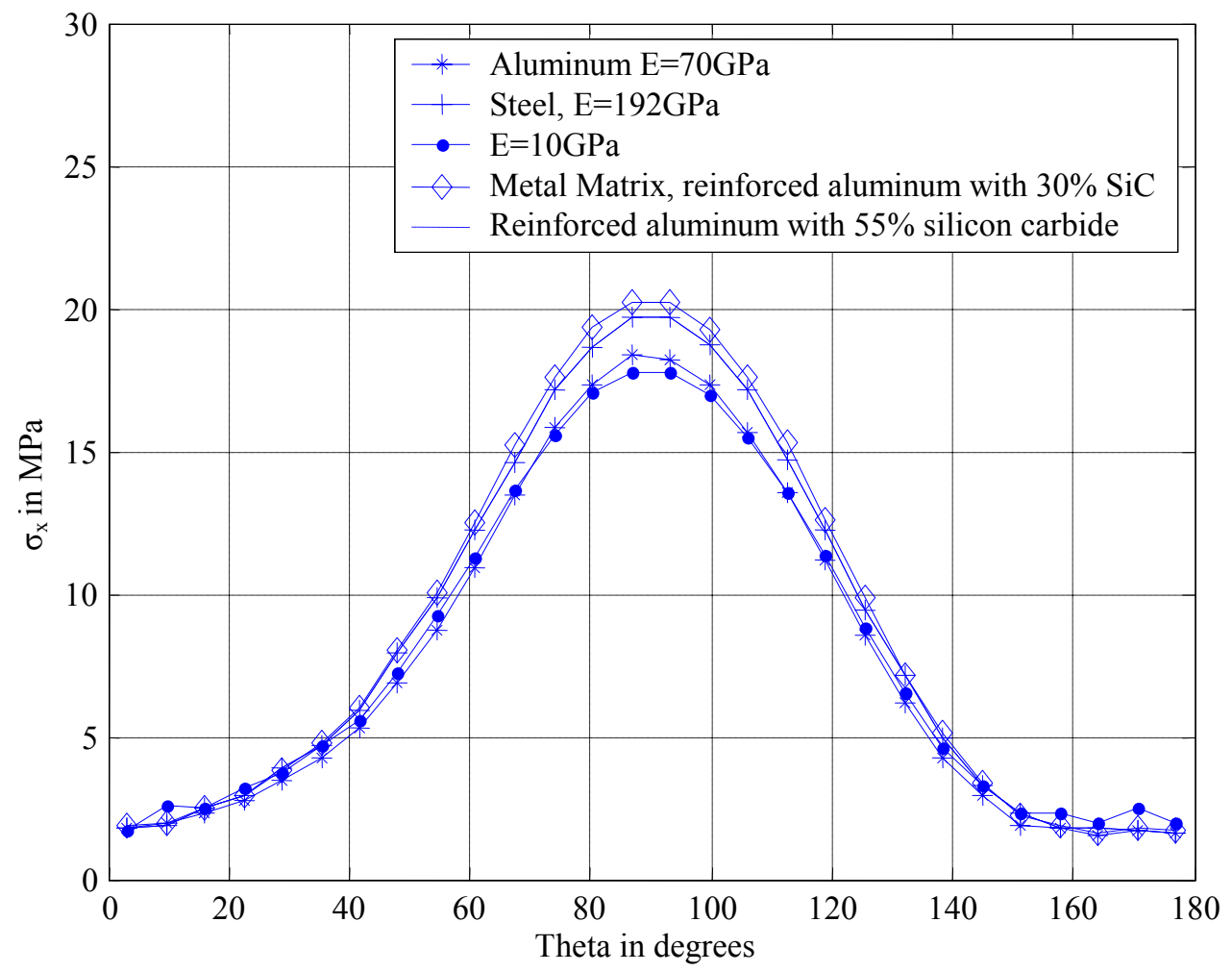

Figure 5.9 Variations Around the Hole of $\sigma_{x x}$-stresses in the Middle Plate for Various Material Systems Used in the Plates

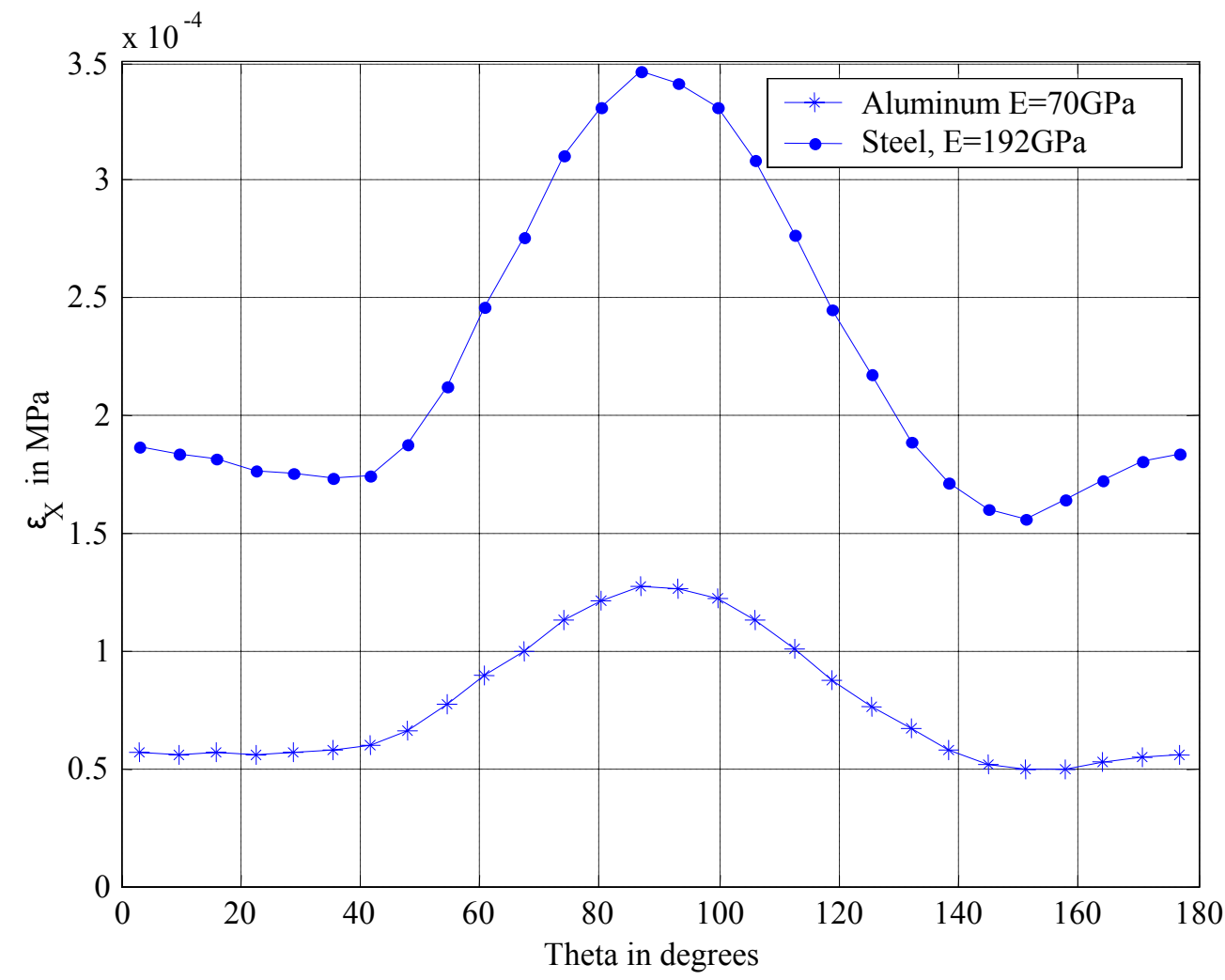

Figure 5.10 Variations Around the Hole of the Normal Strain Component in the $x$-Direction, $\varepsilon_{\mathrm{xx}}$, for Various Material Systems in the Middle Plate 


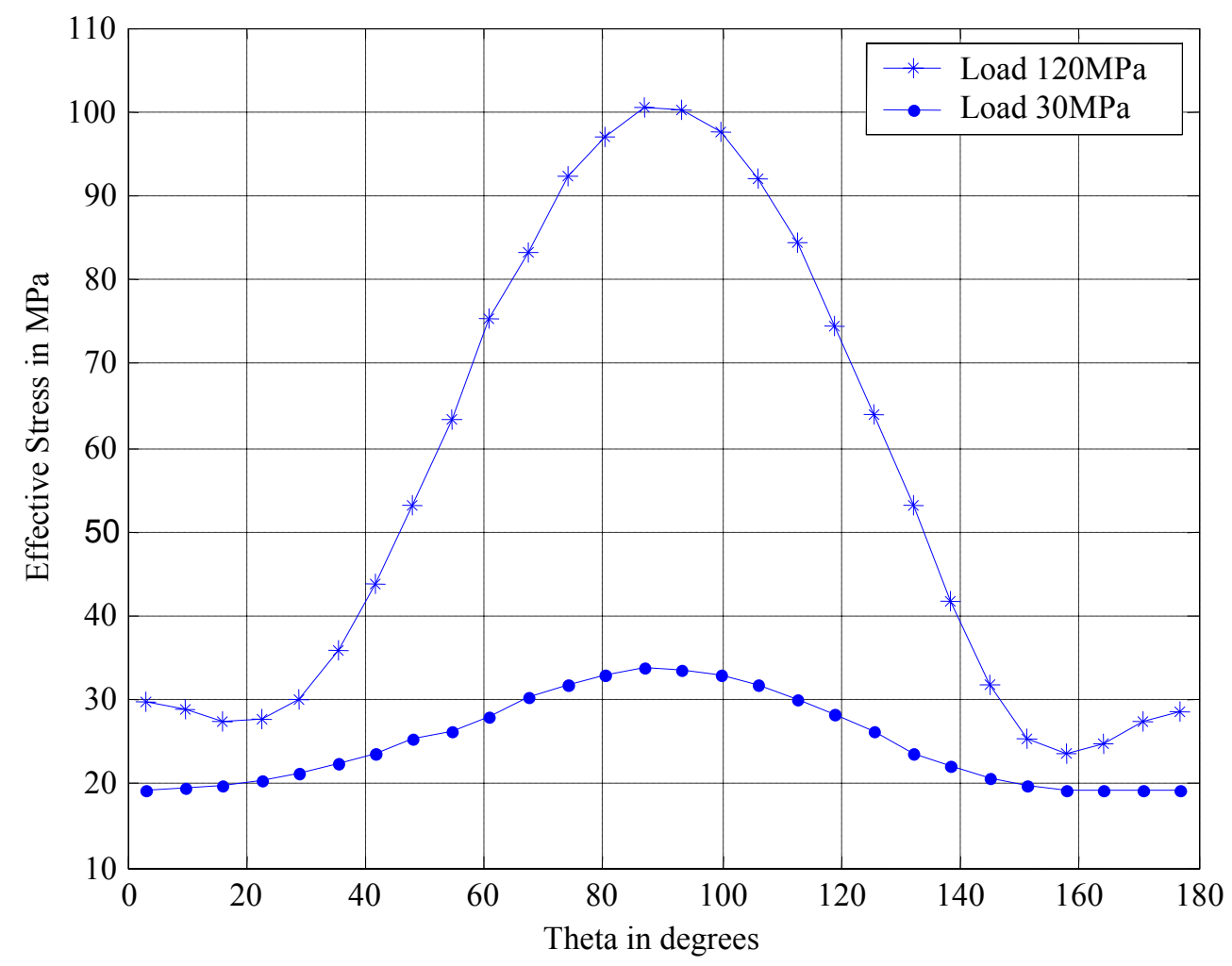

Figure 5.11 Variations of Von Mises Stress Around the Hole in the Middle Plate for Different Values of the Load Applied

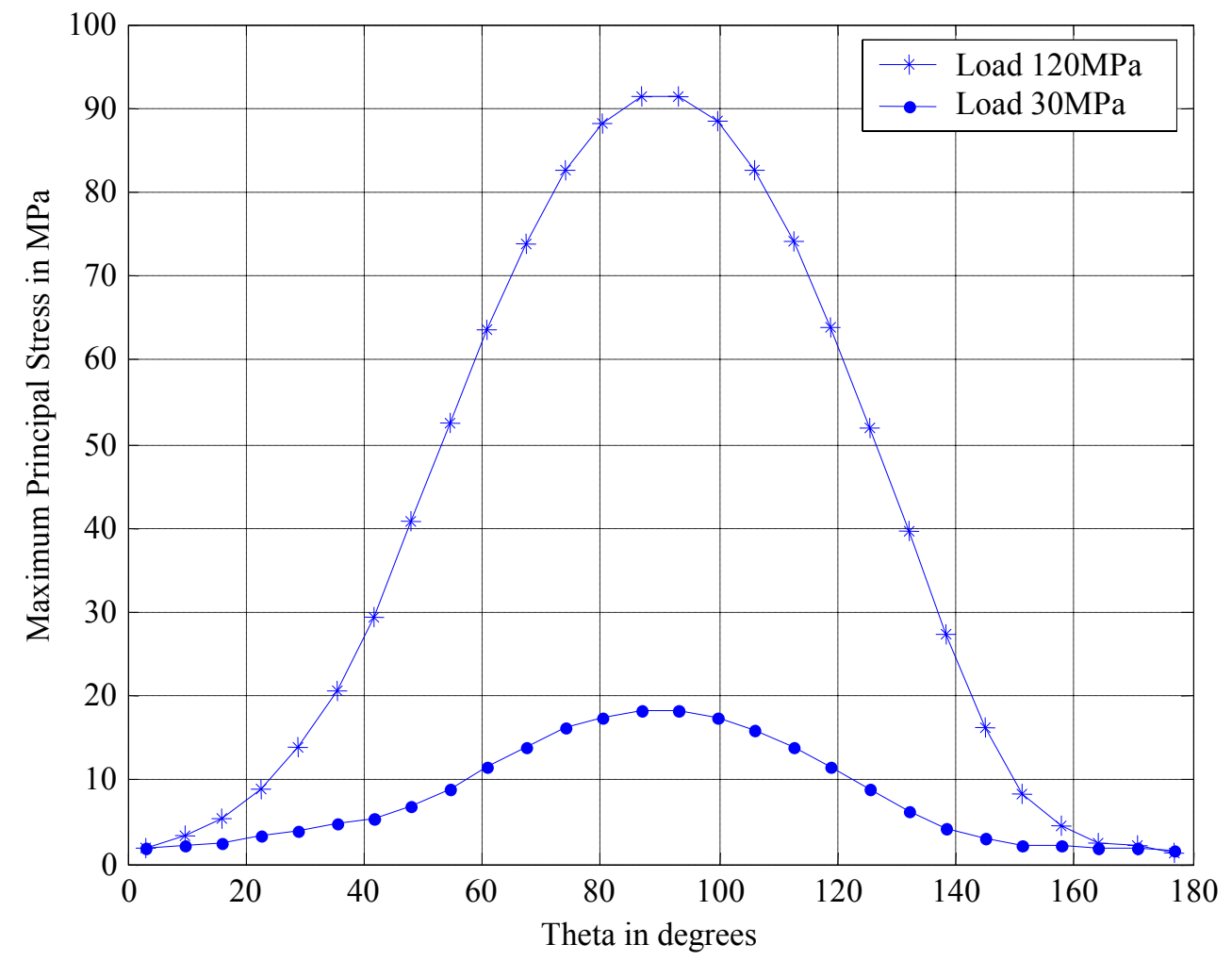

Figure 5.12 Variations of Maximum Principal Stress Around the Hole in the Middle Plate for Different Values of the Load Applied 




$-1.645 \mathrm{E}+00$

$1.173 \mathrm{E}+00$

$3.931 \mathrm{E}+00$

$6.809 \mathrm{E}+00$

$3.627 \mathrm{E}+00$

$1.244 \mathrm{E}+01$

$1.526 \mathrm{E}+01$

$1.808 \mathrm{E}+01$

$2.030 \mathrm{E}+01$

$2.372 \mathrm{E}+01$

$2.653 \mathrm{E}+01$

$2.935 \mathrm{E}+01$

$3.217 \mathrm{E}+01$

Figure 5.13.1 Predicted Distribution of Normal Stresses in $x$-Direction $\left(\sigma_{x x}\right)$ in the Middle Plate for a Load of 30MPa



$1.011 \mathrm{E}+00$

$1.204 \mathrm{E}+01$

$2.308 \mathrm{E}+01$

$3.411 \mathrm{E}+01$

$4.514 \mathrm{E}+01$

$5.617 \mathrm{E}+01$

$6.721 \mathrm{E}+01$

$7.824 \mathrm{E}+01$

$8.927 \mathrm{E}+01$

$1.003 \mathrm{E}+02$

$1.113 \mathrm{E}+02$

$1.224 \mathrm{E}+02$

$1.334 \mathrm{E}+02$

Figure 5.13.2 Predicted Distribution of Normal Stresses in $x$-Direction $\left(\sigma_{\mathrm{xx}}\right)$ in the Middle Plate for a Load of 120MPa 


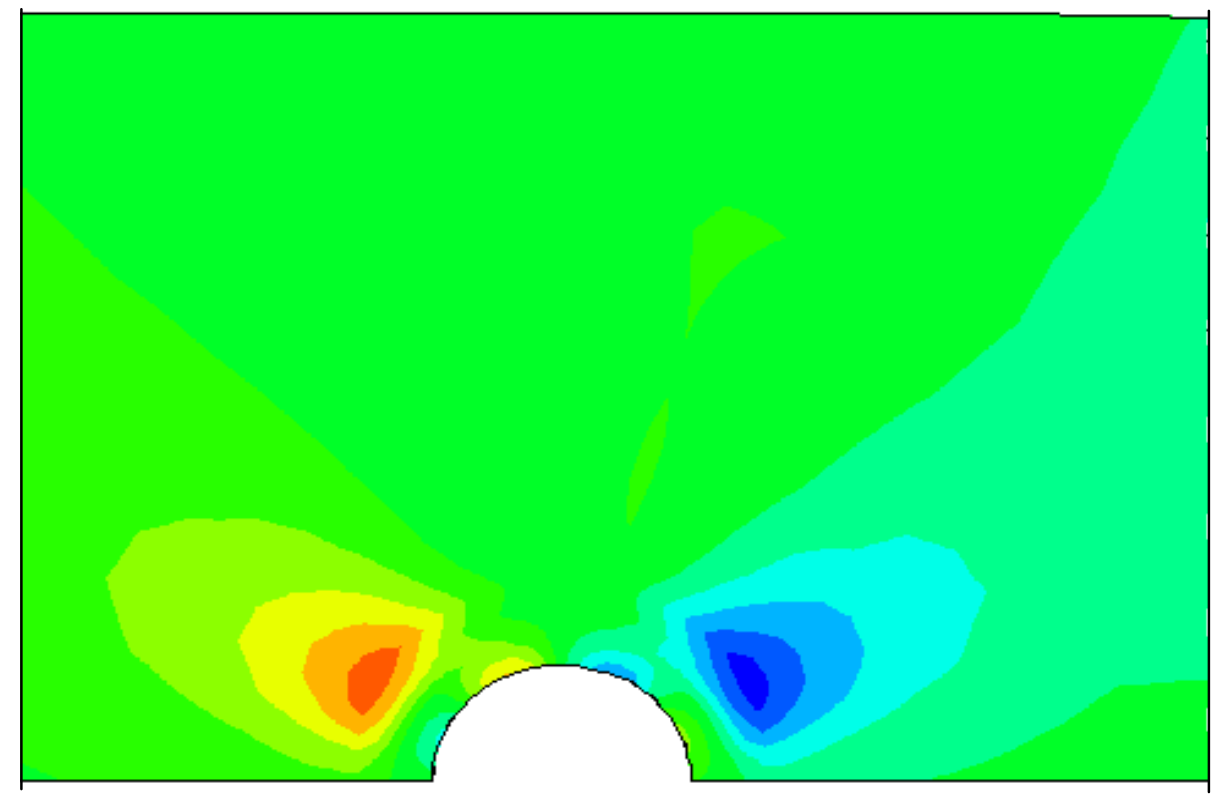

$-4.451 \mathrm{E}+00$

$-3.661 \mathrm{E}+00$

$-2.870 \mathrm{E}+00$

$-2.080 \mathrm{E}+00$

$-1.290 \mathrm{E}+00$

$-4.999 \mathrm{E}-01$

$2.902 \mathrm{E}-01$

$1.080 \mathrm{E}+00$

$1.871 \mathrm{E}+00$

$2.661 \mathrm{E}+00$

$3.451 \mathrm{E}+00$

$4.241 \mathrm{E}+00$

$5.031 \mathrm{E}+00$

Figure 5.14.1 Predicted Distribution of Shear Stress $\left(\tau_{\mathrm{xy}}\right)$ in the Middle Plate for a Tensile Load



$-8.024 \mathrm{E}+00$

$-6.675 \mathrm{E}+00$

$-5.326 \mathrm{E}+00$

$-3.977 \mathrm{E}+00$

$-2.628 \mathrm{E}+00$

$-1.279 \mathrm{E}+00$

$-7.044 \mathrm{E}-02$

$1.419 \mathrm{E}+00$

$2.768 \mathrm{E}+00$

$4.118 \mathrm{E}+00$

$5.467 \mathrm{E}+00$

$6.816 \mathrm{E}+00$

$8.165 \mathrm{E}+00$

Figure 5.14.2 Predicted Distribution of Shear Stress $\left(\tau_{x y}\right)$ in the Middle Plate for a Compressive Load 


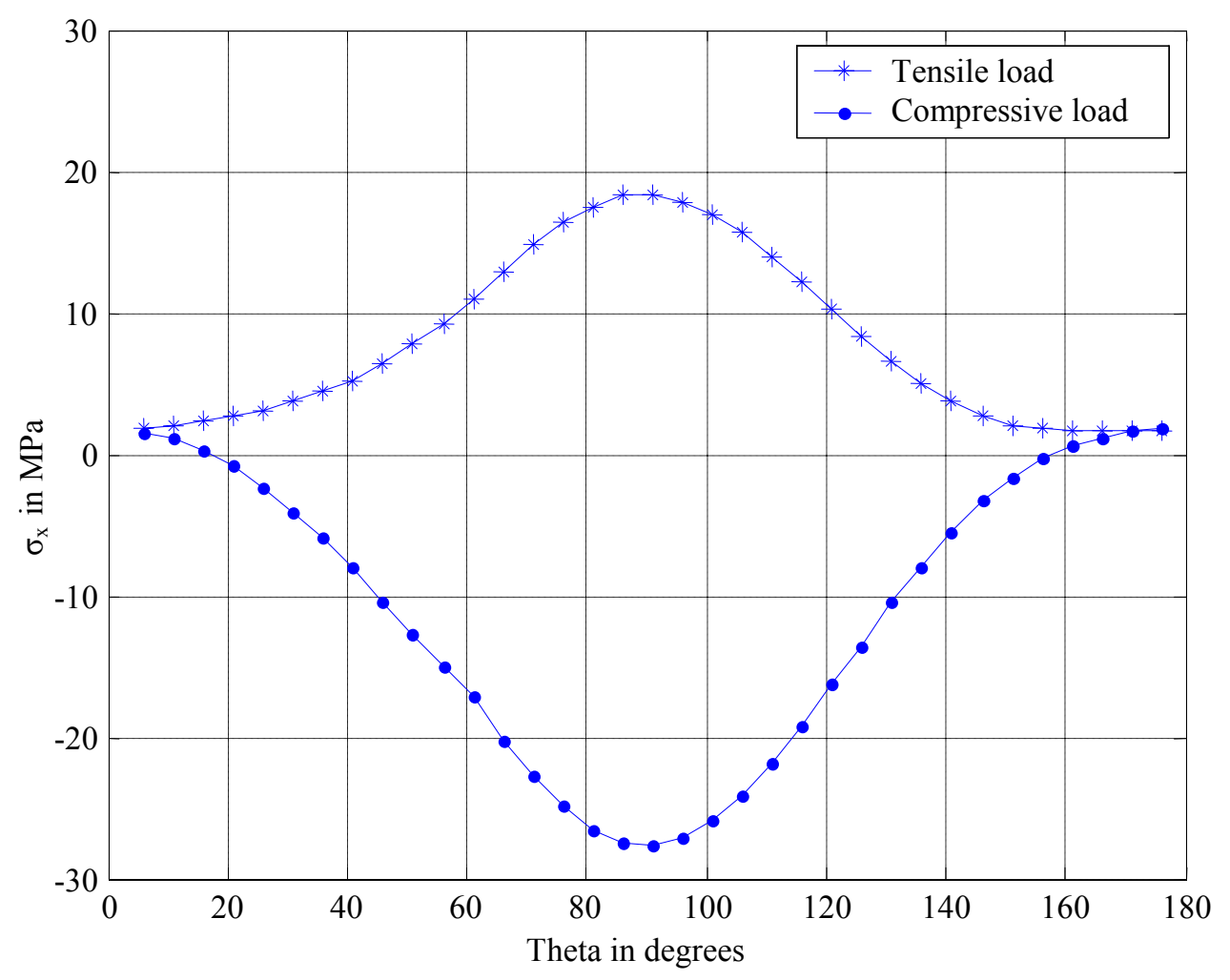

Figure 5.15 Predicted Distribution of $\left(\sigma_{\mathrm{xx}}\right)$ Stress Components Around the Hole in the Middle Plate for Different Loads

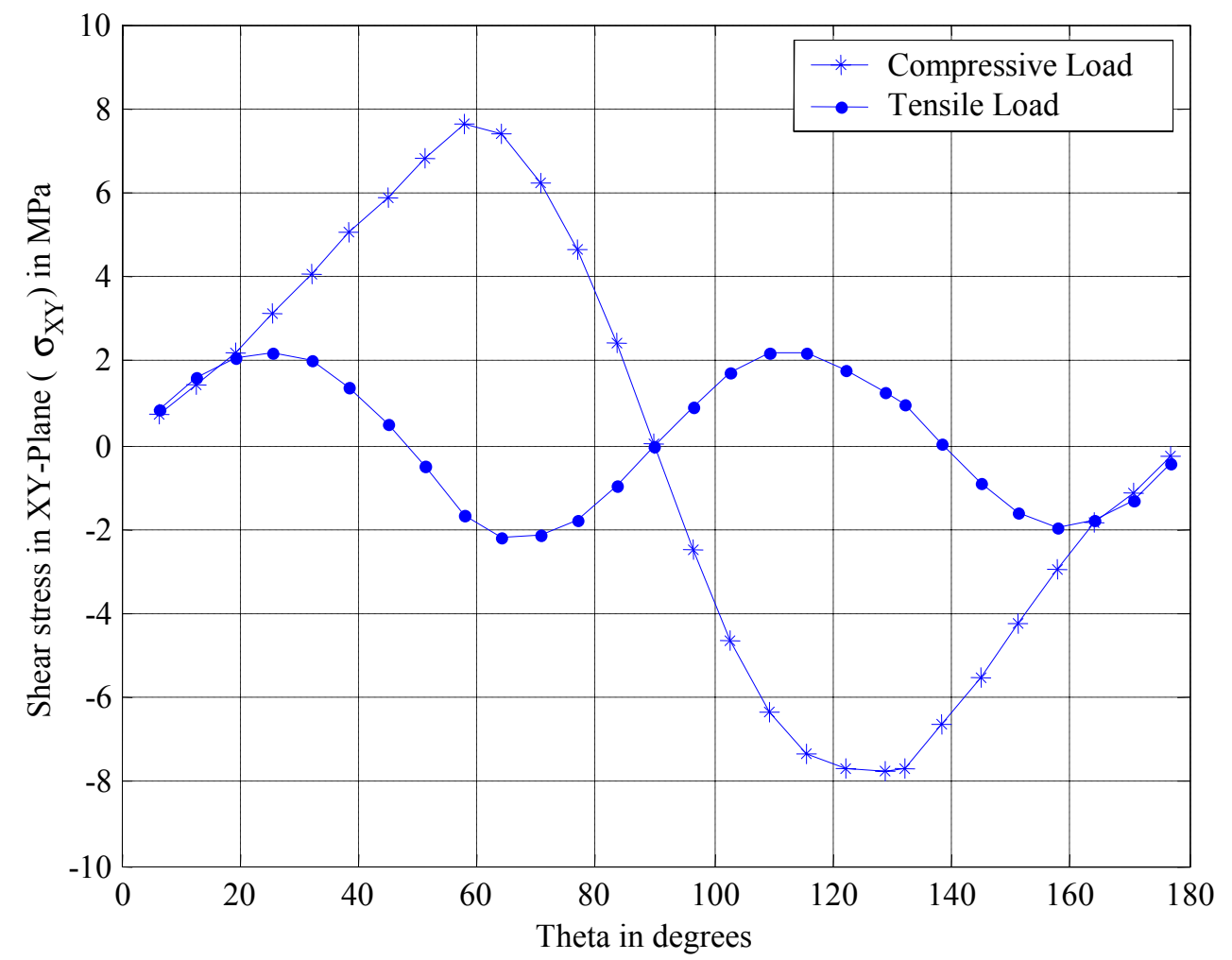

Figure 5.16 Predicted Variations of Shear Stress Around the Hole in the XY-Plane $\left(\tau_{\mathrm{xy}}\right)$ for Different Loads in the Middle Plate 


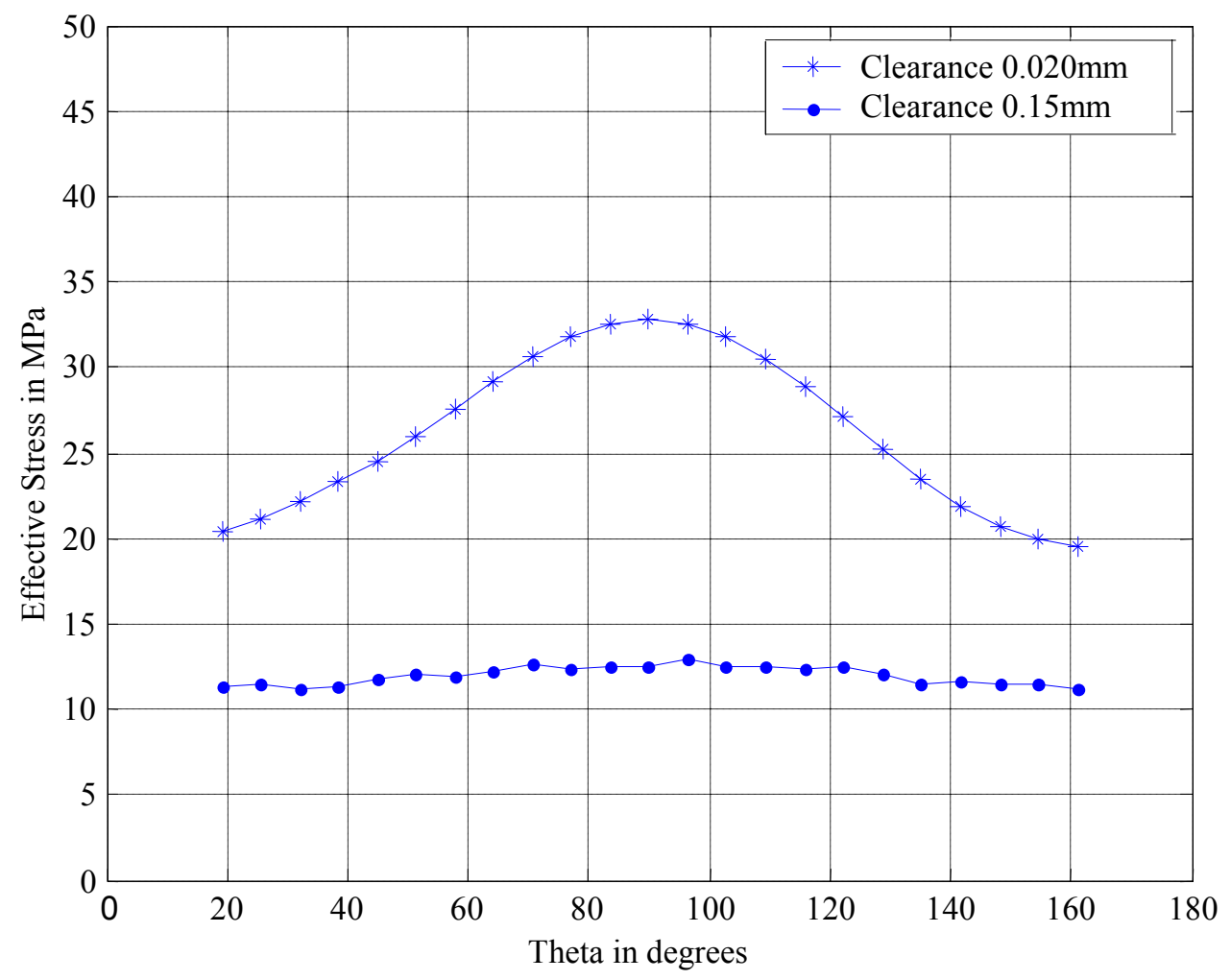

Figure 5.17 Variations of Von Mises Stress Around the Hole in the Middle Plate for Various Values of Clearances

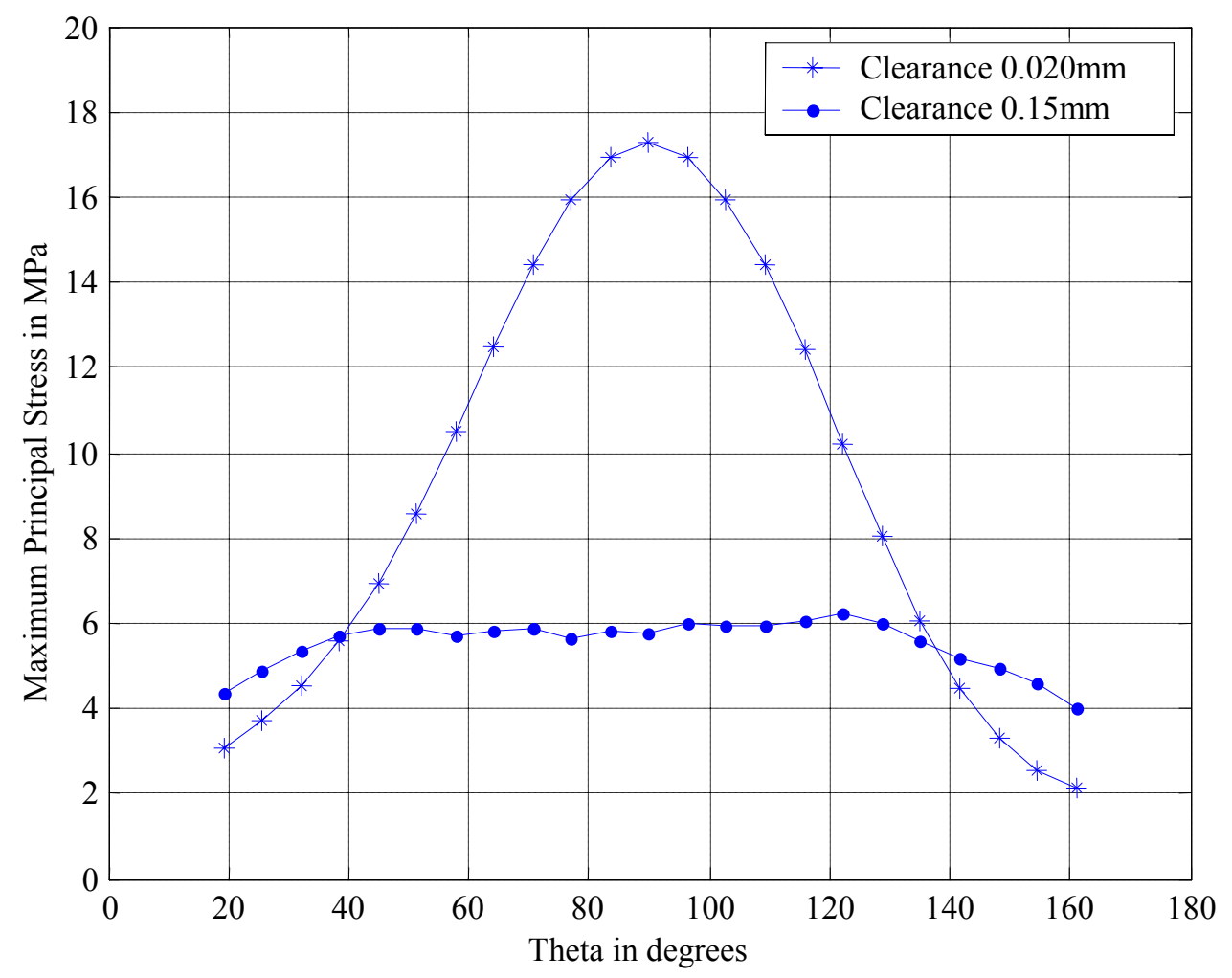

Figure 5.18 Distribution of Maximum Principal Stress Around the Hole in the Middle Plate for Various Values of Clearances 


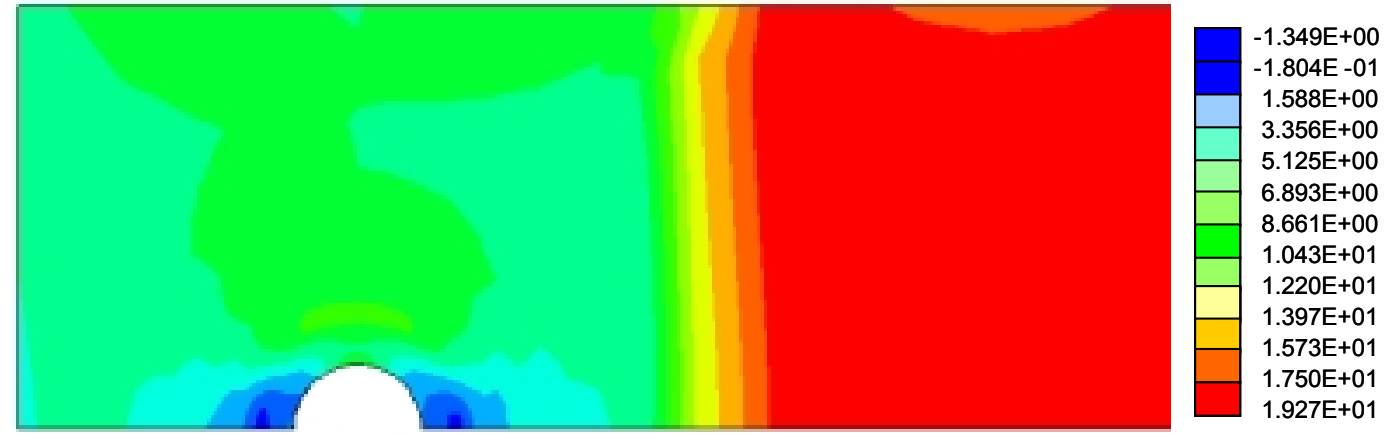

Figure 5.19 Predicted Distribution of Normal Stresses in x-direction $\left(\sigma_{\mathrm{xx}}\right)$ for a Clearance of $0.02 \mathrm{~mm}$ in the Lower Plate



$-4.411 \mathrm{E}+00$

$-1.043 \mathrm{E}+00$

$2.312 \mathrm{E}+00$

$5.674 \mathrm{E}+00$

$9.006 \mathrm{E}+00$

$1.240 \mathrm{E}+01$

$1.576 \mathrm{E}+01$

$1.912 \mathrm{E}+01$

$2.248 \mathrm{E}+01$

$2.584 \mathrm{E}+01$

$2.921 \mathrm{E}+01$

$3.257 \mathrm{E}+01$

$3.593 \mathrm{E}+01$

Figure 5.20 Predicted Distribution of Normal Stresses in x-direction $\left(\sigma_{\mathrm{xx}}\right)$ for a Clearance of $0.15 \mathrm{~mm}$ in the Lower Plate 


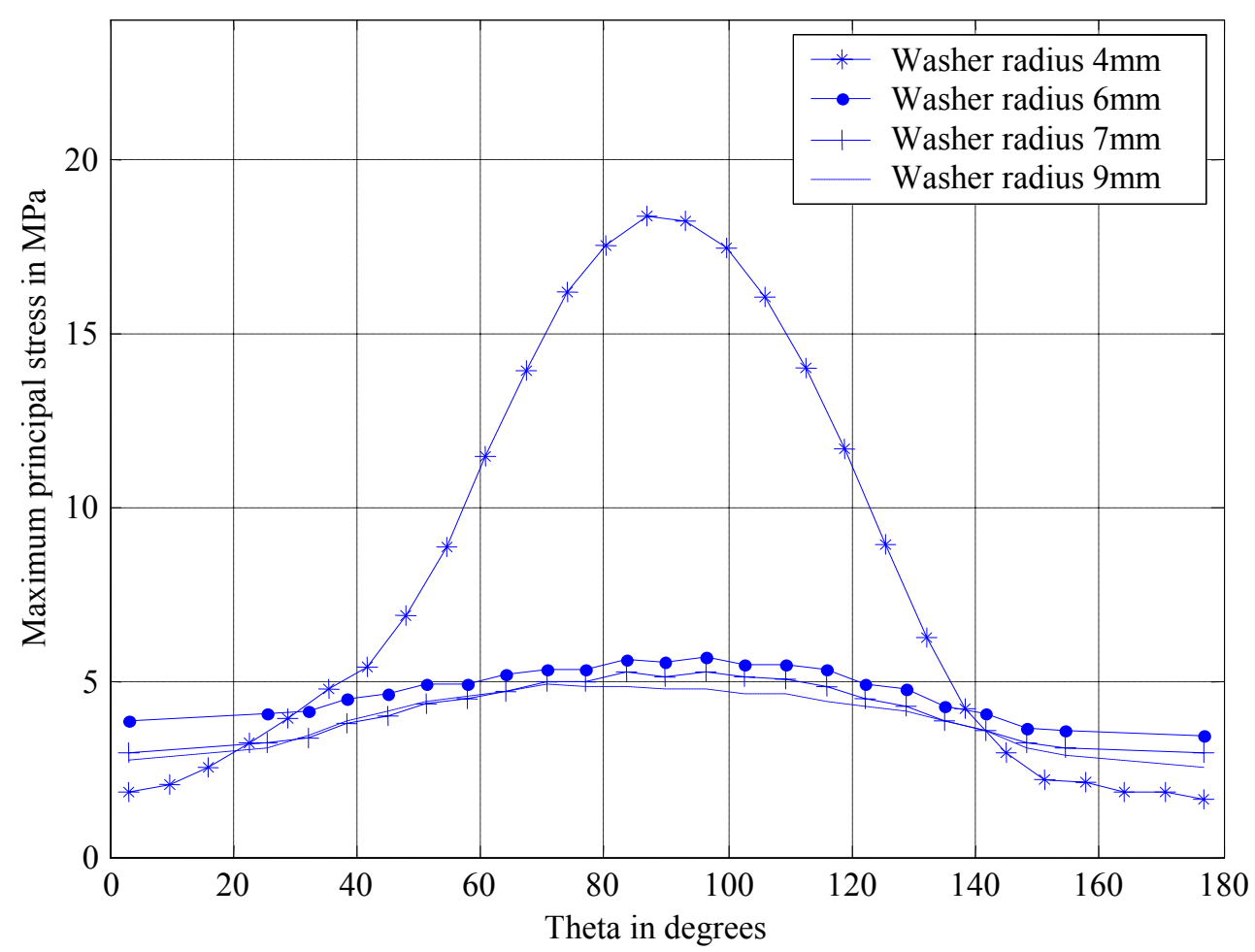

Figure 5.21 Variations of Maximum Principal Stresses Around the Hole in the Middle Plate for Various Radii of the Washer

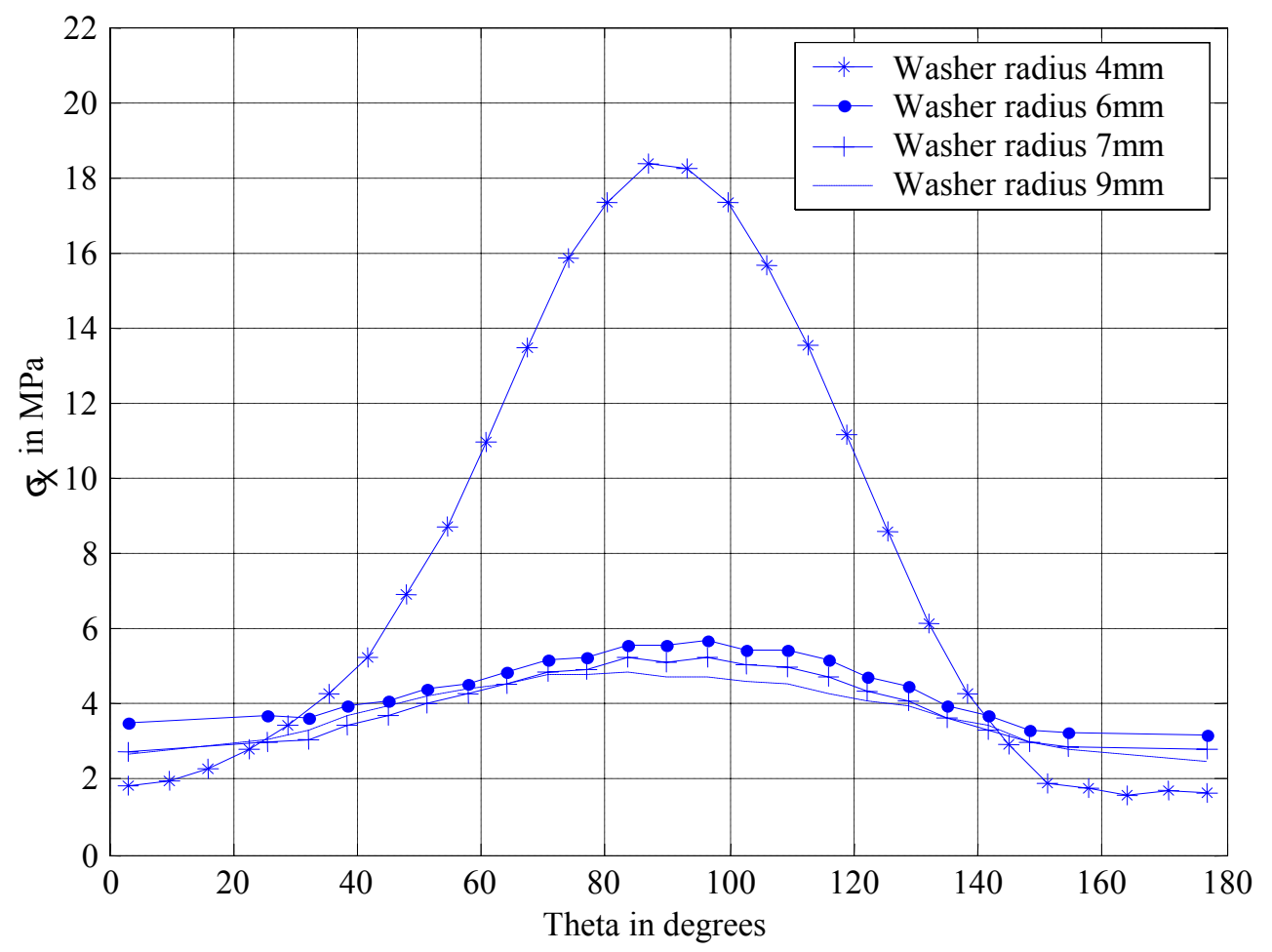

Figure 5.22 Variations of the Stress Around the Hole in the Middle Plate for Various Radii of the Washer 


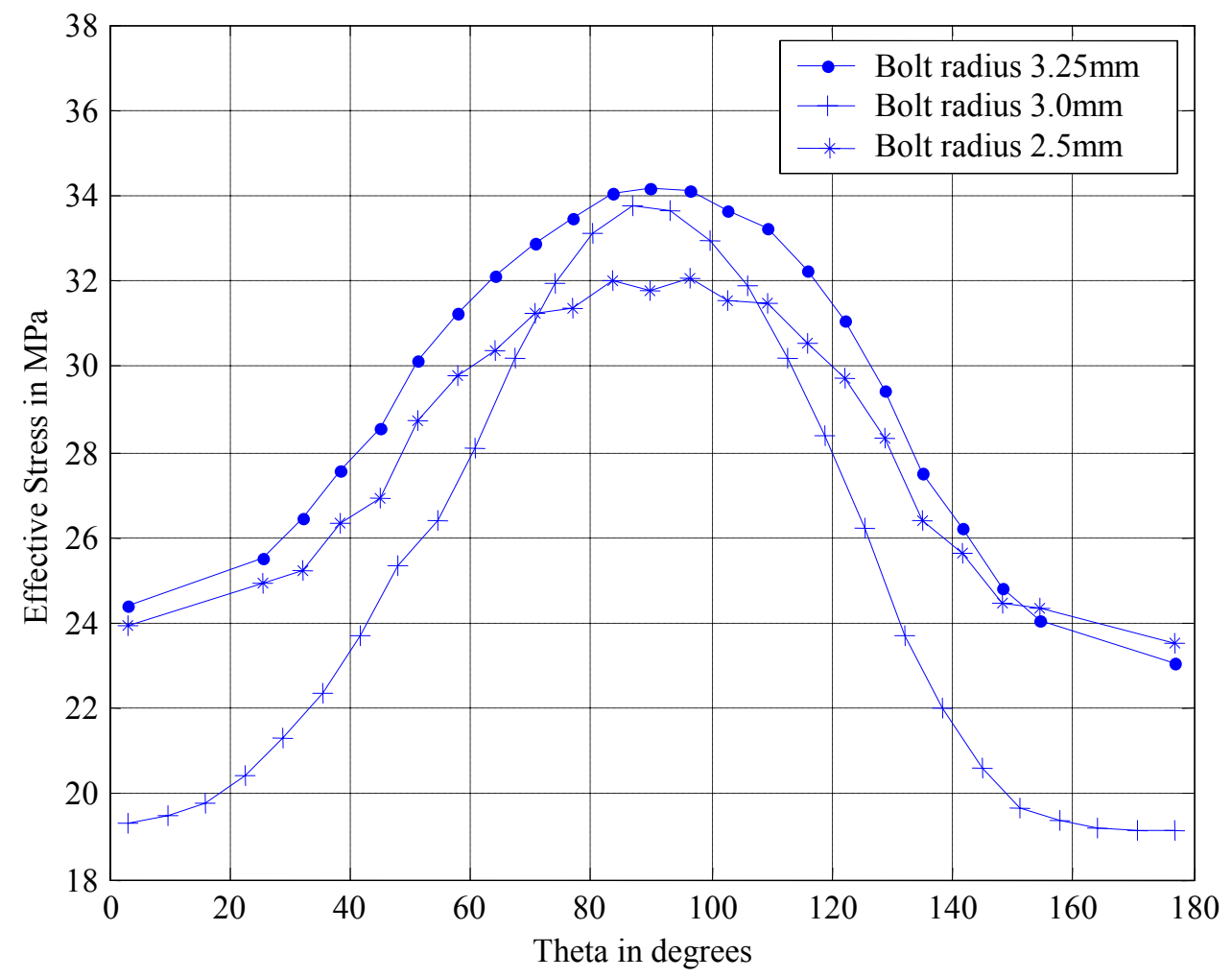

Figure 5.23 Variations of Von Mises Stress Around the Hole in the Middle Plate for Various Values of the Bolt Diameter

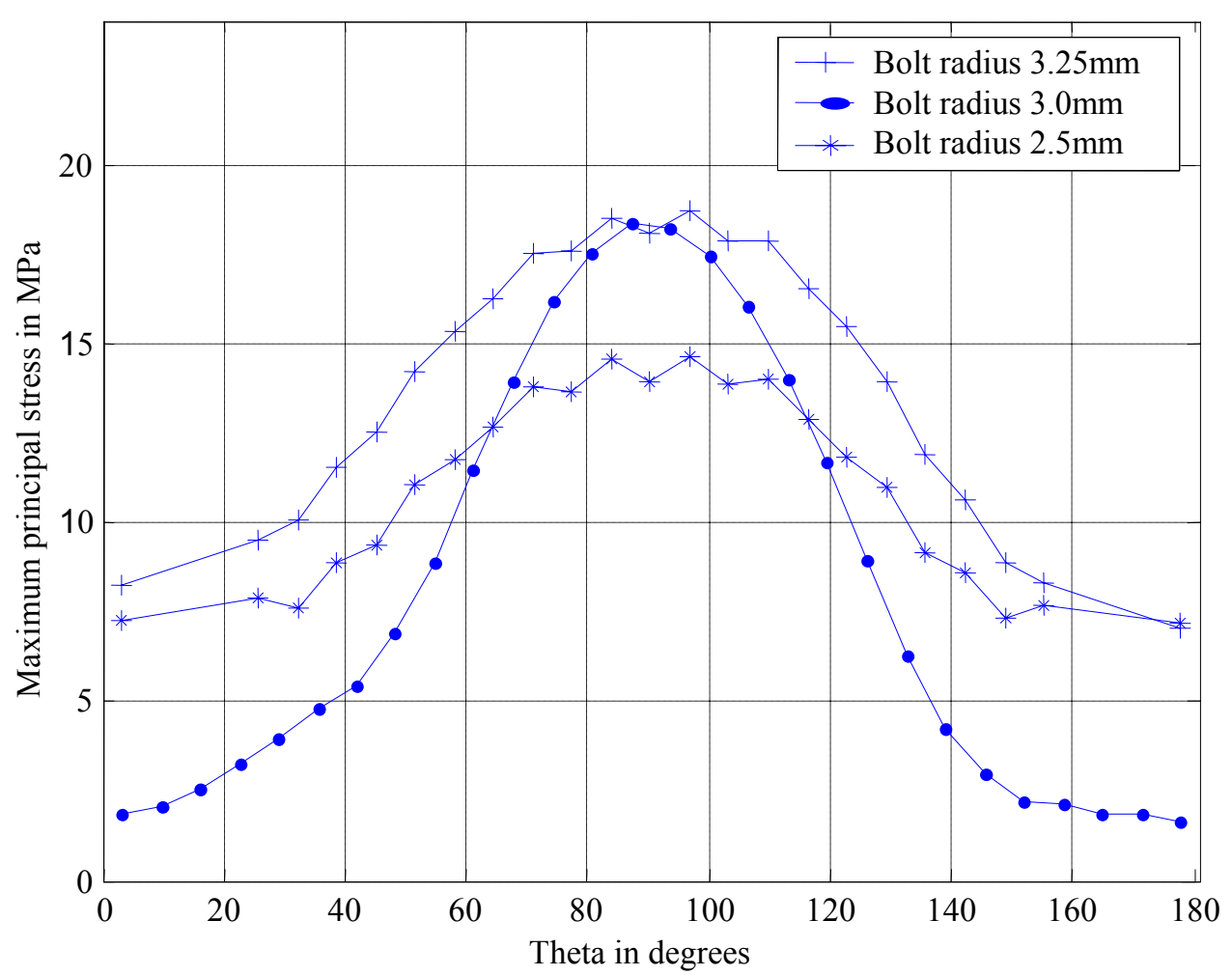

Figure 5.24 Variations of Maximum Principal Stresses Around the Hole in the Middle Plate for Various Values of the Bolt Diameter 


\section{CHAPTER SIX}

\section{CONCLUSIONS}

The behavior of bolted joints in composite structures is of high concern due to its complexity and dependency on many material and geometric variables. Reliable and effective design of structural joints requires extensive knowledge of the multiple parameters that affect their behavior, as well as accurate calculations of stress distributions. A three-dimensional finite element model has been developed to study the effects of various parameters on the stress fields around the hole in single and double lap bolted joints. The results obtained from the finite element analysis have been validated by using a simplified closed-form model, which consists of an infinite, elastic plate with a circular hole subjected to uniform uniaxial loading. The stresses predicted by the closed -

form model along the $\mathrm{x}$ and $\mathrm{y}$ axes are compared with the corresponding values from the finite element analysis and good agreement was obtained.

The primary conclusions of the investigation described in this thesis are summarized below:

a) An increase in the bolt tightening pressure increases the average effective stress around the hole, both for single and double- lap joints.

b) The Young's Modulus of the connected plates has an insignificant effect on the stress distributions around the hole. The strain levels around the hole however increase as the Young's Modulus decreases. 
c) In single lap joints, the effective stress around the hole increases when the bolt diameter or the washer diameter increases. This effect is, most likely, due to the bending associated with the asymmetric loading of the joint.

d) When the clearance between the hole and the bolt increases, the level of stresses around the hole decreases.

e) In double lap joints, an increase in the washer or bolt diameter results in a decrease of the effective stress around the hole.

\subsection{Future Work}

In single lap bolted joints, it is important to study the complex modes of failure associated with the bending effects caused by the loading eccentricity. Critical problems of mechanical joint failures such as shear-out, delamination, or bending have to be investigated further, in the context of the specific characteristics of composite materials. The complex damage mechanisms, such as fiber micro buckling and inter-laminar cracking involved in bearing failures requires further investigations. 


\section{References:}

1. Boresi, A.P., Schmidt, R.J., and Sidebottom, O.M., (1993), “Advanced Mechanics of Materials", John Wiley \& Sons, INC.

2. Chen, W.F. and Han, D.J., (1987), “Plasticity for Structural Engineers”, Gua Liu Book Co., Ltd, Taiwan.

3. Cope. D. A. and Lacy. T.E., (2000), Stress Intensity Determination in Lap Joints with Mechanical Fasteners, $41^{\text {st }}$ AIAA/ASME/ASCEIAHS/ASC Structures, Structural Dynamics, and Material conference and Exhibit, pp. 1-10.

4. Fukuoka. T., and Takaki. T., (1998), Mechanical Behavior of Bolted Joint in Various clamping Configurations, Journal of Pressure Vessel Technology, vol 120, pp226-231.

5. Gerbert. G., and Båstedt. H., (1993) Centrically Loaded Bolted Joints, Journal of Mechanical Design, vol. 115, pp 701-705.

6. Hallquist, J., (1998), "LS-DYNA Theoretical Manual", Livermore Software Technology Corporation, California.

7. Hibbitt, Karlsson, and Sorensen, ABAQUS, Version 5.5, HKS Inc., 1995.

8. Ireman.T.,(1998). Three Dimensional Stress Analysis of Bolted Single-lap composite Joints, Composite structures, Vol. 43, pp. 195-216.

9. Jung, C. K., and Han, F. S.,(2000), Fatigue Life Prediction of Bolted Joints, Key Engineering Materials, vol. 183-187, pp. 1011-1016. 
10. Lehnhoff, T.F., and Wistehuff, W.E., (1996), Nonlinear Effects on the Stresses and Deformations of Bolted Joints, Journal of Pressure Vessel Technology, vol. 118, pp. 54-58.

11. Lehnhoff.T.F., and Bunyard. B.A., Effect of bolt threads on the Stiffness of Bolted Joints, Journal of Pressure Vessel Technology, vol. 381, pp. 141-146.

12. Mark .H. L., IDEAS, Master Series, SDRC Inc., 1995.

13. Menzemer. C.C., Fei. L., and Srivatsan. T. S., (1999), Design Criteria for Bolted Connection Elements in Aluminum Alloy 6601, Journal of Mechanical Design, vol. 121, pp. 348-358.

14. Pratt, J. D., and Pardoen, G., (2002), Comparative Behavior of Single-Bolted and Dual-Bolted Lap Joints, Journal of Aerospace Engineering, vol. 15, no. 2, pp. 5563.

15. Shankar. K., and Dhamari. R., (2002), Fatigue Behavior of Aluminum Alloy 7075 Bolted Joints Treated with Oily Film Corrosion Compounds, Materials and Design, vol 23, pp. 209-216.

16. Weeton.J.W., Peters.D.M., and Thomas. K.L, 'Engineers' Guide To Composite Materials", 1987.

17. Winter (1956). Tests on Bolted Connections in Light Gage Steel, Journal of Structural Division, vol. 82, pp. 920-1-25. 